SRNL-STI-2011-00214

Revision 1

Keywords carbon, oxalate, formate, nitrate

Retention: permanent

\title{
UNCERTAINTIES OF ANION AND TOC MEASUREMENTS AT THE DWPF LABORATORY
}

T.B. Edwards

April 2011

Applied Computational Engineering and Statistics Savannah River National Laboratory

Aiken, SC 29808

This document was prepared in conjunction with work accomplished under Contract No. DE-AC09-08SR22470 with the U.S. Department of Energy.

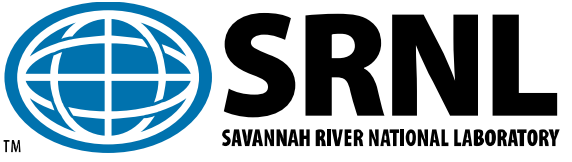


SRNL-STI-2011-00214

Revision 1

\section{DISCLAIMER}

This work was prepared under an agreement with and funded by the U.S. Government. Neither the U.S. Government or its employees, nor any of its contractors, subcontractors or their employees, makes any express or implied: 1. warranty or assumes any legal liability for the accuracy, completeness, or for the use or results of such use of any information, product, or process disclosed; or 2. representation that such use or results of such use would not infringe privately owned rights; or 3. endorsement or recommendation of any specifically identified commercial product, process, or service. Any views and opinions of authors expressed in this work do not necessarily state or reflect those of the United States Government, or its contractors, or subcontractors.

This document was prepared in conjunction with work accomplished under Contract No. DE-AC09-08SR22470 with the U.S. Department of Energy. 
SRNL-STI-2011-00214

Revision 1

\section{REVIEWS AND APPROVALS}

\section{AUTHOR:}

T. B. Edwards, Applied Computational Engineering and Statistics

Date Savannah River National Laboratory

\section{TECHNICAL REVIEWER:}

E. P. Shine, Applied Computational Engineering and Statistics

Date

Savannah River National Laboratory

APPROVERS:

P. L. Lee, Manager, Applied Computational Engineering and Statistics

Date

Savannah River National Laboratory

C. C. Herman, Manager, Process Technology Programs

Date

Savannah River National Laboratory

R. T. McNew, Manager, Waste Laboratory Services

Date

Savannah River Remediation

J. E. Occhipinti, Manager, Waste Solidification Engineering

Date

Savannah River Remediation 


\section{EXECUTIVE SUMMARY}

The Savannah River Remediation (SRR) Defense Waste Processing Facility (DWPF) has identified a technical issue related to the amount of antifoam added to the Chemical Process Cell (CPC). Specifically, due to the long duration of the concentration and reflux cycles for the Sludge Receipt and Adjustment Tank (SRAT), additional antifoam has been required. The additional antifoam has been found to impact the melter flammability analysis as an additional source of carbon and hydrogen. To better understand and control the carbon and hydrogen contributors to the melter flammability analysis, SRR's Waste Solidification Engineering (WSE) requested that the Savannah River National Laboratory (SRNL) conduct an error evaluation of the measurements of key Slurry Mix Evaporator (SME) anions. Measurements for these anions, which included formate, nitrate, and oxalate, and for total organic carbon from recent SME batches were provided to SRNL by DWPF Laboratory Operations personnel.

The measurements generated by the DWPF Laboratory for recent SME batches are presented in this report, an evaluation of the uncertainties of these measurements is provided, and approaches for assessing the impact of these uncertainties on DWPF's strategies for controlling melter flammability and for monitoring antifoam additions are investigated. 


\section{TABLE OF CONTENTS}

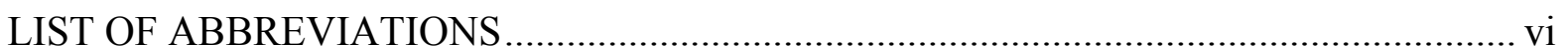

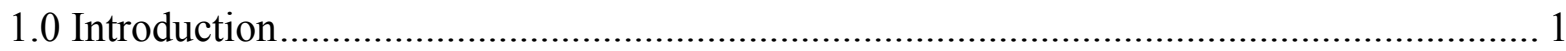

2.0 Measurements Provided by DWPF Lab OPS .......................................................... 1

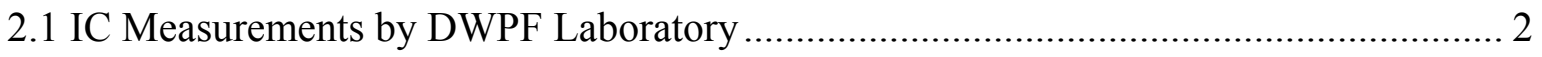

2.1.1 Formate, Nitrate, and Oxalate Standards ........................................................ 2

2.1.2 SME Sample Results for Formate, Nitrate, and Oxalate..................................... 3

2.2 TOC Measurements by DWPF Laboratory ........................................................ 4

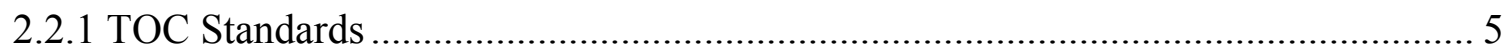

2.2.2 TOC Measurements of SME Samples ............................................................... 6

3.0 The Maximum TOC/Nitrate Ratio at 60\% LFL ........................................................... 6

3.1 Assessing the Nitrate Content of the SME .............................................................. 7

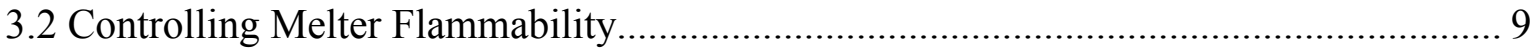

3.3 Meeting the Constraint of the TOC to Nitrate Ratio .................................................... 11

4.0 Estimation of Carbon Attributable to Antifoam Additions............................................. 12

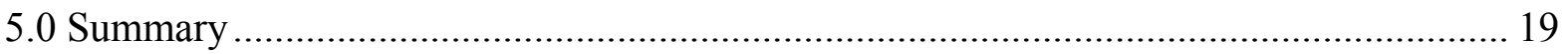

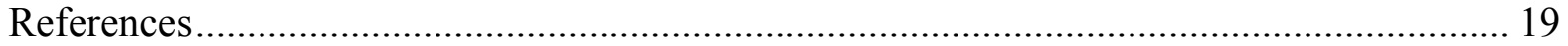

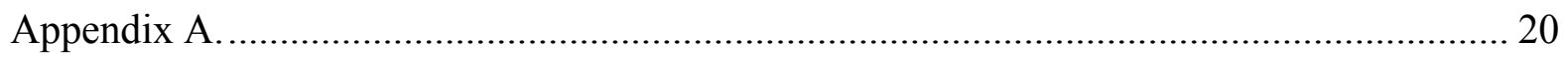




\section{LIST OF ABBREVIATIONS}

$\begin{array}{ll}\text { CPC } & \text { Chemical Process Cell } \\ \text { DWPF } & \text { Defense Waste Processing Facility } \\ \text { IC } & \text { Ion Chromatography } \\ \text { JMP } & \text { Statistical software package from SAS Institute, Inc. [4] } \\ \text { Lab OPS } & \text { Laboratory Operations } \\ \text { LFL } & \text { Lower Flammability Limit } \\ \text { ppm } & \text { parts per million } \\ \text { SB6 } & \text { Sludge Batch 6 } \\ \text { SB7a } & \text { Sludge Batch 7a } \\ \text { SME } & \text { Slurry Mix Evaporator } \\ \text { SRNL } & \text { Savannah River National Laboratory } \\ \text { SRR } & \text { Savannah River Remediation } \\ \text { TOC } & \text { Total Organic Carbon } \\ \text { TTQAP } & \text { Task Technical and Quality Assurance Plan } \\ \text { TTR } & \text { Technical Task Request } \\ \text { WSE } & \text { Waste Solidification Engineering }\end{array}$


SRNL-STI-2011-00214

Revision 1

\subsection{INTRODUCTION}

The Savannah River Remediation (SRR) Defense Waste Processing Facility (DWPF) has identified a technical issue related to the amount of antifoam added to the Chemical Process Cell (CPC). Specifically, due to the long duration of the concentration and reflux cycles for the Sludge Receipt and Adjustment Tank (SRAT), additional antifoam has been required. The additional antifoam has been found to impact the melter flammability analysis as an additional source of carbon and hydrogen. To better understand and control the carbon and hydrogen contributors to the melter flammability analysis, SRR's Waste Solidification Engineering (WSE) has requested, via a Technical Task Request (TTR) [1], that the Savannah River National Laboratory (SRNL) conduct an error evaluation of the measurements of key Slurry Mix Evaporator (SME) anions. SRNL issued a Task Technical and Quality Assurance Plan (TTQAP) [2] in response to that request, and the work reported here was conducted under the auspices of that TTQAP.

The TTR instructs SRNL to conduct an error evaluation of anion measurements generated by the DWPF Laboratory using Ion Chromatography (IC) performed on SME samples. The anions of interest include nitrate, oxalate, and formate. Recent measurements of SME samples for these anions as well as measurements of total organic carbon (TOC) were provided to SRNL by DWPF Laboratory Operations (Lab OPS) personnel for this evaluation. This work was closely coordinated with the efforts of others within SRNL that are investigating the Chemical Process Cell (CPC) contributions to the melter flammability [3]. The objective of that investigation was to develop a more comprehensive melter flammability control strategy that when implemented in DWPF will rely on process measurements. Accounting for the uncertainty of the measurements is necessary for successful implementation. The error evaluations conducted as part of this task will facilitate the integration of appropriate uncertainties for the measurements utilized in that control strategy.

The flammability control strategy presented in [3] relies on SME measurements of TOC and nitrate while one of the uses by WSE of the oxalate and formate measurement data will be the estimation of the amount of carbon coming from antifoam additions. The estimation is to be conducted by backing out contributions to the measured TOC concentration in the SME from the oxalate and the formate concentrations that are measured in the SME. The resulting adjusted TOC value will provide a basis for WSE to estimate the amount of antifoam that was added for that SME batch. The uncertainties of the oxalate, formate, and TOC measurements provided by the evaluations conducted as part of this task will allow for the propagation of their uncertainties into the estimated quantity of carbon coming from the added antifoam.

The purpose of this technical report is to present the measurements generated by the DWPF Laboratory for recent SME batches, to conduct an evaluation of their uncertainties, and to provide the approach for propagating the uncertainties associated with these measurements into DWPF's strategies for controlling melter flammability and for monitoring antifoam additions. JMP Version 7.0.2 was used to support the analyses presented in this report [4].

\subsection{Measurements Provided by DWPF Lab OPS}

Measurements generated by the DWPF Laboratory for recent SME batches were provided to SRNL by Lab OPS personnel. These data are presented and their uncertainties investigated as part of this study. Section 2.1 discusses the IC measurement data and Section 2.2 discusses the TOC measurement data. Measurements of SME samples as well as standards were analyzed as part of these investigations. 


\subsection{IC Measurements by DWPF Laboratory}

Table A1 in Appendix A provides the IC measurement data generated by the DWPF Laboratory for 21 recent SME batches. Included in these results for each of the SME batches are measurements for formate, nitrate, and oxalate for four SME samples along with standards at 2 parts per million (ppm) and $16 \mathrm{ppm}$ for each of these anions.

\subsubsection{Formate, Nitrate, and Oxalate Standards}

Exhibit A1 in Appendix A provides plots of the DWPF Laboratory measurements from Table A1 for the $2 \mathrm{ppm}$ and $16 \mathrm{ppm}$ standards for formate, nitrate, and oxalate. Colors are used in these plots to represent the IC instrument that was used for the analyses and symbols (- for the before and + for the after) for the sequencing of the measurements of the standards relative to the processing of the SME samples. The measurements are grouped by SME batch number, and the IC instrument used to conduct the measurement is indicated. The set of measurements for each standard (e.g., the measurements for the $2 \mathrm{ppm}$ formate standard) is investigated using a random effects analysis of variance to estimate the variation from one SME batch to the next SME batch in the measurements for that standard. For this analysis, the SME batch is a pseudo variable for time between the measurements of the standard. That is, the variance estimated by this approach, if statistically significant, is the variation that may be affecting the measurement of the SME samples that will not be reduced by the replication of the analyses (i.e., by more SME samples being analyzed or by the existing SME samples being analyzed more times). For the results of Exhibit A1, the estimate of this variance for each set of measurements is statistically significant at the 5\% level. Statistical significance is indicated in the portion of the exhibit as shown in Exhibit 1 for the measurements of the 2 ppm formate standard.

\section{Tests wrt Random Effects \\ Source SS MS Num DF Num F Ratio Prob $>$ F \\ Batch \#\&Random $0.10346 \quad 0.00517 \quad 20 \quad 4.3281 \quad 0.0008$ \\ Exhibit 1. Illustration of JMP Results Indicating a Statistically Significant Batch to Batch Variability}

The "Prob $>$ F" value in this exhibit being less than 0.05 indicates a statistically significant batch to batch variance for the measurements of the $2 \mathrm{ppm}$ formate standard. If the "Prob $>$ F" value is greater than 0.05 , there is no indication of a statistically significant batch to batch variance. The estimate of the variance is provided in the portion of the exhibit as shown in Exhibit 2 for the measurements of the 2 ppm formate standard.

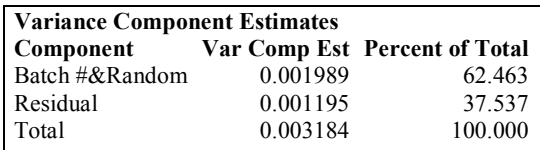

\section{Exhibit 2. Illustration of JMP Results Indicating a Statistically Significant} Batch to Batch Variability

The variance component of interest here is that labeled as "Batch\#\&Random," which is estimated as 0.001989 or over $62 \%$ of the total variance of the measurements for the $2 \mathrm{ppm}$ formate standard. The estimate of the standard deviation of the batch to batch effect is computed as the square root of 0.001989 , which is 0.0446 . Expressing this variation as a percentage of the nominal value, 2 , for this standard leads to a percent relative standard deviation of $2.23 \%$. 
The measurements of the other anion standards may be interpreted in a similar manner, and in each case the estimate of the batch to batch variance is statistically significant at the $5 \%$ level. This variance will need to be appropriately accounted for in determining the uncertainties of the SME measurements for formate, nitrate, and oxalate. To facilitate that process an analysis of variance was conducted using the measurements for both standards for each of the anions. In this analysis, the concentration of the standard (i.e., the $2 \mathrm{ppm}$ and $16 \mathrm{ppm}$ ) was added as a fixed effect in the model with the batch to batch variation included once again as a random effect with the variance of this effect being of interest. The results from this analysis of variance for the formate, nitrate, and oxalate measurements are provided in Exhibit A3 in Appendix A. These results may be interpreted in a manner similar to that described for the results of Exhibit A2. This leads to the conclusion that there is a statistically significant batch to batch variance in the measurements of the standards for formate, for nitrate, and for oxalate. The estimate of the batch to batch component of variation from Exhibit A3 for each anion is provided in Table 1. Also in this table for each anion is the average of the measurements of the standards and the expression of the batch to batch variation as a percent relative (to the average) standard deviation for each anion.

Table 1. Summary Information from Exhibit A3

\begin{tabular}{|c|c|c|c|}
\hline Anion & $\begin{array}{c}\text { Batch to Batch } \\
\text { Variance Component } \\
\text { Estimate }\end{array}$ & $\begin{array}{c}\text { Average of the } \\
\text { Measurements of the } \\
\text { Standards }\end{array}$ & $\begin{array}{c}\text { \% Relative Standard } \\
\text { Deviation (\%RSD) }\end{array}$ \\
\hline Formate & 0.0208 & 9.24 & $1.56 \%$ \\
\hline Nitrate & 0.0359 & 9.08 & $2.09 \%$ \\
\hline Oxalate & 0.0280 & 9.11 & $1.84 \%$ \\
\hline
\end{tabular}

For each anion, this estimated variance is considered as a contributor to the uncertainty in the measurements of the SME samples for this anion. Accounting for this variation as part of the uncertainty in the measurements of each of these anions is illustrated in the discussions that follow.

An additional investigation into the measurements of these standards is provided by Exhibit A4 in Appendix A. This exhibit provides a histogram and summary statistics for the mean of the measurements for each SME batch of each of the standards for each anion. A 95\% confidence interval for the mean of each set of measurements is included as part of these results. If the nominal value of the standard is included in the confidence interval determined for the mean of that standard, then there is no indication of a statistically significant bias in the measurements at a $5 \%$ significance level. This leads to the following conclusions. For the formate results, there are statistically significant biases in the measurements for the $2 \mathrm{ppm}$ and $16 \mathrm{ppm}$ standards; the means of the measurements for both standards are high relative to the nominal values of the standards. For the nitrate results, there is no indication of a statistically significant bias for either the 2 or the $16 \mathrm{ppm}$ standards. For the oxalate values, there is a bias in the $2 \mathrm{ppm}$ results (the mean of the measurements of the $2 \mathrm{ppm}$ oxalate standard are biased high), but there is no indication of a statistically significant bias for the measurements of the $16 \mathrm{ppm}$ oxalate standard. How to conservatively account for the effects of a potential bias in the formate measurements on a value derived from these measurements will depend on the derivation itself. This issue is addressed below as part of subsequent discussions presented in this report.

\subsubsection{SME Sample Results for Formate, Nitrate, and Oxalate}

Exhibit A5 in Appendix A provides the plots of the formate, nitrate, and oxalate measurements of the SME samples. For each anion, a plot is provided of the measurements as milligram of anion per 
kilogram of slurry, which may also be interpreted as ppm. In addition, the measurements of the SME samples are shown as ppm per diluted sample. The latter plot for each anion provides an indication of how the measurements fall within the interval covered by the standards (i.e., 2 to $16 \mathrm{ppm}$ ). For both plots, the measurements are grouped by SME batch, and the IC instrument used for the measurements is indicated. Note that only a limited plot of the oxalate measurements is provided since the measurements for this anion have been below the detection limit of the IC process for most of the SME batches included in this study.

For each set of measurements in Exhibit A5, an analysis of variance was conducted with the objective of estimating two components of variation: the batch to batch component and the within batch (or residual) component. The results from these analyses are provided in Exhibit A6 of Appendix A. For the SME measurements of each anion, the batch to batch component is a statistically significant (at the $5 \%$ level) component of the variability in the measurements for the anion. Furthermore, the estimate of the residual variance may be interpreted as the square of a pooled estimate of the standard deviation of the measurements for the anion over the set of samples from a given SME batch. For example, consider the results for the formate $\mathrm{mg} / \mathrm{kg}$ slurry measurements. The estimated residual variance is $1,488,412$ ( $15.9 \%$ of the total variance of these measurements). The square root of that number is $1220 \mathrm{mg} / \mathrm{kg}$ slurry. Expressed as a percent of the mean response for the measurements (38233.42 $\mathrm{mg} / \mathrm{kg}$ slurry), this becomes a percent relative standard deviation (\%RSD) of $3.2 \%$. Based upon this \%RSD, the estimate of the 1-sigma standard uncertainty for the average of the formate measurements in $\mathrm{mg} / \mathrm{kg}$ slurry for $4 \mathrm{SME}$ samples would be (on a relative basis) $3.2 \% / 2=1.6 \%$. A similar interpretation of the results for the measurements for nitrate leads to the estimate of the 1sigma standard uncertainty for the average of the nitrate measurements in $\mathrm{mg} / \mathrm{kg}$ slurry for $4 \mathrm{SME}$ samples as $100 \%(689.0958 / 22777.24) / 2=1.5 \%$. Note that there is insufficient oxalate data in Table A1 that is above the detection limit to allow for this type of analysis to be conducted for measurements of this anion.

Another, but similar, analysis of variance for these measurements is provided in Exhibit A7 of Appendix A. In these results, the differences among the averages of the measurements for an anion from one SME batch to another are interpreted as fixed effects with the estimated residual variance, once again, being representative of the repeatability of the sampling and analytical steps associated with these measurements for a given SME batch. The estimated residual variances from these analyses are identical to those of Exhibit A6. Once again, note that there is limited oxalate data to support this analysis for the SME measurements of this anion.

While the 1-sigma standard uncertainties for the average of the measurements for formate and the average of the measurements for nitrate for a given SME batch will be directly determined from the measurements of the SME samples for these anions, this pooled estimate may be used as an aid in understanding the impact of this variation on the uncertainty of values derived using measurements of these anions.

\subsection{TOC Measurements by DWPF Laboratory}

Table A2 in Appendix A provides the TOC measurement data generated by the DWPF Laboratory for ten recent SME batches. For each SME batch, this table provides four measurements: the results from two SME samples each being measured twice. Opening and closing measurements for TOC standards (one at $1 \mathrm{ppm}$ and one at $20 \mathrm{ppm}$ ) are also part of the analytical protocol for measuring the TOC concentrations of SME samples, and the measurements for these standards are also provided in Table A2. 


\subsubsection{TOC Standards}

The measurements in Table A2 of each of the TOC standards are plotted in Exhibit A8 in Appendix A. These measurements are grouped by SME batch and organized in line with the analytical protocol: the opening and closing measurements associated with the first SME sample and then the measurements associated with the second SME sample.

Some patterns are evident in these plots. For the $1 \mathrm{ppm}$ standard, the measurement of the closing standard is almost always larger than the measurement of the corresponding opening standard for the SME batches represented in Exhibit A8. For the 20 ppm standard, the average of the measurements for the opening and closing standards for the first SME sample is almost always larger than the average of the opening and closing standards for the second SME sample. These patterns in the measurements are also revealed in the residual plots associated with the analyses of variance provided in Exhibit A9 of Appendix A. The batch to batch differences in the measurements of the standards are considered as the realizations of a random effect whose variance is estimated as part of the results of the exhibit. The residual plot in this exhibit for the $1 \mathrm{ppm}$ standard shows a pattern of the residuals of the closing standard (red) being typically above the horizontal line at zero while the residuals of the opening standard (blue) are typically below the horizontal line at zero. For the $20 \mathrm{ppm}$ standard, the pattern revealed in the residual plot is that of the small squares (first SME sample) being typically above the horizontal line at zero while the pluses (second SME sample) are typically below the horizontal line at zero. While these patterns are not anticipated to affect the results of this investigation, a more thorough study into the possible causes of these patterns may provide an opportunity for an improvement in the protocol used for the TOC measurements.

Another outcome from the analyses of Exhibit A9 is the indication of a statistically significant (at the $5 \%$ level) batch to batch variance in the measurements of each of these TOC standards. This random effect is considered as a contributor to the uncertainty of the TOC measurements of the SME samples. Exhibit A10 of Appendix A provides an analysis of variance to estimate the variance of this random effect. In this analysis, the concentration of the TOC standard (i.e., the $1 \mathrm{ppm}$ and $20 \mathrm{ppm}$ ) was added to the model as a fixed effect along with a random term for the batch to batch effect, with the variance of this random effect being of interest. The results presented in Exhibit A9 may be interpreted in a manner similar to that described earlier for the interpretation of the analysis of the anion measurements. This leads to the conclusion that there is a statistically significant (at the $5 \%$ level) batch to batch variance for the measurements of the TOC standards. The estimate of this variance component relative to the average of the measurements for these standards may be expressed as $100 \%$ $(0.011827)^{0.5} / 10.41663=1.04 \%$. Thus, this estimated variance is a contributor to the uncertainty in the TOC measurements of the SME samples. Accounting for this variation as part of the uncertainty in the TOC measurements is illustrated in the discussions that follow.

An additional investigation into the measurements of the TOC standards is provided by Exhibit A11 in Appendix A. This exhibit provides a histogram and summary statistics for the measurements for the $1 \mathrm{ppm}$ and $20 \mathrm{ppm}$ TOC standards grouped by their position (opening or closing/first or second sample) in the analytical protocol. A 95\% confidence interval for the mean of each set of measurements is included as part of these results. If the nominal value of the standard is included in the confidence interval determined for the mean of that standard, then there is no indication of a statistically significant bias in the measurements at a 5\% significance level. This leads to the following conclusions. For the $1 \mathrm{ppm}$ standard, the average for the opening set of measurements for the first SME sample, the average for the opening set of measurements for the second SME sample, and the closing set of measurements for the second SME sample all indicate a statistically significant (at the 5\% level) low bias in these results. A statistically significant low bias is also indicated (at the $5 \%$ level) for the measurements of the opening $20 \mathrm{ppm}$ standard for the second SME sample. 
However, there is no indication of a statistically significant (at the $5 \%$ level) bias in the measurements of the closing $1 \mathrm{ppm}$ standard for the first SME sample or in the measurements of the opening and closing $20 \mathrm{ppm}$ standard for the first SME sample or in the measurements of the closing $20 \mathrm{ppm}$ standard for the second SME sample. Thus, there does not appear to be a consistent bias in the measurements over the TOC standards, and as a consequence, for this uncertainty investigation, no adjustment for bias will be applied to the TOC measurements generated by the DWPF Laboratory for the SME samples.

\subsubsection{TOC Measurements of SME Samples}

A plot of the TOC measurements in Table A2 for the SME samples is provided in Exhibit A12 of Appendix A. The measurements are grouped by SME batch and arranged by sample number and analytical replicate. Table 2 provides summary statistics for these measurements.

Table 2. Summary Information for the TOC Measurements of the SME Samples

\begin{tabular}{|c|c|c|c|c|c|}
\hline Batch \# & $\mathbf{N}$ & $\begin{array}{c}\text { Mean } \\
\text { (TOC (ppm)) }\end{array}$ & $\begin{array}{c}\text { Standard } \\
\text { Deviation } \\
\text { (TOC (ppm)) }\end{array}$ & $\begin{array}{c}\text { Standard Error } \\
\text { of the Mean } \\
\text { (TOC (ppm)) }\end{array}$ & $\begin{array}{c}\text { \%Relative } \\
\text { Standard Error }\end{array}$ \\
\hline 559 & 4 & 14639.5 & 91.07 & 45.535 & 0.31 \\
\hline 560 & 4 & 14136.8 & 84.49 & 42.244 & 0.30 \\
\hline 561 & 4 & 12780.8 & 32.39 & 16.193 & 0.13 \\
\hline 562 & 4 & 12428.0 & 63.77 & 31.885 & 0.26 \\
\hline 563 & 4 & 12856.3 & 117.37 & 58.686 & 0.46 \\
\hline 564 & 4 & 13207.0 & 59.43 & 29.713 & 0.22 \\
\hline 565 & 4 & 12633.3 & 188.71 & 94.355 & 0.75 \\
\hline 566 & 4 & 13489.0 & 363.38 & 181.688 & 1.35 \\
\hline 567 & 4 & 10652.3 & 145.67 & 72.834 & 0.68 \\
\hline 568 & 4 & 11628.8 & 54.91 & 27.457 & 0.24 \\
\hline
\end{tabular}

The TOC concentration that is reported for each of the SME batches represented in Table 2 is given in the third column of Table 2. The value in this column, for a given SME batch, is the average of four measurements, and thus, the 1-sigma standard uncertainty (or the standard error) for this average is the sample standard deviation for the four values divided by 2 (i.e., the square root of the number of measurements in the sample, 4). The sample standard deviation values for the SME batches are provided in the fourth column of Table 2; the values of the standard error are provided in the fifth column; and these values as percentages of the means (i.e., as \% relative standard errors) are given in the last column of Table 2 . As seen in Table 2, the $\%$ relative standard errors fall in the interval from $0.13 \%$ to $1.35 \%$. The determination of the 1 -sigma standard relative uncertainty of the average TOC measurement for a given SME batch, the \% relative standard error, is to be computed as shown here from the 4 measurements provided by DWPF Laboratory for the given SME batch. While this approach is applicable for the data that generated the results in Table 2, for the approach to better represent the uncertainty of the average of the 4 measurements in the future, it is recommended that the TOC analytical protocol be changed from 2 SME samples each being analyzed in duplicate to 4 SME samples each sample being analyzed only once.

\subsection{The MaXimum TOC/Nitrate Ratio at 60\% LFL}

As stated in the Introduction, efforts are underway at SRNL to develop a comprehensive melter flammability control strategy. The strategy for Sludge Batch 6 (SB6) and Sludge Batch 7a (SB7a) has been developed by Choi [3], and it relies on the contents of the SME satisfying a constraint on the ratio of TOC to nitrate. Before a SME batch is to be transferred to the melter, WSE must establish that the ratio of the TOC concentration to the nitrate concentration satisfies the restrictions imposed 
by Choi's analysis. However, since the implementation of the strategy in DWPF will rely on process measurements, WSE must account for the uncertainties of the measurements to confidently achieve a successful implementation. The uncertainties of these measurements were investigated in the earlier discussion, and they will be revisited now in the context of the implementation of Choi's melter flammability control strategy.

The constraint on the TOC to nitrate ratio developed by Choi maintains the contributors to the melter flammability issue to less than $60 \%$ of their lower flammability limit (LFL) [3]. The maximum allowable TOC to nitrate ratio was determined by Choi as a polynomial function of the nitrate concentration, and a different functional constraint was developed for each sludge batch: SB6 and SB7a. Since both constraints were developed over the interval of nitrate concentrations from 15,000 ppm to $30,000 \mathrm{ppm}$, that interval of nitrate concentrations is the range of applicability for these functions. If the contents of a SME batch yield an average nitrate measurement outside of the interval from 15,000 to $30,000 \mathrm{ppm}$, then satisfying the constraint on the TOC to nitrate ratio may not be a reliable control for addressing melter flammability concerns for that SME batch. In the sections that follow, the impacts of the TOC and nitrate measurement uncertainties that were determined in the earlier discussions of this report, on the assessment of the nitrate content of the SME and for controlling melter flammability are investigated.

\subsection{Assessing the Nitrate Content of the SME}

To implement the melter flammability control strategy described in [3], there is a need to assure with high confidence that the $\mathrm{NO}_{3}$ content of the SME falls within the interval from 15,000 to 30,000 ppm. Demonstrating that this condition is met for a given SME batch will rely on the four nitrate measurements from that batch. The average of these measurements may be represented by $\overline{\mathrm{NO}_{3}}$ and the standard error, or the 1-sigma standard uncertainty of this value, which is computed from the four nitrate values, may be represented by $\mathrm{se}_{\overline{\mathrm{NO}_{3}}}$. In addition from the discussion above, a batch to batch 1-sigma uncertainty of $2.09 \%$ was identified, by a review of measurements from the nitrate standards, as affecting the nitrate measurements. Following the guidelines and notational conventions presented in [5] (which may differ somewhat from the notation typically used in statistical models), an input term, $\delta_{\mathrm{NO}_{3}}$, representing this random effect in added to the measurement equation for the $\mathrm{NO}_{3}$ content in the SME. If $\mathrm{Y}_{\mathrm{NO}_{3}}$ is used to represent the estimated $\mathrm{NO}_{3}$ content of the SME, then the measurement equation for the measurand, $\mathrm{Y}_{\mathrm{NO}_{3}}$, may be written as:

Equation 1.

$$
\mathrm{Y}_{\mathrm{NO}_{3}}=\overline{\mathrm{NO}_{3}}+\delta_{\mathrm{NO}_{3}}
$$

where $\overline{\mathrm{NO}_{3}}$ represents the average of the $\mathrm{NO}_{3}$ concentration measurements for the 4 samples of the given SME batch. It has a 1-sigma standard uncertainty of $\mathrm{se}_{\overline{\mathrm{NO}_{3}}}$, and

$\delta_{\mathrm{NO}_{3}}$ represents the batch to batch source of variation affecting the nitrate measurements for a SME batch. For the evaluation of $\mathrm{Y}_{\mathrm{NO}_{3}}$ by equation (1), the value of $\delta_{\mathrm{NO}_{3}}$ is zero. Its 1-sigma standard uncertainty is represented by $\mathrm{s}_{\delta_{\mathrm{NO}_{3}}}$ and based upon the analyses presented above that value is given by $2.09 \%$ of the $\overline{\mathrm{NO}_{3}}$ value. 
The guidance provided in [5] relies on the use of a Taylor's series expansion of the measurement equation to approximate the variance of the measurand. The expression of this approximation is simplified if the errors associated with the inputs to the measurement equation are uncorrelated, which is the case for the errors associated with the two input terms of equation $(1)^{f}$. For this simple measurement equation, the variance of $\mathrm{Y}_{\mathrm{NO}_{3}}$ is equal to its Taylor's series expansion, and the estimation of the variance of $\mathrm{Y}_{\mathrm{NO}_{3}}$ is facilitated by estimating the standard deviations of $\overline{\mathrm{NO}_{3}}$ and $\delta_{\mathrm{NO}_{3}}$ by se $\frac{}{\mathrm{NO}_{3}}$ and $\mathrm{s}_{\delta_{\mathrm{NO}_{3}}}$, respectively, as indicated in equation (2):

Equation 2.

$$
\text { Est. } \operatorname{Var}\left(\mathrm{Y}_{\mathrm{NO}_{3}}\right)=\left(\operatorname{se} \frac{\mathrm{NO}_{3}}{2}+\left(\mathrm{s}_{\delta_{\mathrm{NO}_{3}}}\right)^{2}\right.
$$

where Est. $\operatorname{Var}\left(\mathrm{Y}_{\mathrm{NO}_{3}}\right)$ represents the estimated variance of $\mathrm{Y}_{\mathrm{NO}_{3}}$, the estimated nitrate content of the SME.

Thus, $\sqrt{\text { Est.Var }\left(\mathrm{Y}_{\mathrm{NO}_{3}}\right)}$ is the 1-sigma standard uncertainty of the estimated nitrate content of the SME. To determine the uncertainty at $95 \%$ confidence, $\sqrt{\text { Est.Var }\left(\mathrm{Y}_{\mathrm{NO}_{3}}\right)}$ must be multiplied by an appropriate Student's t statistic; in this case, a two-tailed t statistic is to be used. For this situation, 3 degrees of freedom will be assumed for the estimated variance of $\mathrm{Y}_{\mathrm{NO}_{3}}$. This is conservative since 3

degrees of freedom are associated with the 1-sigma standard uncertainty of $\overline{\mathrm{NO}_{3}}$ and even more degrees of freedom are associated with the 1-sigma standard uncertainty for $\delta_{\mathrm{NO}_{3}}$. The upper 2.5\%tail of the Student's t distribution with 3 degrees of freedom is 3.182. Thus, the expanded uncertainty of the estimated nitrate concentration in the $\mathrm{SME}, \mathrm{Y}_{\mathrm{NO}_{3}}$, is given by:

\section{Equation 3.}

Uncertainty of $\mathrm{Y}_{\mathrm{NO}_{3}}$ at $95 \%$ confidence $=3.182 \times \sqrt{\text { Est. } \operatorname{Var}\left(\mathrm{Y}_{\mathrm{NO}_{3}}\right)}=3.182 \times \sqrt{\left(\mathrm{se}_{\mathrm{NO}_{3}}\right)^{2}+\left(\mathrm{s}_{\delta_{\mathrm{NO}_{3}}}\right)^{2}}$

To illustrate these calculations, consider the four nitrate measurements for SME batch 566 from Table A1. The values in ppm are 23700, 23604, 23229, and 23433. The sample mean of these values, $\overline{\mathrm{NO}_{3}}$, is given by 23491.5 , and the 1-sigma standard uncertainty of the sample mean is given by sample standard deviation divided by the square root of the sample size, or 206.928/2=103.464. With $\mathrm{s}_{\delta_{\mathrm{NO}_{3}}}$ determined by $0.0209 \times 23491.5=490.972$, the expanded uncertainty at $95 \%$ confidence for the estimated nitrate content of the SME is given by $3.182 \times \sqrt{(103.464)^{2}+(490.972)^{2}}=1596.81$. Thus, with $95 \%$ confidence the nitrate content of SME batch 566 is within 1596.81 of 23491.5 ppm or within the interval from $21894.7 \mathrm{ppm}$ to $25088.3 \mathrm{ppm}$.

The errors associated with the terms in the other measurement equations investigated as part of this study are also assumed to be uncorrelated. 
SRNL-STI-2011-00214

Revision 1

\subsection{Controlling Melter Flammability}

Of the two polynomials relating the TOC to nitrate ratio to nitrate concentration, the one for SB6 is the more restrictive [3]. It is a quadratic equation of the form:

Equation 4.

$$
\left[\mathrm{TOC} / \mathrm{NO}_{3}\right]=7.2791 \mathrm{E}-10 \times\left[\mathrm{NO}_{3}\right]^{2}-5.0035 \mathrm{E}-05 \times\left[\mathrm{NO}_{3}\right]+1.5347
$$

where the term $\left[\mathrm{TOC} / \mathrm{NO}_{3}\right]$ on the left hand side of the equation represents the maximum allowable TOC to nitrate ratio required to maintain the system below the $60 \% \mathrm{LFL}$, while the $\mathrm{NO}_{3}$ term on the right hand side represents the nitrate content of the SME in ppm.

The direct utilization of equation (4) for melter flammability control yields this acceptability equation for a given SME batch:

Equation 5.

$$
\mathrm{D}=\mathrm{R}\left[\mathrm{TOC} / \mathrm{NO}_{3}\right] \times \overline{\mathrm{NO}_{3}}-\overline{\mathrm{TOC}}-\text { other }_{\mathrm{C}}>0
$$

where $\mathrm{D}$ is the measurand, and it represents the difference in ppm between the carbon allowed by equation (4) and the carbon content of the SME,

$\mathrm{R}\left[\mathrm{TOC} / \mathrm{NO}_{3}\right]$ represents the quadratic equation (4) relating the TOC to nitrate ratio to nitrate concentration,

$\overline{\mathrm{NO}_{3}}$ represents the average of the $\mathrm{NO}_{3}$ concentration measurements for the samples of the given SME batch,

$\overline{\mathrm{TOC}}$ represents the average of the TOC concentration measurements for the samples of the given SME batch, and

other ${ }_{C}$ represents carbon that is present in the SME in a form that is not measured by the TOC analytical protocol. Note, however, that such carbon was included in the determination of the TOC to nitrate ratio of equation (4) [3].

The form of equation (5) is such that the value of $\mathrm{D}$ must be positive. That is, the amount of TOC allowed by the use of equation (4) must be greater than the TOC content of the given SME, and this must be true with high confidence after accounting for the uncertainties in the measurements used to make this determination.

Since the allowable amount of TOC for the SME batch is determined as a quadratic function of the nitrate content, the allowable amount of TOC is determined by multiplying equation (4) by the measured nitrate content of the given SME as indicated in equation (5). Substituting the quadratic function into equation (5) leads to: 
Equation 6.

$$
\mathrm{D}=7.2791 \mathrm{E}-10 \times\left(\overline{\mathrm{NO}_{3}}\right)^{3}-5.0035 \mathrm{E}-05 \times\left(\overline{\mathrm{NO}_{3}}\right)^{2}+1.5347 \times\left(\overline{\mathrm{NO}_{3}}\right)-\overline{\mathrm{TOC}}-\text { other }_{\mathrm{C}}>0
$$

Following the approach and notational conventions of [5], equation (6) is modified to make it a more complete measurement equation for the determination of $\mathrm{D}$. In the discussion above, a batch to batch 1-sigma relative uncertainty of $2.09 \%$ was identified as affecting the nitrate measurements and a batch to batch 1-sigma relative uncertainty of $1.04 \%$ was identified as affecting the TOC measurements. Representing the errors for these sources of variation as $\delta_{\mathrm{NO}_{3}}$ and $\delta_{\mathrm{TOC}}$, respectively, they may be added to equation (6) to obtain a more complete measurement equation for $\mathrm{D}$ as follows:

Equation 7.

$$
\begin{gathered}
\mathrm{D}=7.2791 \mathrm{E}-10 \times\left(\overline{\mathrm{NO}_{3}}+\delta_{\mathrm{NO}_{3}}\right)^{3}-5.0035 \mathrm{E}-05 \times\left(\overline{\mathrm{NO}_{3}}+\delta_{\mathrm{NO}_{3}}\right)^{2}+1.5347 \times\left(\overline{\mathrm{NO}_{3}}+\delta_{\mathrm{NO}_{3}}\right) \\
-\left(\overline{\mathrm{TOC}}+\delta_{\mathrm{TOC}}\right)-\text { other }_{\mathrm{C}}>0
\end{gathered}
$$

The values of $\delta_{\mathrm{NO}_{3}}$ and $\delta_{\mathrm{TOC}}$ are zero in the determination of the value of $\mathrm{D}$, but including these terms in the equation for $\mathrm{D}$ allows for their contributions to the variance of $\mathrm{D}$ to be included in the variance propagation for equation (7).

A Taylor's series expansion approach is used to estimate the variance of D [5]. Assuming that the errors in equation (7) are uncorrelated and that the value for other $\mathrm{C}_{\mathrm{C}}$ is bounding and thus may be considered to be without error, the Taylor's series expansion approach yields:

Equation 8.

$$
\operatorname{var}(\mathrm{D}) \approx\left(\frac{\partial \mathrm{D}}{\partial \overline{\mathrm{NO}_{3}}}\right)^{2} \times\left(\mathrm{se}_{\mathrm{NO}_{3}}\right)^{2}+\left(\frac{\partial \mathrm{D}}{\partial \delta_{\mathrm{NO}_{3}}}\right)^{2} \times\left(\mathrm{s}_{\delta_{\mathrm{NO}_{3}}}\right)^{2}+\left(\frac{\partial \mathrm{D}}{\partial \overline{\mathrm{TOC}}}\right)^{2} \times\left(\mathrm{se}_{\overline{\mathrm{TOC}}}\right)^{2}+\left(\frac{\partial \mathrm{D}}{\partial \delta_{\mathrm{TOC}}}\right)^{2} \times\left(\mathrm{s}_{\delta_{\mathrm{TOC}}}\right)^{2}
$$

where $\frac{\partial \mathrm{D}}{\partial \bullet}$ represents the partial derivative of $\mathrm{D}$ with respect to the variable $(\bullet), \mathrm{se}_{\frac{\mathrm{NO}_{3}}{}}$ represents the 1-sigma standard uncertainty of the average nitrate measurement of the SME samples, $\mathrm{s}_{\mathrm{NO}_{3}}$ represents the 1-sigma standard uncertainty of the batch to batch variation in the nitrate measurements (based upon the analyses presented here that value is given by $2.09 \%$ of the $\overline{\mathrm{NO}_{3}}$ value), $\mathrm{se} \overline{\mathrm{TOC}}$ represents the 1-sigma standard uncertainty of the average TOC measurement of the SME samples, and $\mathrm{s}_{\delta_{\mathrm{TOC}}}$ represents the 1-sigma standard uncertainty of the batch to batch variation in the TOC measurements (based upon the analyses presented here that value is given by $1.04 \%$ of the $\overline{\mathrm{TOC}}$ value). Once again, note that no error term is introduced in equation (8) for the other $_{C}$ input of equation (7). 
Using this approach, the variance of $\mathrm{D}$ is estimated by:

Equation 9.

$$
\begin{aligned}
\operatorname{var}(\mathrm{D}) \approx & \left(7.2791 \mathrm{E}-10 \times 3 \times\left(\overline{\mathrm{NO}_{3}}+\delta_{\mathrm{NO}_{3}}\right)^{2}-5.0035 \mathrm{E}-05 \times 2 \times\left(\overline{\mathrm{NO}_{3}}+\delta_{\mathrm{NO}_{3}}\right)^{1}+1.5347\right)^{2} \times\left(\mathrm{se} \frac{\mathrm{NO}_{3}}{{ }^{2}}\right. \\
& +\left(7.2791 \mathrm{E}-10 \times 3 \times\left(\overline{\mathrm{NO}_{3}}+\delta_{\mathrm{NO}_{3}}\right)^{2}-5.0035 \mathrm{E}-05 \times 2 \times\left(\overline{\mathrm{NO}_{3}}+\delta_{\mathrm{NO}_{3}}\right)^{1}+1.5347\right)^{2} \times\left(\mathrm{s}_{\delta_{\mathrm{NO}_{3}}}\right)^{2} \\
& +\left(\operatorname{se} \frac{}{\mathrm{TOC}}\right)^{2}+\left(\mathrm{s}_{\delta_{\mathrm{TOC}}}\right)^{2}
\end{aligned}
$$

In evaluating equation (9), all of the 1-sigma standard uncertainties are to be expressed in ppm. For example, $\mathrm{s}_{\delta \mathrm{TOC}}$, which was described as being based on a $1.04 \%$ relative error, would be expressed as $0.0104 \times \overline{\mathrm{TOC}}$.

\subsection{Meeting the Constraint of the TOC to Nitrate Ratio}

In meeting the constraint of the TOC to nitrate ratio, the value for the degrees of freedom for the estimate of the variance of $\mathrm{D}$ is taken to be 3 . This is a conservative approach since it relies on only the degrees of freedom associated with the standard errors of the nitrate and TOC sample means. As indicated in equations (7), the value of D must be positive. To assure that the value of D is sufficiently positive it must be larger than its estimated uncertainty at $95 \%$ confidence. To determine the uncertainty at $95 \%$ confidence, the square root of the estimate of the variance of $\mathrm{D}$ must be multiplied by an appropriate Student's t statistic. Since only a one-sided expression of the uncertainty of $\mathrm{D}$ is needed, a one-tailed $\mathrm{t}$ statistic may be used. For 3 degrees of freedom, the upper 5\%-tail of the Student's t distribution is 2.353. Thus, the SME batch is acceptable from a melter flammability perspective if:

Equation 10.

$$
\mathrm{D}-\mathrm{t}_{(0.05,3)} \times(\text { Est. } \operatorname{var}(\mathrm{D}))^{0.5}>0
$$

Where $\mathrm{D}$ is determined using equation (7),

$\mathrm{t}_{(0.05,3)}$ is the upper 5\%-tail of the Student's t distribution (i.e., 2.353), and

Est. $\operatorname{var}(\mathrm{D})$ represents the estimate of the variance of D computed using equation (9).

To illustrate these calculations, they were performed for the nitrate and TOC values for SME batch 566 from Table A1 and Table A2, respectively. Exhibit 3 provides the results of these calculations. From this exhibit, the estimated difference as determined by equation (7) is $4148.0 \mathrm{ppm}$ with a 1sigma standard uncertainty (determined by the square root of the estimated variance of equation (9)) of $301.3 \mathrm{ppm}$. From equation (10), these results lead to an expanded uncertainty for the difference of $709.1 \mathrm{ppm}$. Since the estimated difference (4148.0) is greater than its expanded uncertainty (709.1), the TOC to nitrate ratio for the SME batch is acceptable. For completeness, the calculation of the confidence interval for the nitrate content of this batch is also shown as part of the results of the exhibit, and it demonstrates, once again, acceptable nitrate content for this SME batch. 


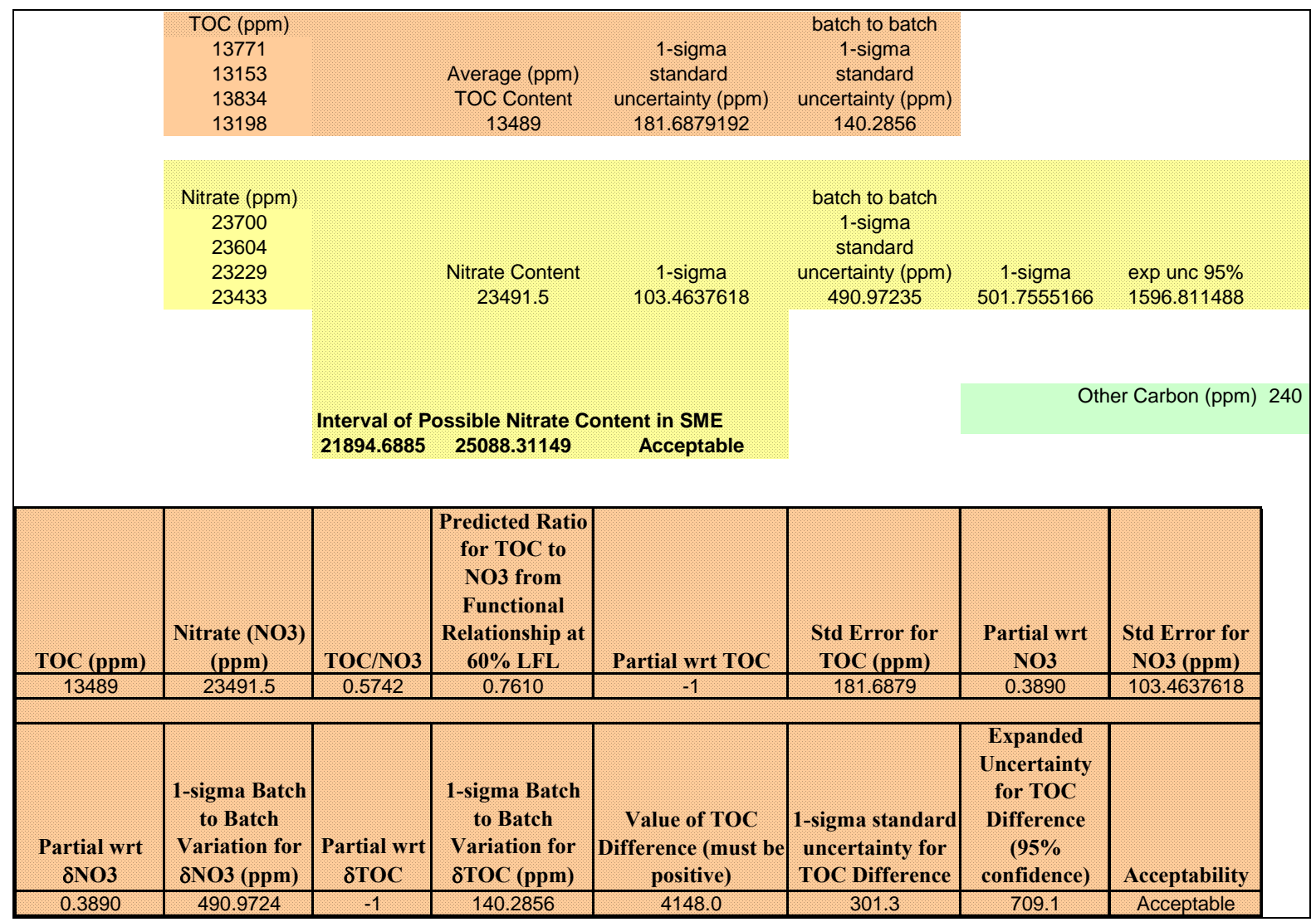

Exhibit 3. Illustration of the Calculations for Equations (7), (9), and (10)

\subsection{Estimation of Carbon Attributable to Antifoam Additions}

Another use of the measurements investigated in this study is in the estimation of the amount carbon attributable to the antifoam added during DWPF's preparation of a given SME batch. One way of estimating the amount of carbon from the added antifoam is through the use of measurements of the SME contents. The estimation of the amount of carbon from the antifoam added during processing based upon the analysis of the SME samples is to be conducted by backing out contributions to the measured TOC concentration in the SME from the oxalate and the formate concentrations that are measured in the SME. The resulting adjusted TOC value will provide a basis for WSE to estimate the amount of antifoam that was added during the preparation of the given SME batch.

The uncertainties of the oxalate, formate, and TOC measurements provided by the evaluations performed above must be appropriately propagated into the estimated quantity of carbon from the added antifoam to determine the uncertainty of that estimated quantity. This process of adjusting the measured TOC may be framed as indicated by equation (11).

Equation 11.

$$
\text { Antifoam }_{\mathrm{C}}=\overline{\mathrm{TOC}}-\mathrm{f}_{\mathrm{C}} \times \overline{\text { formate }}-\mathrm{o}_{\mathrm{C}} \times \overline{\text { oxalate }}
$$


SRNL-STI-2011-00214

Revision 1

where Antifoam $_{C}$ is the measurand and it represents the adjusted concentration in ppm of the carbon attributable to antifoam,

$\overline{\mathrm{TOC}}$ is (as above) the average of the TOC measurements in ppm for the samples from the given SME batch,

formate is the average of the formate measurements in ppm for the samples from the SME batch,

$\overline{\text { oxalate }}$ is the average of the oxalate measurements in ppm for the samples from the SME batch,

$\mathrm{f}_{\mathrm{C}}$ is the conversion factor needed to determine the carbon contributed by the formate content of the SME in ppm, and

$\mathrm{o}_{\mathrm{C}}$ is the conversion factor needed to determine the carbon contributed by the oxalate content of the SME in ppm.

The conversion factor for formate is $0.26681 \mathrm{ppm}$ carbon per ppm of formate as determined by:

Equation 12.

$\frac{1 \mathrm{mg} \text { formate }}{\text { kg SMESlurry }} \times \frac{1 \text { gram }}{1000 \mathrm{mg}} \times \frac{1 \text { gmole formate }}{45.0177 \mathrm{~g} \text { formate }} \times \frac{1 \text { gmole carbon }}{1 \text { gmole formate }} \times \frac{12.011 \mathrm{~g} \text { carbon }}{1 \text { gmole carbon }} \times \frac{1000 \mathrm{mg}}{1 \text { gram }}=0.266806 \frac{1 \mathrm{mg} \text { carbon }}{\mathrm{kg} \mathrm{SMESlurry}}$

and for oxalate, the factor is $0.27292 \mathrm{ppm}$ carbon per ppm of oxalate as determined by

Equation 13.

$\frac{1 \mathrm{mg} \text { oxalate }}{\mathrm{kg} \text { SMESlurry }} \times \frac{1 \text { gram }}{1000 \mathrm{mg}} \times \frac{1 \text { gmole oxalate }}{88.019 \mathrm{~g} \text { oxalate }} \times \frac{2 \text { gmole carbon }}{1 \text { gmole oxalate }} \times \frac{12.011 \mathrm{~g} \text { carbon }}{1 \text { gmole carbon }} \times \frac{1000 \mathrm{mg}}{1 \text { gram }}=0.27292 \frac{1 \mathrm{mg} \text { carbon }}{\mathrm{kg} \text { SMESlurry }}$

In using equation (11) to estimate the carbon content of the SME adjusted for contributions from sources other than antifoam, note the impact of oxalate values being below the detection limit of the analytical process. There are such values in Table A1 for oxalate, and they are represented in the table by values such as $<500 \mathrm{ppm}$. Representing the value for oxalate in equation (11) as a 0 leads to a conservative estimate of the amount of antifoam that was added since the TOC content would not be reduced at all for any carbon contribution by oxalate. However, if the measured oxalate concentrations are above detection, the adjusted TOC value is determined as indicated by (11). Thus, there are two equations to represent the carbon content of the SME due to antifoam: one equation without an oxalate term and one with an oxalate term.

In addition, equation (11) is to be modified in a conservative manner to handle the potential bias in the formate results (as suggested by the results from the formate standards, which were presented above). From the results of the formate standards, there was a consistently high bias for both the 2 and $16 \mathrm{ppm}$ standards. While both biases are comparable on a relative basis, the relative bias of the 2 ppm results are greater and will be used to provide a conservative result. The mean of the measurements of the 2 ppm standard in Exhibit A4, was 2.069 so an estimate of the bias is given by 
$2.069-2=0.069$ or $3.45 \%$. An upper bound on this bias, using the $95 \%$ confidence interval for the mean provided in Exhibit A4, is given by $2.092-2=0.092$ or $4.6 \%$ of the nominal $2 \mathrm{ppm}$ value. In determining the estimated amount of carbon from antifoam additions, the formate measurement will be adjusted for the potential bias, and that adjustment will be made by reducing the amount of carbon contributed by the formate by $4.6 \%$ (i.e., by multiplying the average formate content by 0.954 ).

This approach leads to the following pair of equations:

Equation 14.

$$
\text { Antifoam }_{1 \mathrm{C}}=\overline{\mathrm{TOC}}-\mathrm{f}_{\mathrm{C}} \times \overline{\text { formate }} \times 0.954-\mathrm{o}_{\mathrm{C}} \times \overline{\text { oxalate }}
$$

where Antifoam ${ }_{1 \mathrm{C}}$ is the measurand, and it represents the estimated amount of carbon attributable to antifoam when the oxalate measurements are above their detection limit,

$\overline{\text { TOC }}$ represents the average TOC measurement in ppm for the SME batch,

$\overline{\text { formate }}$ is the average of the formate measurements in ppm for the samples from the SME batch,

$\overline{\text { oxalate }}$ is the average of the oxalate measurements in ppm for the samples from the SME batch, where all of the oxalate values are above detection,

$\mathrm{f}_{\mathrm{C}}$ is the conversion factor needed to determine the carbon contributed by the formate content of the SME in ppm, and

$\mathrm{o}_{\mathrm{C}}$ is the conversion factor needed to determine the carbon contributed by the oxalate content of the SME in ppm.

Equation 15.

$$
\text { Antifoam }_{2 \mathrm{C}}=\overline{\mathrm{TOC}}-\mathrm{f}_{\mathrm{C}} \times \overline{\text { formate }} \times 0.954
$$

where Antifoam ${ }_{2 \mathrm{C}}$ is the measurand, and it represents the estimated amount of carbon in ppm attributable to antifoam when all of the oxalate values are below detection,

$\overline{\mathrm{TOC}}$ represents the average TOC measurement in ppm for the SME batch,

$\overline{\text { formate }}$ is the average of the formate measurements in ppm for the samples from the SME batch, and

$\mathrm{f}_{\mathrm{C}}$ is the conversion factor needed to determine the carbon contributed by the formate content of the SME in ppm. 
Note that in Equation (15), there is no contribution to the carbon content of the SME from oxalate and the formate content is reduced by $4.6 \%$ to account for (in a bounding way) the potential bias in the formate measurements.

Two equations have been developed to estimate the carbon content attributable to antifoam for a given SME batch. The uncertainties of the two estimates resulting from the use of these equations are now determined. To facilitate this process, the equations are modified using notational conventions suggested by [5] to develop more complete measurement equations. This involves introducing terms for the batch to batch effects for formate, $\delta_{\text {formate }}$, and oxalate, $\delta_{\text {oxalate }}$, (the necessity for these terms is indicated in Table 1) and for TOC, $\delta_{\text {TOC }}$, (as utilized in the previous section). The measurement equations resulting from these additions are given by:

Equation 16.

$$
\text { Antifoam }_{1 \mathrm{C}}=\overline{\mathrm{TOC}}+\delta_{\mathrm{TOC}}-\mathrm{f}_{\mathrm{C}} \times\left(\overline{\text { formate }}+\delta_{\text {formate }}\right) \times 0.954-\mathrm{o}_{\mathrm{C}} \times\left(\overline{\text { oxalate }}+\delta_{\text {oxalate }}\right)
$$

Equation 17.

$$
\text { Antifoam } 2 \mathrm{C}=\overline{\mathrm{TOC}}+\delta_{\mathrm{TOC}}-\mathrm{f}_{\mathrm{C}} \times\left(\overline{\text { formate }}+\delta_{\text {formate }}\right) \times 0.954
$$

where Antifoam $\mathrm{m}_{1 \mathrm{C}}$ is the measurand of equation (16), and it represents the estimated amount of carbon in ppm attributable to antifoam when the oxalate values for the SME batch are all above detection,

Antifoam $_{2 \mathrm{C}}$ is the measurand of equation (17), and it represents the estimated amount of carbon in ppm attributable to antifoam when the oxalate values for the SME batch are all below detection,

$\overline{\mathrm{TOC}}$ represents the average TOC measurement in ppm for the SME batch,

$\delta_{\mathrm{TOC}}$ represents the random batch to batch variation in the TOC measurements,

$\overline{\text { formate }}$ is the average of the formate measurements in ppm for the samples from the SME batch,

$\delta_{\text {oxalate }}$ represents the random the batch to batch variation in the oxalate measurements,

$\overline{\text { oxalate }}$ is the average of the oxalate measurements in ppm for the samples from the SME batch with all of the measurements being above detection,

$\delta_{\text {formate }}$ represents the random the batch to batch variation in the formate measurements,

$\mathrm{f}_{\mathrm{C}}$ is the conversion factor needed to determine the carbon contributed by the formate content of the SME in ppm, and

$\mathrm{o}_{\mathrm{C}}$ is the conversion factor needed to determine the carbon contributed by the oxalate content of the SME in ppm. 
For the evaluation of equations (16) and (17), the values of $\delta_{\mathrm{TOC}}, \delta_{\text {formate }}$, and $\delta_{\text {oxalate }}$ are taken to be zero. The variances of the estimates of the carbon contribution from the antifoam for both of these equations will be estimated using a Taylor's series expansion approach as utilized above. The resulting estimates of the variances are provided in the following pair of equations:

Equation 18.

$$
\begin{aligned}
\operatorname{var}\left(\text { Antifoam }_{1 \mathrm{C}}\right) & \approx\left(\mathrm{se}_{\mathrm{TOC}}\right)^{2}+\left(\mathrm{s}_{\delta_{\mathrm{TOC}}}\right)^{2}+\left(\mathrm{f}_{\mathrm{C}} \times 0.954\right)^{2} \times\left(\left(\mathrm{se}_{\text {formate }}\right)^{2}+\left(\mathrm{s}_{\delta_{\text {formate }}}\right)^{2}\right) \\
& +\left(\mathrm{o}_{\mathrm{C}}\right)^{2} \times\left(\left(\mathrm{se}_{\text {oxalate }}\right)^{2}+\left(\mathrm{s}_{\delta_{\text {oxalate }}}\right)^{2}\right)
\end{aligned}
$$

Equation 19

$$
\operatorname{var}(\text { Antifoam } 2 \mathrm{C}) \approx\left(\mathrm{se}_{\overline{\mathrm{TOC}}}\right)^{2}+\left(\mathrm{s}_{\delta_{\mathrm{TOC}}}\right)^{2}+\left(\mathrm{f}_{\mathrm{C}} \times 0.954\right)^{2} \times\left(\left(\mathrm{se}_{\text {formate }}\right)^{2}+\left(\mathrm{s}_{\delta_{\text {formate }}}\right)^{2}\right)
$$

where $\operatorname{var}\left(\right.$ Antifoam $\left._{1 C}\right)$ represents the estimate of the variance of the estimate of the carbon content due to the antifoam with all available oxalate values being above detection,

$\operatorname{var}($ Antifoam 2 C) represents the estimate of the variance of the estimate of the carbon content due to the antifoam with all available oxalate values being below detection,

$\mathrm{f}_{\mathrm{C}}$ is the conversion factor needed to determine the carbon contributed by the formate content of the SME in ppm,

$\mathrm{se}^{\mathrm{TOC}}$ represents the 1-sigma standard uncertainty of the average TOC measurement of the SME samples,

$\mathrm{s}_{\delta_{\mathrm{TOC}}}$ represents the 1-sigma standard uncertainty of the batch to batch variation in the TOC measurements (based upon the analyses presented here that value is given by $1.04 \%$ of the $\overline{\mathrm{TOC}}$ value),

$\mathrm{se} \frac{}{\text { formate }}$ represents the 1-sigma standard uncertainty of the average formate measurement of the SME samples,

$\mathrm{s}_{\delta_{\text {formate }}}$ represents the 1-sigma standard uncertainty of the batch to batch variation in the formate measurements (based upon the results in Table 1 that value is given by $1.56 \%$ of the formate value),

$\mathrm{se}_{\text {oxalate }}$ represents the 1-sigma standard uncertainty of the average oxalate measurement of the SME samples, where all oxalate values are above detection, and

$\mathrm{s}_{\delta_{\text {oxalate }}}$ represents the 1-sigma standard uncertainty of the batch to batch variation in the oxalate measurements (based upon the results in Table 1 that value is given by $1.84 \%$ of the $\overline{\text { oxalate }}$ value), 
The uncertainty of each of the estimated quantities Antifoam ${ }_{1 \mathrm{C}}$ and Antifoam $2 \mathrm{C}$ at $95 \%$ confidence is determined by multiplying the square root of the estimate of their variance by an appropriate Student's t statistic. In this case a one-sided confidence statement is needed; so, an upper 5\%-tail of the Student's t distribution will be used. Again, utilizing a conservative 3 degrees of freedom for each of the estimated variances, the $\mathrm{t}$ value is 2.353 . Thus, the upper limit at $95 \%$ confidence for each estimate of the carbon content of the SME attributable to antifoam is given by:

Equation 20.

(when all available oxalate values for the SME batch are above detection)

$$
\text { Antifoam }_{1 \mathrm{C}}+2.353 \times\left(\text { Est. } \operatorname{var}\left(\text { Antifoam }_{1 \mathrm{C}}\right)\right)^{0.5}
$$

Equation 21.

(when all available oxalate values for the SME batch are below detection)

$$
\text { Antifoam }_{2 \mathrm{C}}+2.353 \times\left(\text { Est. } \operatorname{var}\left(\text { Antifoam }_{2 \mathrm{C}}\right)\right)^{0.5}
$$

A sample calculation is provided in Exhibit 4 utilizing the data from SME batch 366. Note that for this SME batch all of the oxalate data are below detection. Therefore, the calculation represented in the exhibit corresponds to equations (17), (19), and (21). That is, the determination of the quantity of carbon attributable to antifoam uses equation (17). In the exhibit that value is labeled as "Adjusted TOC Quantity - Carbon Attributable to Antifoam (ppm)," and its value is $2734.823 \mathrm{ppm}$. The estimated variance for this quantity is given by equation (19). In the exhibit, the square root of the variance is labeled as "1-sigma standard uncertainty of the Adjusted TOC Quantity," and its value is $299.4 \mathrm{ppm}$. The upper limit, at $95 \%$ confidence, on the quantity of carbon attributable to antifoam is given by equation (21). In the exhibit, this limit is labeled as "Upper Limit at 95\% confidence for the Carbon from Antifoam Additions," and its value is $3439.536 \mathrm{ppm}$. 


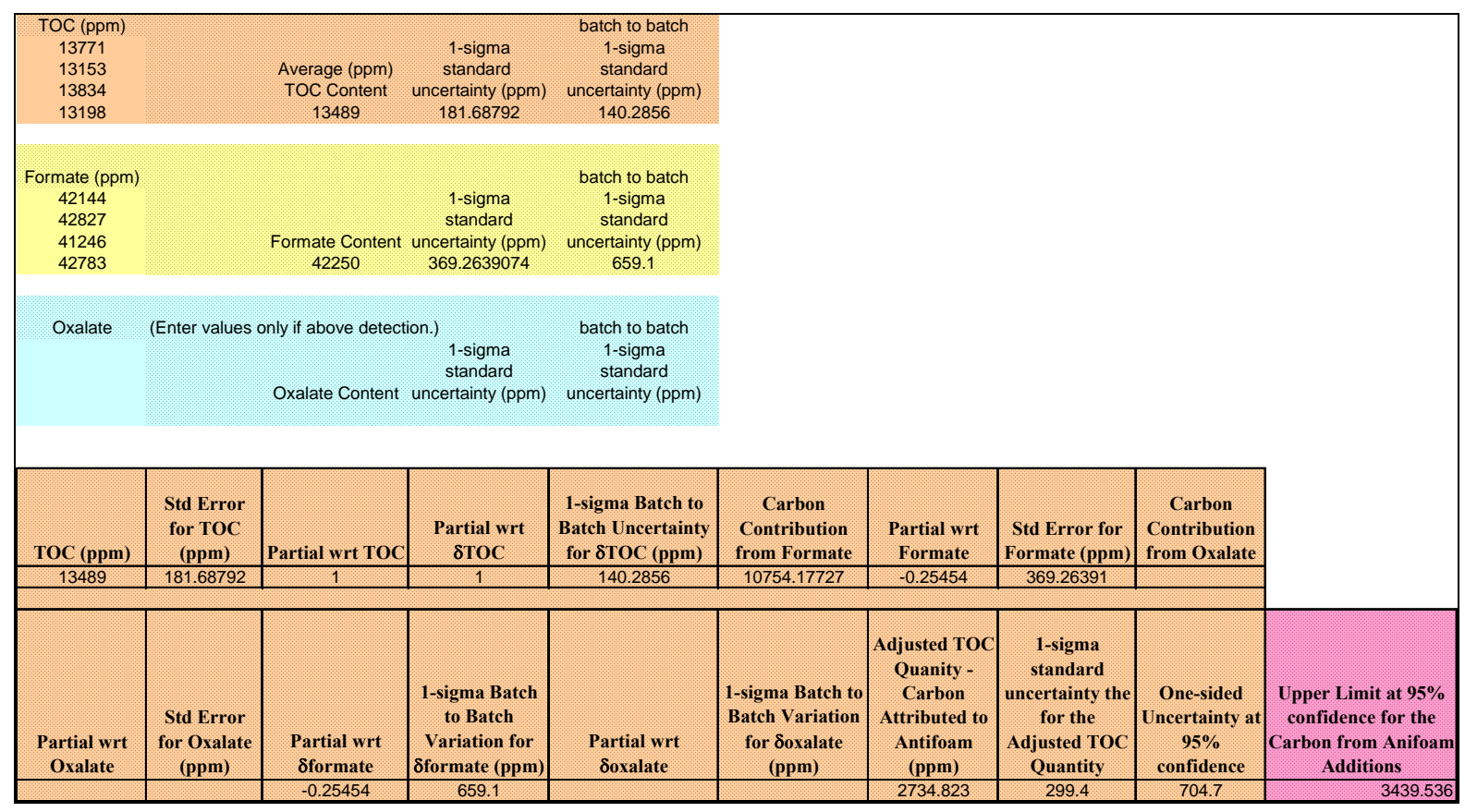

Exhibit 4. Illustration of Calculations of Equations (17), (19), and (21)

A sample calculation is provided in Exhibit 5 utilizing the data from SME batch 366 modified to include simulated, above-detection measurements for oxalate. The oxalate values were determined by multiplying the detection limits for these measurements given in Table A1 by 10. Therefore, the calculation represented in the exhibit corresponds to the determination of the quantity of carbon attributable to antifoam using equation (16). In the exhibit that value is labeled as "Adjusted TOC Quantity - Carbon Attributable to Antifoam (ppm)," and its value is $1332.69624 \mathrm{ppm}$. The estimated variance for this quantity is given by equation (18). In the exhibit, the square root of the variance is labeled as "1-sigma standard uncertainty of the Adjusted TOC Quantity," and its value is $300.7 \mathrm{ppm}$. The upper limit, at $95 \%$ confidence, on the quantity of carbon attributable to antifoam is given by equation (20). In the exhibit, this limit is labeled as "Upper Limit at 95\% confidence for the Carbon from Antifoam Additions," and its value is 2040.270 ppm. 


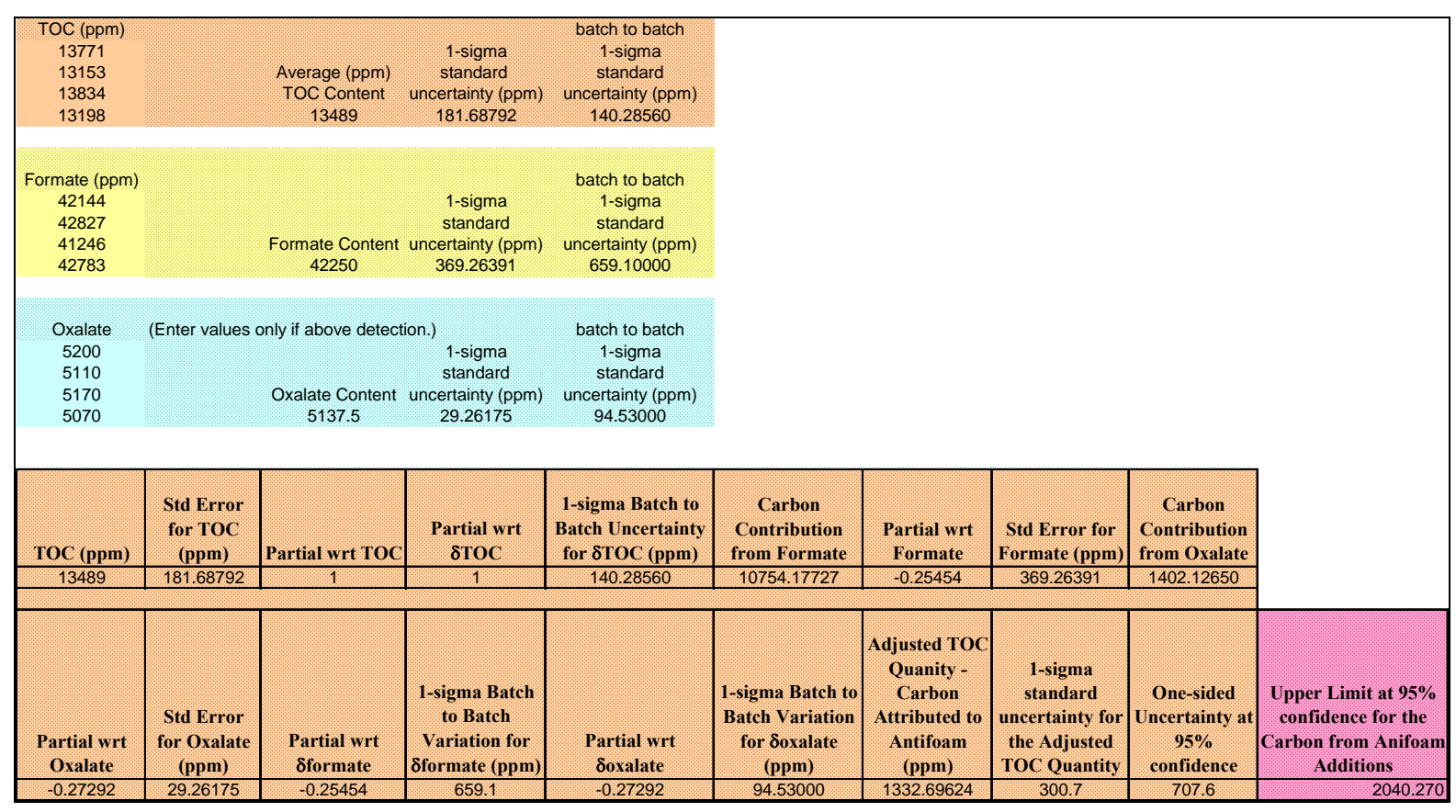

Exhibit 5. Illustration of Calculations of Equations (16), (18), and (20)

\subsection{SUMMARY}

In this report, the formate, nitrate, oxalate, and TOC measurements generated by the DWPF Laboratory for recent SME batches are presented. These measurements were provided to SRNL by DWPF Laboratory OPS personnel. An evaluation of the uncertainties of these measurements is provided as well as approaches for assessing the impact of these uncertainties on DWPF's strategies for controlling melter flammability and for monitoring antifoam additions.

\section{REFERENCES}

[1] Bricker, J.M., “Technical Task Request: IC Analytical Error Analysis,” HLW-DWPF-TTR2011-0012, March 15, 2011.

[2] Edwards, T.B., "Task Technical and Quality Assurance Plan: IC Analytical Error Analysis," SRNL-RP-2011-00647, Revision 0, March, 2011.

[3] Choi, A.S., "DWPF Melter Off-Gas Flammability Assessment (Sludge Batch 6 and for Sludge Batch 7a)," Revision 5, X-CLC-S-00164, April, 2011.

[4] JMP Version 7.0.2, SAS Institute, Inc., Cary NC, 1989-2007.

[5] International Organization for Standardization (ISO), Guide to the Expression of Uncertainty in Measurement, ISO, Geneva, 1993, Corrected and reprinted, 1995. 
SRNL-STI-2011-00214

Revision 1

Appendix A.

Supplemental Tables and Exhibits 
Table A1. DWPF Laboratory Measurements of Anions by IC

(LIMS Numbers in Red: M-14 instrument was used; LIMS Numbers in Blue: M-13 Instrument was used)

\begin{tabular}{|c|c|c|c|c|c|c|c|c|c|c|c|c|c|c|c|c|c|c|c|c|c|c|}
\hline & IC Instrument & M-13 & M-14 & M-14 & M-13 & M-14 & M-14 & M-14 & M-14 & $\mathrm{M}-13$ & M-14 & M-14 & $\mathrm{M}-14$ & M-13 & M-14 & M-13 & M-14 & M-13 & M-14 & M-13 & M-14 & M-14 \\
\hline LIMS number & & 5839 & 5699 & 5623 & 5489 & $5413 / 33$ & 5312 & 5254 & 5167 & $5067 / 133$ & $4877 / 133$ & 4707 & $\begin{array}{l}4567 / 97 / 07 \\
\end{array}$ & 4422 & 4317 & 4253 & 4127 & $4017 / 42$ & 3822 & 3758 & 3602 & 3532 \\
\hline Tank & & SME-1 & SME-1 & SME-1 & SME-1 & SME-1 & SME-1 & SME-1 & SME-1 & SME-1 & SME-1 & SME-1 & SME-1 & SME-1 & SME-1 & SME-1 & SME-1 & SME-1 & SME-1 & SME-1 & SME-1 & SME-1 \\
\hline Batch \# & & 566 & 565 & 564 & 563 & 562 & 561 & 560 & 559 & 558 & 557 & 556 & 555 & 554 & 553 & 552 & 551 & 550 & 549 & 548 & 547 & 546 \\
\hline Date & & $3 / 13 / 11$ & $3 / 8 / 11$ & $3 / 3 / 11$ & $2 / 23 / 11$ & $2 / 18 / 11$ & $2 / 12 / 11$ & $2 / 8 / 11$ & $2 / 3 / 11$ & $\begin{array}{l}1 / 29 / 11 \\
\end{array}$ & $\begin{array}{l}1 / 20 / 11 \\
\end{array}$ & $1 / 11 / 11$ & $1 / 6 / 11$ & $12 / 30 / 11$ & $12 / 23 / 10$ & $12 / 20 / 10$ & $12 / 14 / 10$ & $12 / 10 / 10$ & $11 / 28 / 10$ & $\begin{array}{ll}11 / 23 / 10 \\
\end{array}$ & $11 / 14 / 10$ & $11 / 11 / 10$ \\
\hline $\mathrm{mg} / \mathrm{kg}$ slurry & TOC & 13489 & 12633 & 13207 & 12856 & 12428 & 12781 & 14137 & 14595 & 12185 & 16394 & 14464 & 14043 & 14097 & 13669 & 13140 & 14934 & 15207 & 14070 & 13390 & 12389 & 12780 \\
\hline \multirow{12}{*}{$\mathrm{mg} / \mathrm{kg}$ slurry } & Formate & 42144 & 38476 & 41700 & 42526 & 37874 & 39285 & 40655 & 38610 & 34289 & 40136 & 39474 & 37562 & 41167 & 35639 & 35908 & 38648 & 45575 & 36696 & 34411 & 33028 & 36418 \\
\hline & Formate & 42827 & 39478 & 41251 & 39648 & 36930 & 37927 & 39569 & 37894 & 32272 & 35218 & 39443 & 37822 & 39761 & 36340 & 36059 & 38966 & 49557 & 36429 & 34982 & 34111 & 36032 \\
\hline & Formate & 41246 & 39581 & 41058 & 40330 & 37495 & 39067 & 41389 & 37828 & 32379 & 38621 & 38515 & 39598 & 40162 & 36638 & 36081 & 38343 & 40008 & 36580 & 34602 & 33766 & 36078 \\
\hline & Formate & 42783 & 38684 & 42795 & 40941 & 37970 & 37860 & 40555 & 39327 & 31138 & 37987 & 38400 & 37686 & 39535 & 36739 & 36577 & 38079 & 41955 & 36797 & 34320 & 33993 & 35384 \\
\hline & & & & & & & & & & & & & & & & & & & & & & \\
\hline & $\begin{array}{l}\text { Nitrate } \\
\text { Nitrate }\end{array}$ & $\begin{array}{l}23700 \\
23604\end{array}$ & $\begin{array}{l}23250 \\
23254\end{array}$ & $\frac{22058}{22004}$ & $\frac{22742}{22305}$ & $\frac{23652}{24501}$ & $\begin{array}{l}23163 \\
23108\end{array}$ & $\begin{array}{l}26075 \\
26329\end{array}$ & $\frac{20305}{20782}$ & $\frac{21758}{21807}$ & $\frac{24414}{21339}$ & $\begin{array}{l}21801 \\
21120\end{array}$ & $\frac{23335}{22814}$ & $\frac{27315}{26366}$ & $\begin{array}{l}22162 \\
22706\end{array}$ & $\begin{array}{l}20143 \\
20179\end{array}$ & $\frac{21877}{22027}$ & 25500 & $\begin{array}{l}19740 \\
19089\end{array}$ & $\frac{24397}{24392}$ & $\begin{array}{l}24475 \\
25501\end{array}$ & $\frac{19897}{19644}$ \\
\hline & Nitrate & 23229 & 23273 & 21801 & 22771 & $\frac{24301}{23180}$ & $\frac{2510}{22759}$ & $\frac{20329}{26481}$ & 19817 & $\frac{21804}{22042}$ & $\frac{21339}{23405}$ & $\frac{21120}{20735}$ & $\frac{22814}{22946}$ & $\frac{26366}{26498}$ & $\frac{22706}{22581}$ & $\begin{array}{l}20189 \\
20189\end{array}$ & $\frac{22027}{21622}$ & $\frac{21831}{22351}$ & $\begin{array}{l}110089 \\
20660\end{array}$ & $\frac{24392}{24123}$ & $\begin{array}{l}25001 \\
25226\end{array}$ & $\frac{19644}{19513}$ \\
\hline & $\begin{array}{l}\text { Nitrate } \\
\end{array}$ & 23433 & 23000 & 22361 & 22313 & 24453 & 23148 & 26010 & 19792 & 21003 & 22948 & 20725 & 22347 & 26057 & 23033 & 20596 & 21781 & 23811 & 19736 & 24181 & 25600 & 19291 \\
\hline & Oxalate & $<520$ & $<542$ & $<513$ & 605 & $<496$ & $<517$ & $\begin{array}{l}563 \\
\end{array}$ & $<484$ & $<487$ & $<542$ & $<515$ & $\begin{array}{l}<542 \\
\end{array}$ & $<515$ & $\begin{array}{c}<500 \\
\end{array}$ & $<490$ & $<507$ & 764 & $<501$ & $<483$ & $<533$ & $<491$ \\
\hline & Oxalate & $<511$ & $<534$ & $<514$ & 585 & $<505$ & $<510$ & 565 & $<513$ & $\begin{array}{l}<503 \\
\end{array}$ & $<551$ & $<498$ & $<488$ & $<481$ & $<506$ & $<485$ & $<538$ & 891 & $<495$ & $<485$ & $<550$ & $<506$ \\
\hline & Oxalate & $<517$ & $<512$ & $<506$ & 501 & $<497$ & $<515$ & 570 & $<503$ & $<498$ & $<500$ & $<517$ & $<536$ & $<505$ & $<503$ & $<492$ & $<521$ & 750 & $<492$ & $<493$ & $<527$ & $<485$ \\
\hline & Oxalate & $<507$ & $<516$ & $<497$ & 599 & $<492$ & $<518$ & 553 & $<498$ & $<490$ & $<548$ & $<500$ & $<530$ & $<500$ & $<509$ & $<491$ & $<493$ & 779 & $<495$ & $<477$ & $<549$ & $<473$ \\
\hline Actual ppm & Formate & 8.02 & 7.00 & 794 & 8.34 & 7.51 & 770 & 7.78 & 7.72 & & 7. & 784 & 697 & 847 & & 72 & & 840 & 725 & & 614 & 712 \\
\hline $\begin{array}{l}\text { Actual ppm } \\
\text { from IC }\end{array}$ & Formate & 8.31 & 7.30 & 7.93 & 7.91 & 7.22 & 7.10 & 7.80 & 7.12 & 6.95 & 6.48 & 8.18 & $\begin{array}{l}0.91 \\
7.51 \\
\end{array}$ & 8.47 & $\begin{array}{l}7.14 \\
7.17 \\
\end{array}$ & 7.22 & 6.97 & $\frac{8.40}{8.83}$ & 7.25 & $\frac{7.01}{7.07}$ & 6.14 & $\frac{7.12}{6.97}$ \\
\hline \multirow[t]{10}{*}{ instrument } & Formate & 8.15 & 7.50 & 7.91 & 7.97 & 7.36 & 7.69 & 7.94 & 7.54 & 6.39 & 7.64 & 7.56 & 7.11 & 7.76 & 7.35 & 7.22 & 7.04 & 7.16 & 7.33 & 7.00 & 5.97 & 7.34 \\
\hline & Formate & 8.07 & 7.35 & 8.44 & 8.11 & 7.50 & 7.36 & 8.02 & 7.65 & 6.36 & 6.82 & 7.93 & 6.83 & 7.48 & 7.13 & 7.37 & 7.43 & 7.70 & 7.29 & 7.21 & 6.48 & 7.41 \\
\hline & Nitrate & 4.51 & 4.23 & 4.20 & 4.46 & 4.69 & 4.54 & 4.99 & 4.06 & 4.41 & 4.55 & 4.33 & 4.32 & 5.62 & 4.44 & 4.05 & 4.07 & 4.70 & 3.90 & 4.88 & 4.55 & 3.89 \\
\hline & Nitrate & 4.58 & 4.30 & 4.23 & 4.45 & 4.79 & 4.60 & 5.19 & 4.02 & 4.23 & 4.09 & 4.38 & 4.53 & 5.61 & 4.48 & 4.13 & 3.94 & 4.96 & 3.82 & 4.97 & 4.62 & 3.80 \\
\hline & Nitrate & 4.59 & 4.41 & 4.20 & 4.50 & 4.55 & 4.48 & 5.08 & 3.95 & 4.34 & 4.63 & 4.07 & 4.12 & 5.12 & 4.53 & 4.04 & 3.97 & 4.00 & 4.14 & 4.93 & 4.46 & 3.97 \\
\hline & Nitrate & 4.42 & $\begin{array}{l}4.37 \\
\end{array}$ & 4.41 & 4.42 & 4.83 & 4.50 & 5.15 & 3.85 & 4.29 & 4.12 & 4.28 & 4.05 & 4.93 & 4.47 & 4.15 & 4.25 & 4.37 & 3.90 & 5.07 & 4.88 & 4.04 \\
\hline & $\begin{array}{l}\text { Oxalate } \\
\end{array}$ & & & & 1.21 & & & & & & & & & & & & & 1.47 & & & & \\
\hline & Oxalate & & & & 1.15 & & & & & & & & & & & & & 1.64 & & & & \\
\hline & Oxalate & & & & 1.01 & & & & & & & & & & & & & 1.37 & & & & \\
\hline & $\begin{array}{l}\text { Oxalate } \\
\end{array}$ & & & & 1.21 & & & & & & & & & & & & & 1.42 & & & & \\
\hline & & & & & & & & & & & & & & & & & & & & & & \\
\hline 2 ppm Before & Formate & 2.01 & 1.96 & 2.09 & 1.95 & 2.07 & 2.06 & 1.99 & 2.04 & 2.01 & 2.04 & 1.98 & 2.11 & $\frac{2.17}{202}$ & 2.06 & 2.10 & 2.09 & 2.09 & 2.09 & $\frac{2.08}{2.12}$ & $\frac{2.10}{2.09}$ & $\frac{2.11}{2.15}$ \\
\hline$\frac{2 \mathrm{ppm} \text { Before }}{2 \mathrm{ppm} \text { Before }}$ & $\begin{array}{l}\text { Nitrate } \\
\text { Oxalate }\end{array}$ & $\frac{1.89}{2.10}$ & $\frac{2.14}{2.07}$ & $\frac{2.10}{2.08}$ & $\frac{1.87}{2.05}$ & $\frac{2.06}{2.08}$ & $\frac{2.09}{2.07}$ & $\frac{2.05}{2.03}$ & $\frac{2.03}{2.05}$ & $\frac{1.97}{2.13}$ & $\frac{2.05}{2.09}$ & $\frac{1.93}{2.11}$ & $\frac{1.95}{2.02}$ & $\frac{2.02}{2.17}$ & $\begin{array}{l}1.90 \\
2.10\end{array}$ & $\frac{1.98}{2.12}$ & $\frac{2.00}{2.07}$ & $\frac{1.99}{2.20}$ & $\frac{1.91}{2.10}$ & $\frac{2.12}{2.18}$ & $\frac{2.09}{2.23}$ & $\frac{2.15}{2.23}$ \\
\hline & & & & & & & & & & & & & & & & & & & & & & \\
\hline $16 \mathrm{ppm}$ Before & Formate & 16.36 & 16.36 & 16.57 & 15.83 & 16.13 & 16.40 & 15.88 & 16.31 & 16.49 & 16.44 & 16.71 & 16.82 & 17.11 & 16.31 & 16.88 & 16.15 & 16.60 & 16.17 & 16.06 & 16.47 & 16.46 \\
\hline $16 \mathrm{ppm}$ Before & Nitrate & 16.05 & 16.13 & 16.31 & 15.83 & 15.75 & 16.06 & 15.54 & 16.02 & 15.89 & 15.98 & 16.14 & 16.16 & 16.45 & 15.65 & 16.06 & 15.67 & 16.70 & 15.76 & 16.88 & 16.20 & 17.18 \\
\hline $16 \mathrm{ppm}$ Before & $\begin{array}{l}\text { Oxalate } \\
\end{array}$ & 16.08 & 16.10 & 16.29 & 15.70 & 15.78 & 16.08 & 15.56 & 16.05 & 15.93 & 16.08 & 16.23 & 16.38 & 16.52 & 15.87 & 16.12 & 15.67 & 16.90 & 15.74 & 16.33 & 16.56 & 16.53 \\
\hline & & & & & & & & & & & & & & & & & & & & & & \\
\hline $2 \mathrm{ppm}$ After & Formate & 2.02 & 1.97 & 2.13 & 2.12 & 2.12 & 2.10 & 2.05 & 1.99 & 2.01 & 2.02 & 2.05 & 2.13 & 2.17 & 2.08 & 2.12 & 2.07 & 2.09 & 2.13 & 2.08 & 2.12 & 2.13 \\
\hline $2 \mathrm{ppm} \mathrm{After}$ & Nitrate & 1.89 & 2.06 & 2.15 & 2.10 & 2.05 & 2.15 & 2.11 & 2.18 & 1.97 & 1.92 & 1.96 & 2.00 & 2.00 & 1.95 & 2.00 & 1.95 & 2.05 & 1.98 & 2.10 & 1.99 & 2.12 \\
\hline $2 \mathrm{ppm}$ After & $\begin{array}{l}\text { Oxalate } \\
\end{array}$ & 2.09 & 2.07 & 2.08 & 2.05 & 2.07 & 2.06 & 2.01 & 2.05 & 2.13 & 2.03 & 2.06 & 2.14 & 2.15 & 2.09 & 2.12 & 2.08 & 2.19 & 2.08 & 2.17 & 2.22 & 2.20 \\
\hline $16 \mathrm{ppm}$ After & Formate & 16.37 & & 16 & 15 & & 16. & 15 & 16 & 16 & 16. & 16. & 10 & 17. & 16. & 16.71 & 16.12 & 16.61 & 16.19 & 16.07 & 16.46 & 16.51 \\
\hline $16 \mathrm{ppm}$ After & Nitrate & 16.05 & 16.34 & 16.26 & 15.67 & 15.82 & 16.06 & 15.55 & 16.06 & 15.89 & 15.94 & 16.16 & 16.20 & 16.44 & 16.03 & 16.07 & 15.71 & 16.69 & 15.79 & 16.82 & 16.20 & 17.18 \\
\hline $16 \mathrm{ppm}$ After & Oxalate & 16.08 & 16.13 & 16.30 & 15.60 & 15.84 & 16.08 & 15.58 & 16.06 & 15.93 & 16.06 & 16.25 & 16.40 & 16.52 & 15.88 & 16.13 & 15.68 & 16.68 & 15.74 & 16.30 & 16.50 & 16.51 \\
\hline
\end{tabular}


Table A2. Total Organic Carbon (TOC) Measurements by SME Batch

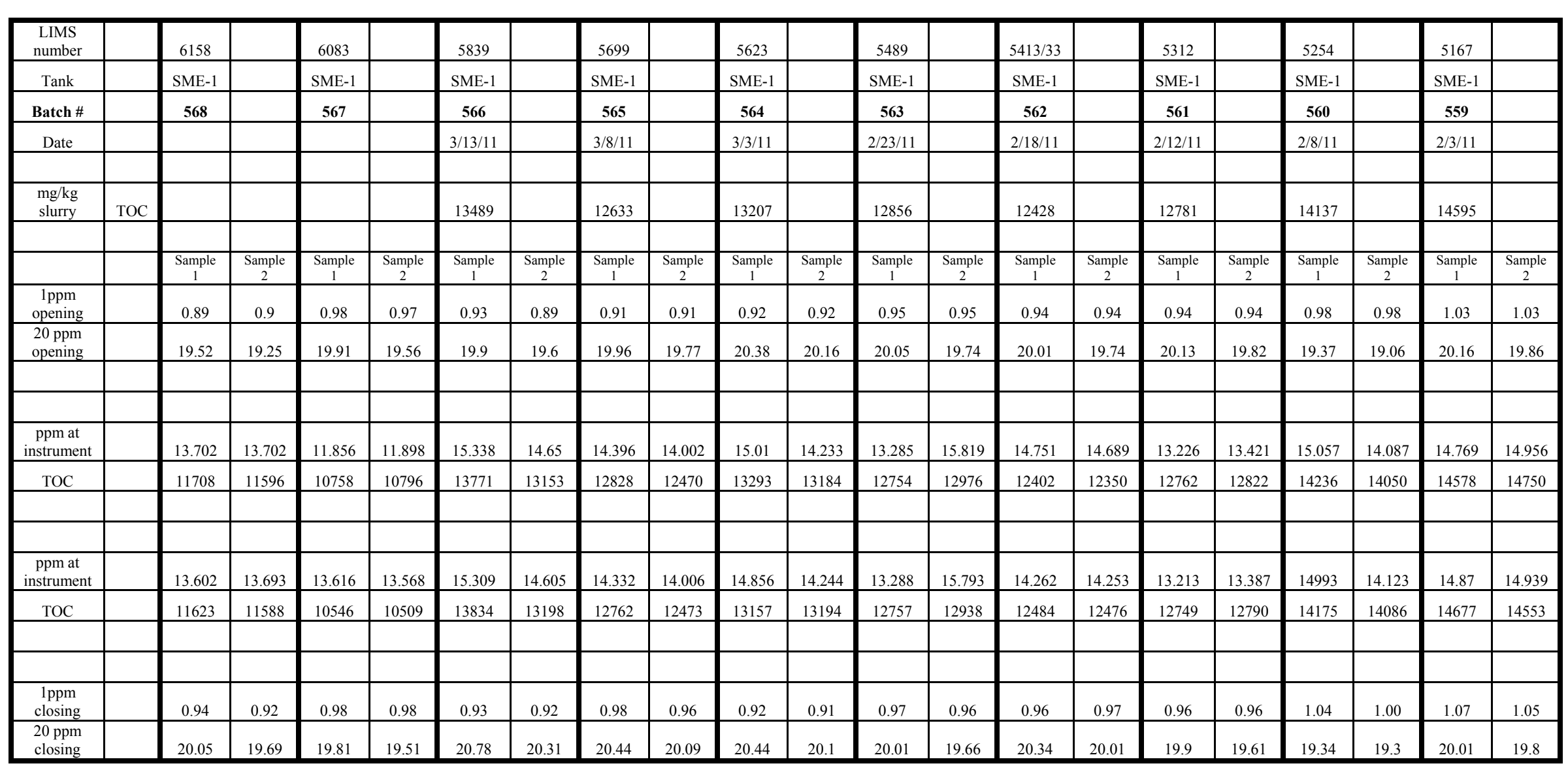




\section{Exhibit A1. Variability Plots of the Measurements of the IC Standards for Formate, Nitrate, and Oxalate}

Standard=Formate, Standard Value $(\mathbf{p p m})=2$ Variability Chart for Measurement

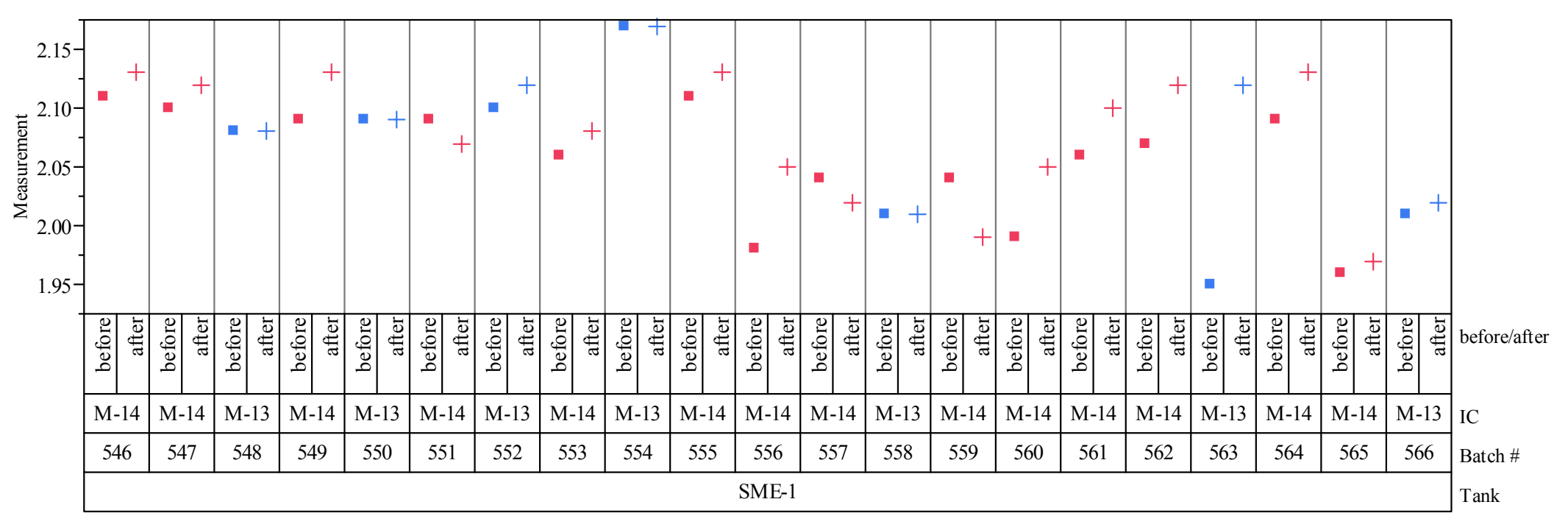

Standard=Formate, Standard Value $(\mathrm{ppm})=16$ Variability Chart for Measurement

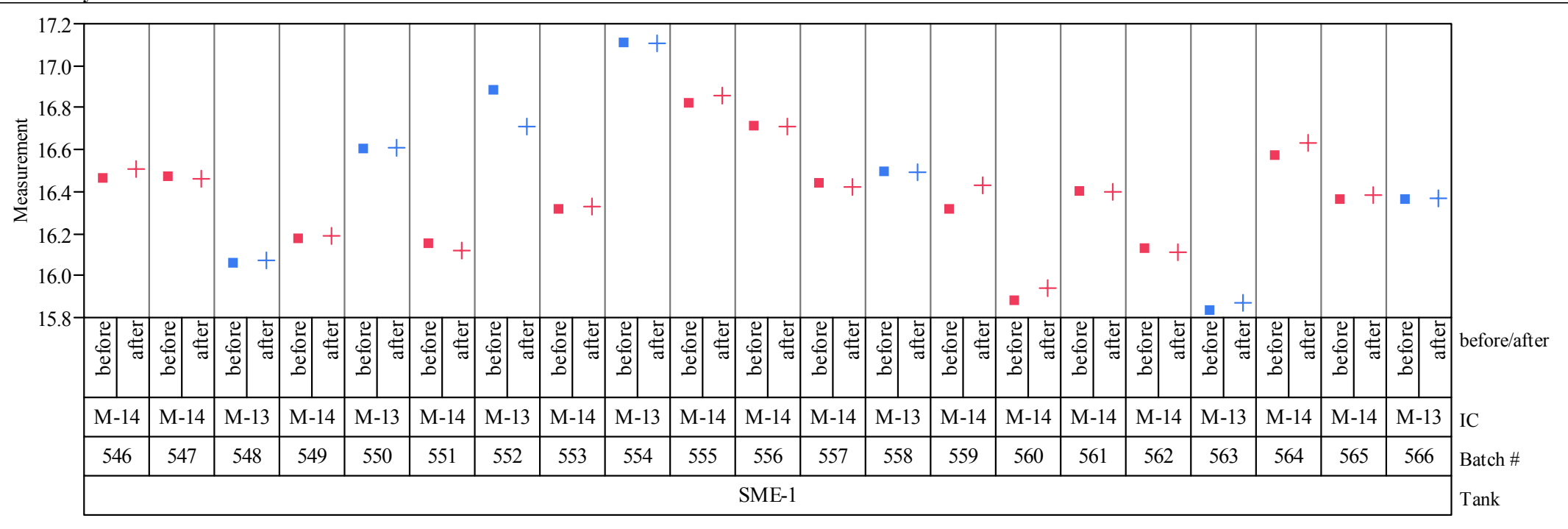




\section{Exhibit A1. Variability Plots of the Measurements of the IC Standards for Formate, Nitrate, and Oxalate}

Standard $=$ Nitrate, Standard Value $(\mathbf{p p m})=2$

Variability Chart for Measurement

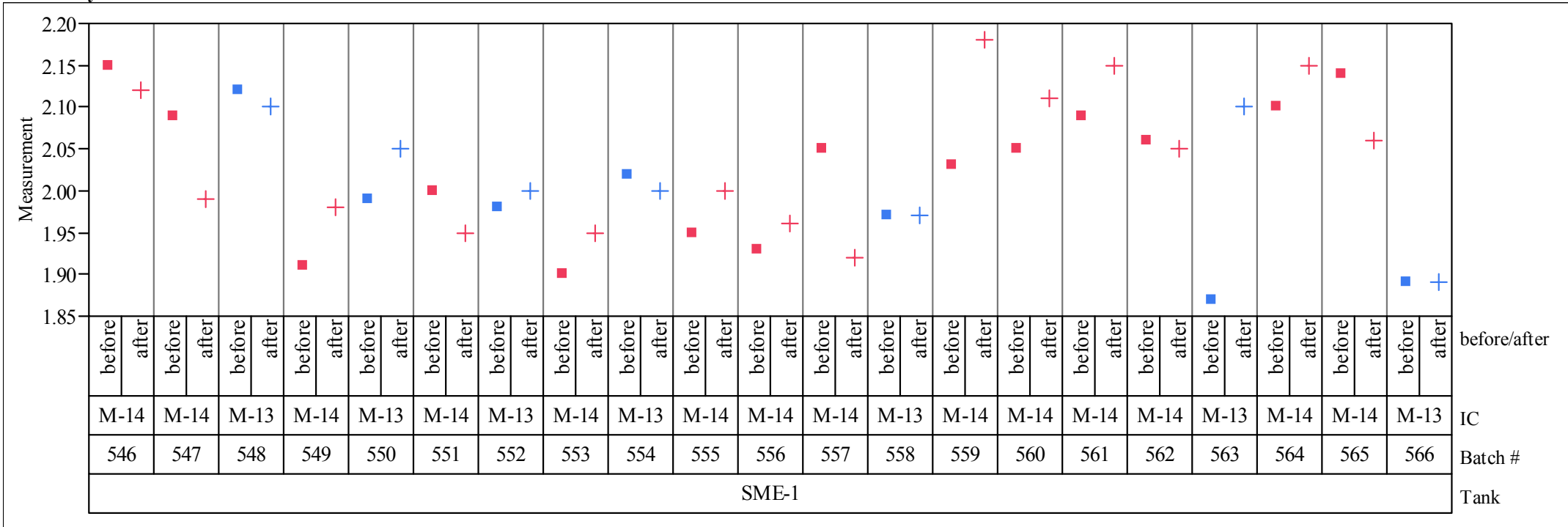

Variability Gauge Standard=Nitrate, Standard Value (ppm)=16 Variability Chart for Measurement

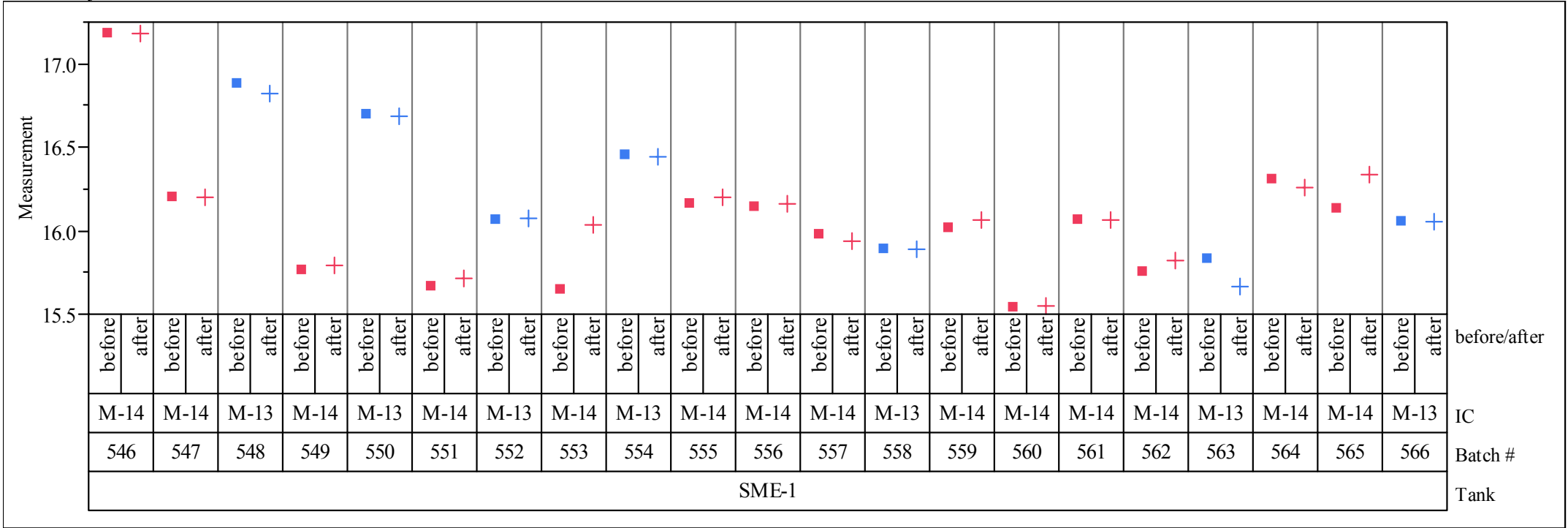




\section{Exhibit A1. Variability Plots of the Measurements of the IC Standards for Formate, Nitrate, and Oxalate}

Standard $=$ Oxalate, Standard Value $(\mathbf{p p m})=\mathbf{2}$

Variability Chart for Measurement

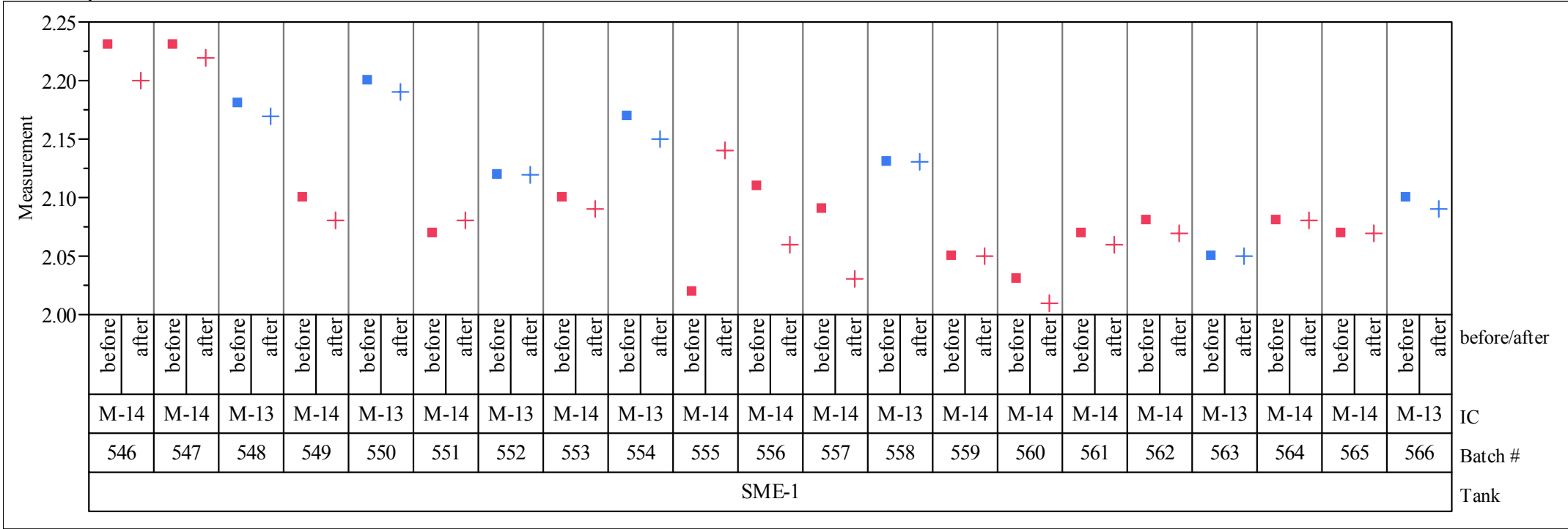

Standard $=$ Oxalate, Standard Value $(\mathrm{ppm})=16$ Variability Chart for Measurement

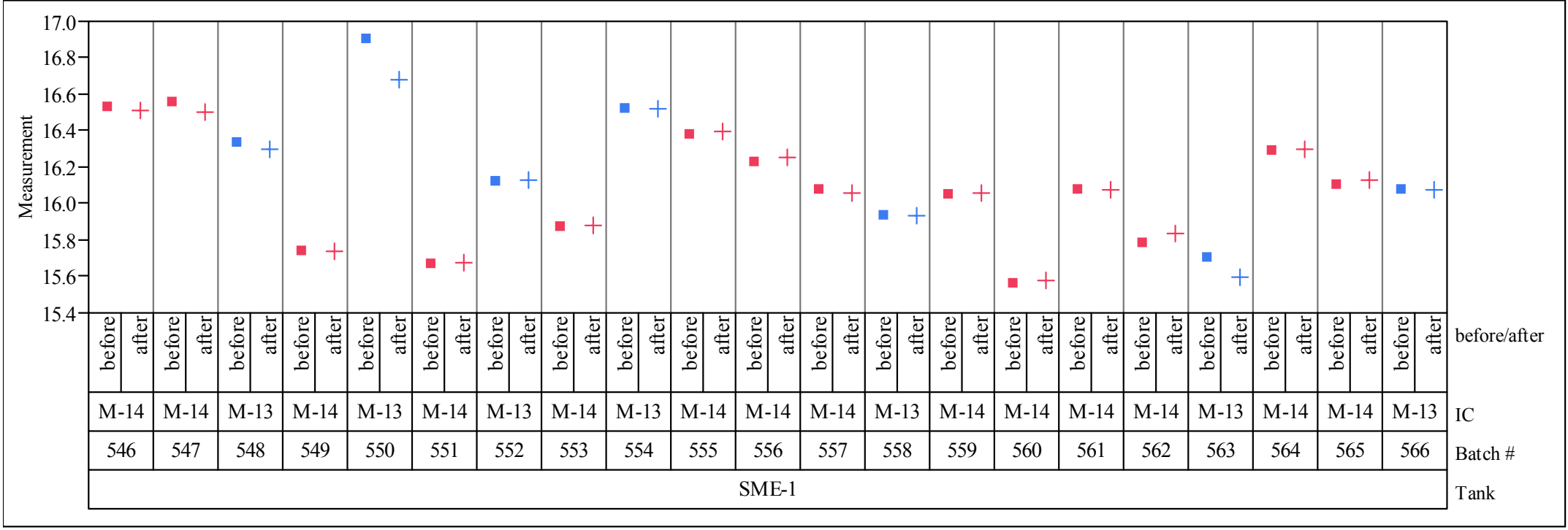




\section{Exhibit A2. Random Effects Model for Batch to Batch Variation in the Measurement of Each Standard}

Response Measurement Standard=Formate, Standard Value $(\mathrm{ppm})=2$ Whole Model

Actual by Predicted Plot

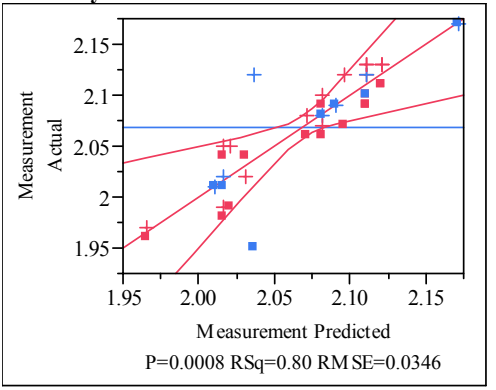

$\begin{array}{lr}\text { Summary of Fit } & \\ \text { RSquare } & 0.804763 \\ \text { RSquare Adj } & 0.618824 \\ \text { Root Mean Square Error } & 0.034572 \\ \text { Mean of Response } & 2.069048 \\ \text { Observations (or Sum Wgts) } & 42\end{array}$

Analysis of Variance

Source DF Sum of Squares Mean Square F Ratio

Model $20 \quad 0.10346190 \quad 0.005173 \quad 4.328$

$\begin{array}{llll}\text { Error } & 21 & 0.02510000 & 0.001195 \text { Prob }>\text { F }\end{array}$

$\begin{array}{lrrr}\text { C. Total } & 41 & 0.12856190 & 0.001195 \\ \end{array}$

Expected Mean Squares

The Mean Square per row by the Variance Component per column

EMS Intercept Batch \#\&Random

$\begin{array}{lll}\text { Intercept } & 0 & 0 \\ \text { Batch \#\&Random } & 0 & 2\end{array}$

plus 1.0 times Residual Error Variance

Variance Component Estimates

Component Var Comp Est Percent of Tota

Batch \#\&Random $\quad 0.001989 \quad 62.463$

$\begin{array}{lll}\text { Residual } & 0.001195 & 37.537\end{array}$

Total $\quad 0.003184 \quad 100.000$

These estimates based on equating Mean Squares to Expected Value.

Test Denominator Synthesis

Source MS Den DF Den Denom MS Synthesis

Batch \#\&Random $\quad 0.0012$

21 Residual

Tests wrt Random Effects

Source SS MS Num DF Num F Ratio Prob $>$ F

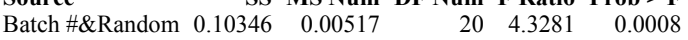

Residual by Predicted Plot

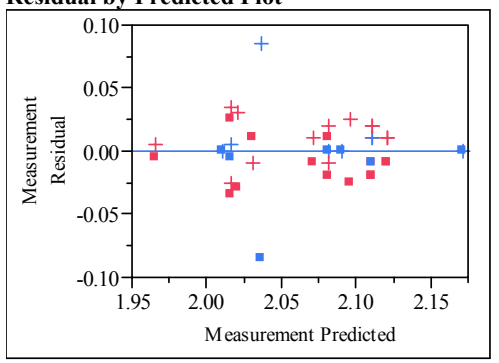

Batch \#\&Random

Effect Test

Sum of Squares F Ratio DF Prob $>$ F

$\begin{array}{lrrr}0.10346190 & 4.3281 & 20 & 0.0008\end{array}$

Denominator MS Synthesis:

Residual
Response Measurement Standard=Formate, Standard Value $(\mathrm{ppm})=16$ Whole Model

Actual by Predicted Plot

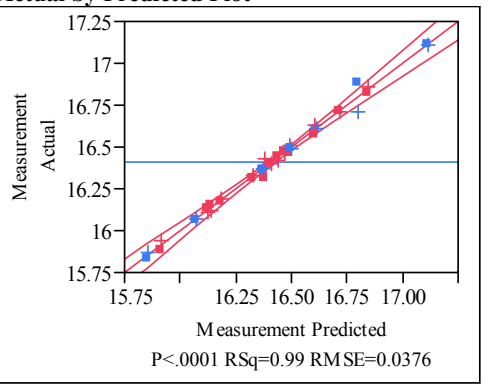

Summary of Fit

RSquare 0.992278

RSquare Adj $\quad 0.984923$

Root Mean Square Error $\quad 0.037639$

Mean of Response $\quad 16.41024$

Observations (or Sum Wgts) $\quad 42$

Analysis of Variance

Source DF Sum of Squares Mean Square F Ratio

$\begin{array}{llllll}\text { Model } & 20 & 3.8227476 & 0.191137 & 134.9205\end{array}$

$\begin{array}{llll}\text { Error } & 21 & 0.0297500 & 0.001417 \text { Prob }>\text { F }\end{array}$

$\begin{array}{llll}\text { C. Total } 41 & 4.8524976 & <.0001\end{array}$

Expected Mean Squares

The Mean Square per row by the Variance Component per column

EMS Intercept Batch \#\&Random

$\begin{array}{lll}\text { Intercept } & 0 & 0 \\ \text { Batch \#\&Random } & 0 & 2\end{array}$

plus 1.0 times Residual Error Variance

Variance Component Estimates

Component Var Comp Est Percent of Total

Batch \#\&Random $\quad 0.09486 \quad 98.529$

Residual $\quad 0.001417 \quad 1.471$

$\begin{array}{lll}\text { Total } & 0.096277 & 100.000\end{array}$

These estimates based on equating Mean Squares to Expected Value.

Test Denominator Synthesis

Source MS Den DF Den Denom MS Synthesis

Batch \#\&Random $0.00142 \quad 21$ Residual

Tests wrt Random Effects

Source SS MS Num DF Num F Ratio Prob $>$ F

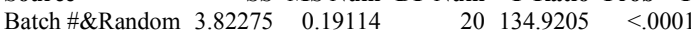

Residual by Predicted Plot

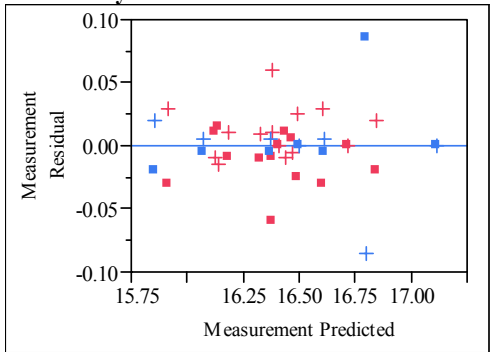

Batch \#\&Random

Effect Test

Sum of Squares F Ratio DF Prob $>$ F

$\begin{array}{llll}3.8227476 & 134.9205 & 20 & <.0001\end{array}$

Denominator MS Synthesis:

Residual 


\section{Exhibit A2. Random Effects Model for Batch to Batch Variation in the Measurement of Each Standard}

Response Measurement Standard $=$ Nitrate, Standard Value $(\mathbf{p p m})=2$ Whole Model

Actual by Predicted Plot

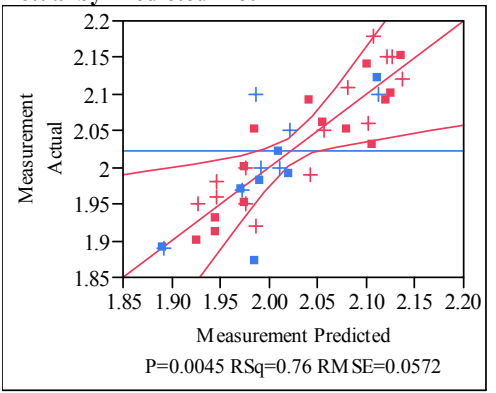

$\begin{array}{lr}\text { Summary of Fit } & \\ \text { RSquare } & 0.758855 \\ \text { RSquare Adj } & 0.529192 \\ \text { Root Mean Square Error } & 0.057217 \\ \text { Mean of Response } & 2.023095 \\ \text { Observations (or Sum Wgts) } & 42\end{array}$

Analysis of Variance

Source DF Sum of Squares Mean Square F Ratio

$\begin{array}{lllll}\text { Model } & 20 & 0.21634762 & 0.010817 \quad 3.3042\end{array}$

$\begin{array}{llll}\text { Error } & 21 & 0.06875000 & 0.003274 \text { Prob }>\text { F }\end{array}$

$\begin{array}{llll}\text { C. Total } 41 & 0.28509762 & 0.0045\end{array}$

Expected Mean Squares

The Mean Square per row by the Variance Component per column

\begin{tabular}{lcr} 
EMS & Intercept & Batch \#\&Random \\
Intercept & 0 & 0 \\
Batch \#\&Random & 0 & 2 \\
plus 1.0 times Residual Error Variance \\
\multicolumn{3}{c}{} \\
\multicolumn{4}{c}{ Variance Component Estimates } \\
Component & Var Comp Est & Percent of Total \\
Batch \#\&Random & 0.003772 & 53.534 \\
Residual & 0.003274 & 46.466 \\
Total & 0.007046 & 100.000
\end{tabular}

These estimates based on equating Mean Squares to Expected Value.

Test Denominator Synthesis

Source MS Den DF Den Denom MS Synthesis

Batch \#\&Random $0.00327 \quad 21$ Residual

$\begin{array}{lrrrrr}\text { Tests wrt Random Effects } & & & & \\ \text { Source } & \text { SS } & \text { MS Num } & \text { DF Num } & \text { F Ratio } & \text { Prob }>\text { F } \\ \text { Batch \#\&Random } & 0.21635 & 0.01082 & 20 & 3.3042 & 0.0045\end{array}$

Residual by Predicted Plot

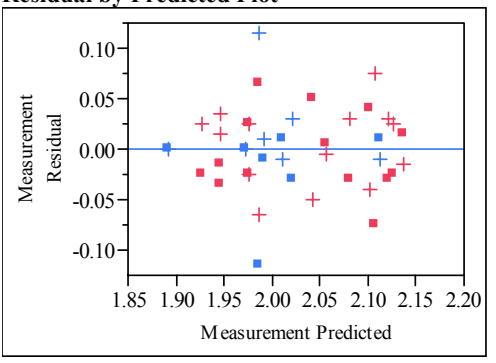

Batch \#\&Random

Sum of Squares F Ratio DF Prob $>$ F

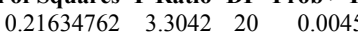

Denominator MS Synthesis:

Residual
Response Measurement Standard=Nitrate, Standard Value (ppm) $=16$ Whole Model

Actual by Predicted Plot

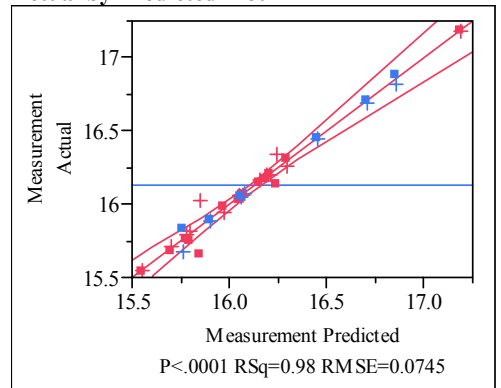

Summary of Fit

RSquare

RSquare Adj

0.982116

0.965083

Root Mean Square Error $\quad 0.074514$

Mean of Response $\quad 16.12714$

Observations (or Sum Wgts) 42

Analysis of Variance

Source DF Sum of Squares Mean Square F Ratio

$\begin{array}{lllll}\text { Model } & 20 & 6.4030571 & 0.320153 & 57.6605\end{array}$

$\begin{array}{llll}\text { Error } & 21 & 0.1166000 & 0.005552 \text { Prob }>\text { F }\end{array}$

$\begin{array}{llll}\text { C. Total } & 41 & 6.5196571 & <.0001\end{array}$

Expected Mean Squares

The Mean Square per row by the Variance Component per column

EMS Intercept Batch \#\&Random

$\begin{array}{lll}\text { Intercept } & 0 & 0 \\ \text { Batch \#\&Random } & 0 & 2\end{array}$

plus 1.0 times Residual Error Variance

Variance Component Estimates

Component Var Comp Est Percent of Total

Batch \#\&Random $\quad 0.1573 \quad 96.591$

$\begin{array}{lrr}\text { Residual } & 0.005552 & 3.409\end{array}$

$\begin{array}{lll}\text { Total } & 0.162853 & 100.000\end{array}$

These estimates based on equating Mean Squares to Expected Value.

Test Denominator Synthesis

Source MS Den DF Den Denom MS Synthesis

Batch \#\&Random $0.00555 \quad 21$ Residual

Tests wrt Random Effects

Source SS MS Num DF Num F Ratio Prob $>$ F

Batch \#\&Random $6.40306 \quad 0.32015 \quad 20 \quad 57.6605 \quad<.0001$

Residual by Predicted Plot

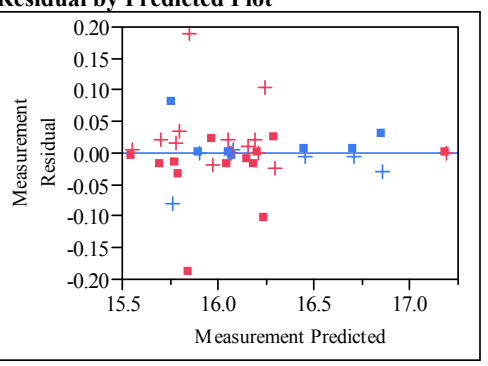

Batch \#\&Random

Effect Test

Sum of Squares F Ratio DF Prob $>$ F

$\begin{array}{llll}6.4030571 & 57.6605 & 20 & <.0001\end{array}$

Denominator MS Synthesis:

Residual 


\section{Exhibit A2. Random Effects Model for Batch to Batch Variation in the Measurement of Each Standard}

Response Measurement Standard $=$ Oxalate, Standard Value $(\mathrm{ppm})=2$ Whole Model

Actual by Predicted Plot

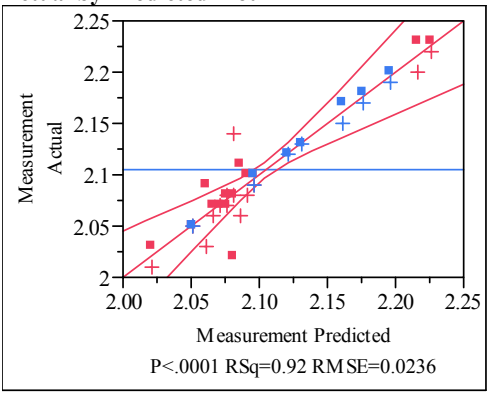

$\begin{array}{lr}\text { Summary of Fit } & \\ \text { RSquare } & 0.917865 \\ \text { RSquare Adj } & 0.83964 \\ \text { Root Mean Square Error } & 0.023604 \\ \text { Mean of Response } & 2.105238 \\ \text { Observations (or Sum Wgts) } & 42\end{array}$

Analysis of Variance

Source DF Sum of Squares Mean Square F Ratio

$\begin{array}{lllll}\text { Model } & 20 & 0.13074762 & 0.006537 & 11.7338\end{array}$

$\begin{array}{lllll}\text { Error } & 21 & 0.01170000 & 0.000557 \text { Prob }>\text { F }\end{array}$

$\begin{array}{llll}\text { C. Total } 41 \quad 0.14244762 & <.0001\end{array}$

Expected Mean Squares

The Mean Square per row by the Variance Component per column

\begin{tabular}{lcr} 
EMS & Intercept & Batch \#\&Random \\
Intercept & 0 & 0 \\
Batch \#\&Random & 0 & 2 \\
plus 1.0 times Residual Error Variance \\
\multicolumn{4}{c}{} \\
\multicolumn{4}{c}{ Variance Component Estimates } \\
Component & Var Comp Est & Percent of Total \\
Batch \#\&Random & 0.00299 & 84.294 \\
Residual & 0.000557 & 15.706 \\
Total & 0.003547 & 100.000
\end{tabular}

These estimates based on equating Mean Squares to Expected Value.

Test Denominator Synthesis

Source MS Den DF Den Denom MS Synthesis

Batch \#\&Random $0.00056 \quad 21$ Residual

Tests wrt Random Effects

Source SS MS Num DF Num F Ratio Prob $>$ F

$\begin{array}{llllll}\text { Batch \#\&Random } & 0.13075 & 0.00654 & 20 & 11.7338 & <.0001\end{array}$

Residual by Predicted Plot

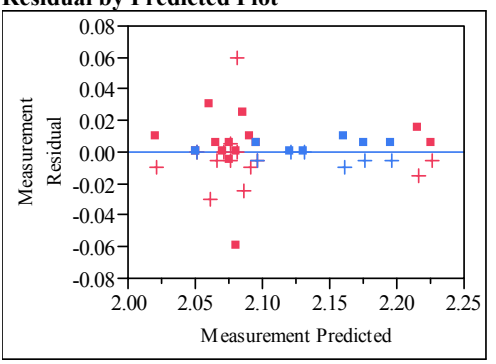

Batch \#\&Random

Sum of Squares F Ratio DF Prob $>$ F

$\begin{array}{lllr}0.13074762 & 11.7338 & 20 & <.0001\end{array}$

Denominator MS Synthesis:

Residual
Response Measurement Standard=Oxalate, Standard Value $(\mathrm{ppm})=16$ Whole Model

Actual by Predicted Plot

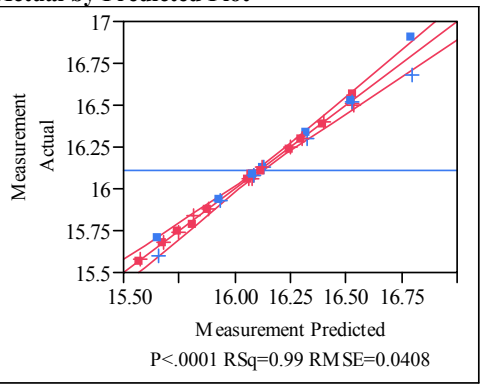

Summary of Fit

RSquare 0.991975

RSquare Adj $\quad 0.98433$

Root Mean Square Error $\quad 0.040796$

Mean of Response $\quad 16.1131$

Observations (or Sum Wgts) $\quad 42$

Analysis of Variance

Source DF Sum of Squares Mean Square F Ratio

$\begin{array}{llllll}\text { Model } & 20 & 4.3199476 & 0.215997 & 129.7838\end{array}$

$\begin{array}{llll}\text { Error } & 21 & 0.0349500 & 0.001664 \text { Prob }>\text { F }\end{array}$

$\begin{array}{llll}\text { C. Total } & 41 & 4.3548976 & <.0001\end{array}$

Expected Mean Squares

The Mean Square per row by the Variance Component per column

$\begin{array}{lrr}\text { EMS } & \text { Intercept } & \text { Batch \#\&Random } \\ \text { Intercept } & 0 & 0 \\ \text { Batch \#\&Random } & 0 & 2\end{array}$

Batch \#\&Random $\quad 0$
plus 1.0 times Residual Error Variance

Variance Component Estimates

Component Var Comp Est Percent of Total

Batch \#\&Random $\quad 0.107167 \quad 98.471$

Residual $\quad 0.001664 \quad 1.529$

$\begin{array}{lll}\text { Total } & 0.108831 & 100.000\end{array}$

These estimates based on equating Mean Squares to Expected Value.

Test Denominator Synthesis

Source MS Den DF Den Denom MS Synthesis

Batch \#\&Random $0.00166 \quad 21$ Residual

Tests wrt Random Effects

Source SS MS Num DF Num F Ratio Prob $>$ F

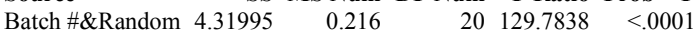

Residual by Predicted Plot

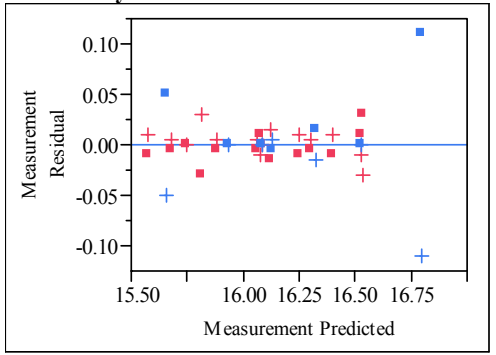

Batch \#\&Random

Effect Test

Sum of Squares F Ratio DF Prob $>$ F

$\begin{array}{llll}4.3199476 & 129.7838 \quad 20 & <.0001\end{array}$

Denominator MS Synthesis:

Residual 
SRNL-STI-2011-00214

Revision 1

\section{Exhibit A3. Random Effects Model for Batch to Batch Variation in the Measurement of the Formate, Nitrate and Oxalate Standards}

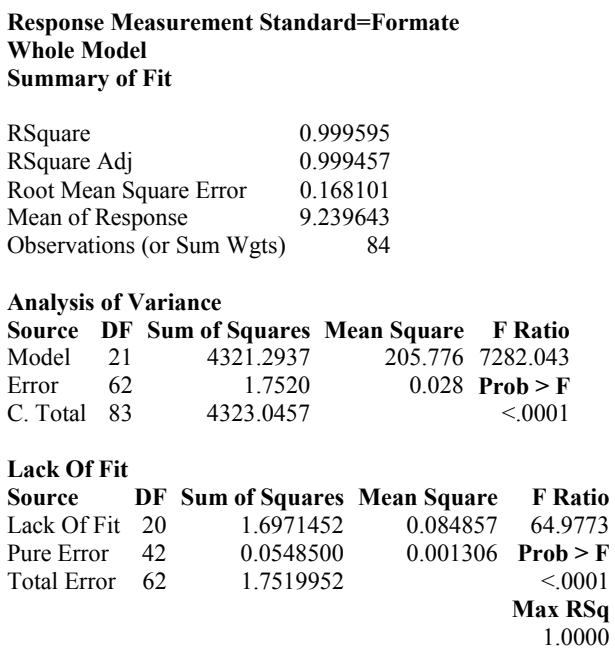

Expected Mean Squares

The Mean Square per row by the Variance Component per column

\begin{tabular}{lrr} 
EMS & Intercept & Standard Value (pp \\
Intercept & 0 \\
Standard Value (ppm) & 0 \\
Batch \#\&Random & 0 \\
\multicolumn{3}{c}{} \\
plus 1.0 times Residual Error Variance \\
\multicolumn{3}{c}{ Variance Component Estimates } \\
Component Var Comp Est & Percent of Total \\
Batch \#\&Random & 0.020799 & 42.397 \\
Residual & 0.028258 & 57.603 \\
Total & 0.049057 & 100.000
\end{tabular}

These estimates based on equating Mean Squares to Expected Value.

$\begin{array}{lrrl}\text { Test Denominator Synthesis } & & \\ \text { Source } & \text { MS Den } & \text { DF Den } & \text { Denom MS Synthesis } \\ \text { Standard Value (ppm) } & 0.02826 & 62 & \text { Residual } \\ \text { Batch \#\&Random } & 0.02826 & 62 & \text { Residual }\end{array}$

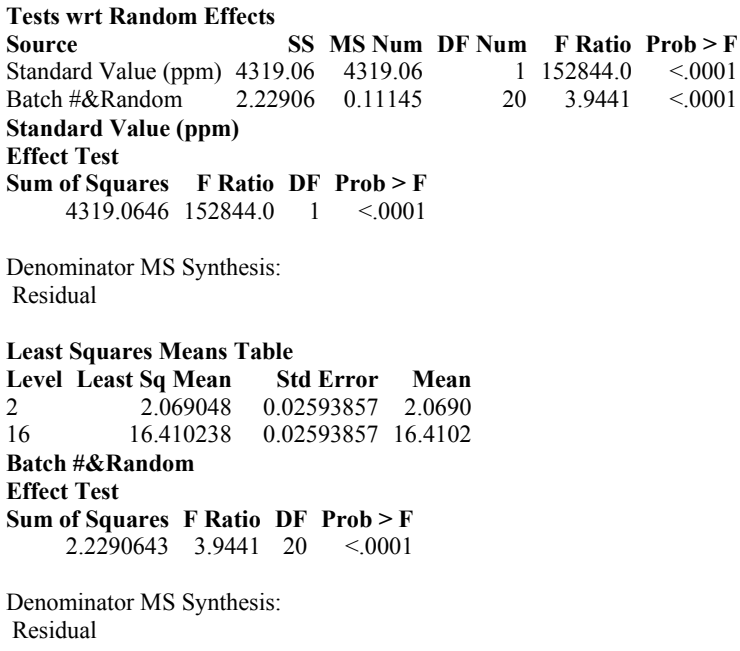

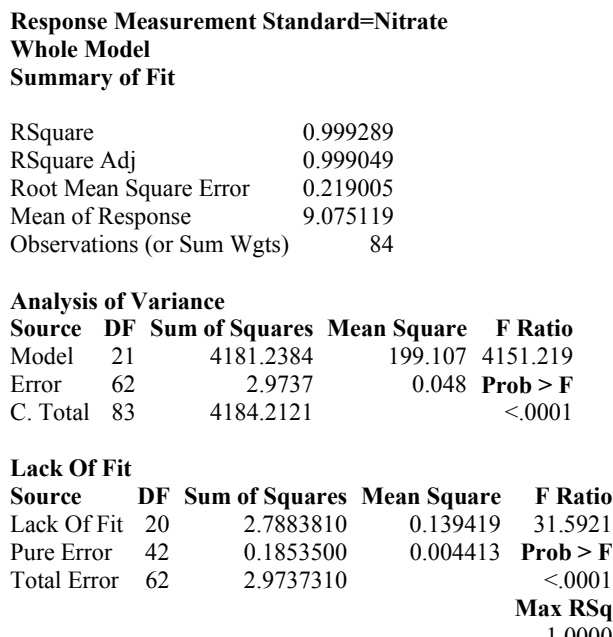

These estimates based on equating Mean Squares to Expected Value.

Test Denominator Synthesis

Source MS Den DF Den Denom MS Synthesis

Standard Value (ppm) $0.04796 \quad 62$ Residual

$\begin{array}{llll}\text { Batch \#\&Random } & 0.04796 & 62 & \text { Residual }\end{array}$

Tests wrt Random Effects

Source SS MS Num DF Num F Ratio Prob $>$ F

$\begin{array}{llllll}\text { Standard Value (ppm) } & 4177.41 & 4177.41 & 1 & 87095.73 & <.0001\end{array}$

$\begin{array}{llllll}\text { Batch \#\&Random } & 3.83102 & 0.19155 & 20 & 3.9937 & <.0001\end{array}$

Standard Value (ppm)

Effect Test

Sum of Squares F Ratio DF Prob $>$ F

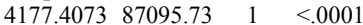

Denominator MS Synthesis:

Residual

Least Squares Means Table

Level Least Sq Mean Std Error Mean

$\begin{array}{llll}2 & 2.023095 & 0.03379328 & 2.0231\end{array}$

$\begin{array}{llll}16 & 16.127143 & 0.03379328 & 16.1271\end{array}$

Batch \#\&Random

Effect Test

Sum of Squares F Ratio DF Prob $>$ F

$\begin{array}{rrrr}3.8310238 & 3.9937 & 20 & <.0001\end{array}$

Denominator MS Synthesis:

Residual 


\section{Exhibit A3. Random Effects Model for Batch to Batch Variation in the Measurement of the Formate,} Nitrate and Oxalate Standards

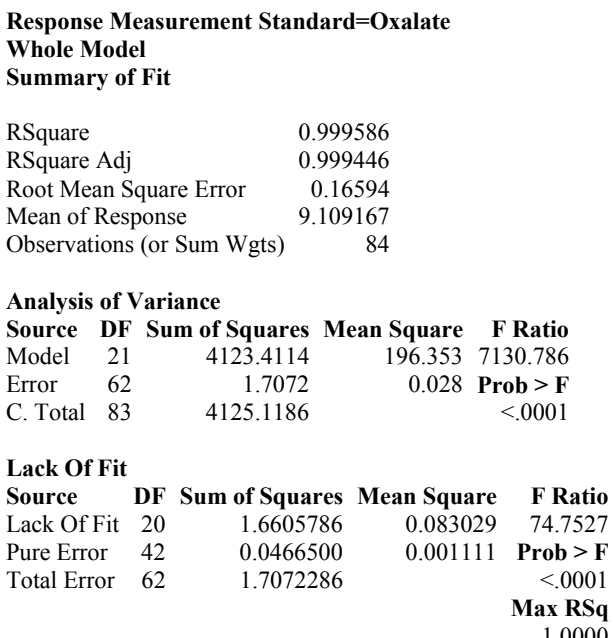

$\begin{array}{rrr}0 & 0 & 0 \\ 0 & 42 & 0 \\ 0 & 0 & 4\end{array}$

plus 1.0 times Residual Error Variance

Variance Component Estimates

$\begin{array}{lrr}\text { Component } & \text { Var Comp Est } & \text { Percent of Total } \\ \text { Batch \#\&Random } & 0.027992 & 50.411 \\ \text { Residual } & 0.027536 & 49.589 \\ \text { Total } & 0.055528 & 100.000\end{array}$

These estimates based on equating Mean Squares to Expected Value.

Test Denominator Synthesis

Source MS Den DF Den Denom MS Synthesis

Standard Value (ppm) $0.02754 \quad 62$ Residual

Batch \#\&Random $0.02754 \quad 62$ Residual

Tests wrt Random Effect

Source SS MS Num DF Num F Ratio Prob $>$ F

$\begin{array}{llllll}\text { Standard Value (ppm) } & 4120.62 & 4120.62 & 1 & 149645.2 & <.0001\end{array}$

$\begin{array}{llllll}\text { Batch \#\&Random } & 2.79012 & 0.13951 & 20 & 5.0663 & <.0001\end{array}$

Standard Value (ppm)

Effect Test

Sum of Squares F Ratio DF Prob $>$ F

$\begin{array}{llll}4120.6213 & 149645.2 & 1 & <.0001\end{array}$

Denominator MS Synthesis:

Residual

Least Squares Means Table

Level Least Sq Mean Std Error Mean

$\begin{array}{llll}2 & 2.105238 & 0.02560503 & 2.1052\end{array}$

$\begin{array}{llll}16 & 16.113095 & 0.02560503 & 16.1131\end{array}$

Batch \#\&Random

Effect Test

Sum of Squares F Ratio DF Prob $>$ F

$\begin{array}{rrrr}2.7901167 & 5.0663 & 20 & <.0001\end{array}$

Denominator MS Synthesis:

Residual 


\section{Exhibit A4. Histograms and Summary Statistics of the Measurements of the Anion Standards}

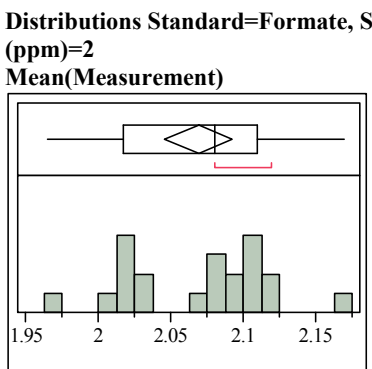

Quantiles

$\begin{array}{llr}100.0 \% & \text { maximum } & 2.1700 \\ 99.5 \% & & 2.1700 \\ 97.5 \% & & 2.1700 \\ 90.0 \% & & 2.1200 \\ 75.0 \% & \text { quartile } & 2.1100 \\ 50.0 \% & \text { median } & 2.0800 \\ 25.0 \% & \text { quartile } & 2.0175 \\ 10.0 \% & & 2.0110 \\ 2.5 \% & & 1.9650 \\ 0.5 \% & & 1.9650 \\ 0.0 \% \quad \text { minimum } & 1.9650 \\ \text { Moments } & \\ & \\ \text { Mean } & \\ \text { Std Dev } & 2.0690476 \\ \text { Std Err Mean } & 0.0508581 \\ \text { upper 95\% Mean } & 2.092198 \\ \text { lower 95\% Mean } & 2.0458973 \\ \text { N } & \end{array}$

Distributions Standard=Formate, Standard Value $(\mathrm{ppm})=16$

Mean(Measurement)

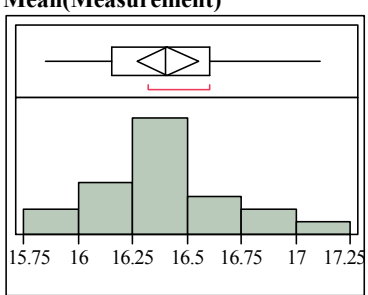

Quantiles

$\begin{array}{lll}100.0 \% & \text { maximum } & 17.110 \\ 99.5 \% & & 17.110 \\ 97.5 \% & & 17.110 \\ 90.0 \% & & 16.831 \\ 75.0 \% & \text { quartile } & 16.603 \\ 50.0 \% & \text { median } & 16.400 \\ 25.0 \% & \text { quartile } & 16.158 \\ 10.0 \% & & 15.941 \\ 2.5 \% & & 15.850 \\ 0.5 \% & & 15.850 \\ 0.0 \% & \text { minimum } & 15.850\end{array}$

Moments

$\begin{array}{lr}\text { Mean } & 16.410238 \\ \text { Std Dev } & 0.3091419 \\ \text { Std Err Mean } & 0.0674603 \\ \text { upper 95\% Mean } & 16.550958 \\ \text { lower 95\% Mean } & 16.269518 \\ \text { N } & 21\end{array}$

Distributions Standard=Nitrate, Standard Value $(\mathbf{p p m})=2$

Mean(Measurement)

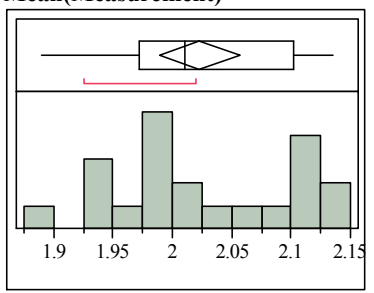

Quantiles

\begin{tabular}{lrr}
$100.0 \%$ & maximum & 2.1350 \\
$99.5 \%$ & & 2.1350 \\
$97.5 \%$ & & 2.1350 \\
$90.0 \%$ & & 2.1240 \\
$75.0 \%$ & quartile & 2.1025 \\
$50.0 \%$ & median & 2.0100 \\
$25.0 \%$ & quartile & 1.9725 \\
$10.0 \%$ & & 1.9290 \\
$2.5 \%$ & 1.8900 \\
$0.5 \%$ & 1.8900 \\
$0.0 \% \quad$ minimum & 1.8900 \\
Moments & \\
\multicolumn{2}{l}{} \\
Mean & 2.0230952 \\
Std Dev & 0.0735438 \\
Std Err Mean & 0.0160486 \\
upper 95\% Mean & 2.056572 \\
lower 95\% Mean & 1.9896185 \\
N &
\end{tabular}

Distributions Standard=Nitrate, Standard Value $($ ppm) $=16$

Mean(Measurement)

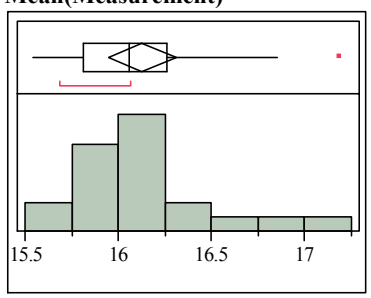

Quantiles

\begin{tabular}{|c|c|}
\hline & \\
\hline $100.0 \%$ maximur & n 17.180 \\
\hline $99.5 \%$ & 17.180 \\
\hline $97.5 \%$ & 17.180 \\
\hline $90.0 \%$ & 16.819 \\
\hline $75.0 \%$ quartile & 16.260 \\
\hline $50.0 \%$ median & 16.060 \\
\hline $25.0 \%$ quartile & 15.813 \\
\hline $10.0 \%$ & 15.702 \\
\hline $2.5 \%$ & 15.545 \\
\hline $0.5 \%$ & 15.545 \\
\hline minimun & 15.545 \\
\hline Moments & \\
\hline Mean & 16.127143 \\
\hline Std Dev & 0.4000955 \\
\hline Std Err Mean & 0.087308 \\
\hline upper $95 \%$ Mean & 16.309264 \\
\hline lower $95 \%$ Mean & 15.945022 \\
\hline & \\
\hline
\end{tabular}

Distributions Standard=Oxalate, Standard Value $(\mathrm{ppm})=2$

Mean(Measurement)

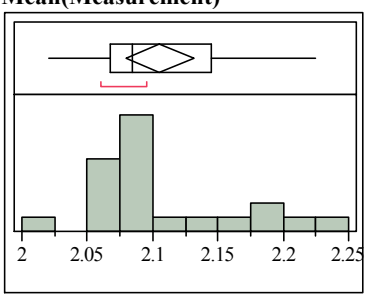

Quantiles

$$
\begin{array}{lrr}
100.0 \% & \text { maximum } & 2.2250 \\
99.5 \% & & 2.2250 \\
97.5 \% & & 2.2250 \\
90.0 \% & & 2.2110 \\
75.0 \% & \text { quartile } & 2.1450 \\
50.0 \% & \text { median } & 2.0850 \\
25.0 \% & \text { quartile } & 2.0675 \\
10.0 \% & & 2.0500 \\
2.5 \% & & 2.0200 \\
0.5 \% & 2.0200 \\
0.0 \% \quad \text { minimum } & 2.0200 \\
\text { Moments } & \\
& \\
\text { Mean } & \\
\text { Std Dev } & 2.1052381 \\
\text { Std Err Mean r } & 0.0571725 \\
\text { upper 95\% Mean } & 2.1312627 \\
\text { lower 95\% Mean } & 2.0792135 \\
\text { N } & 21
\end{array}
$$

Distributions Standard=Oxalate, Standard Value $(p p m)=16$

Mean(Measurement)

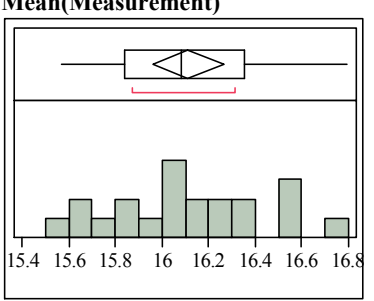

Quantiles

$100.0 \%$ maximum 16.790

$99.5 \% \quad 16.790$

$97.5 \% \quad 16.790$

$90.0 \% \quad 16.528$

$75.0 \%$ quartile $\quad 16.353$

$50.0 \%$ median 16.080

$25.0 \%$ quartile 15.843

$10.0 \% \quad 15.655$

$2.5 \% \quad 15.570$

$0.5 \% \quad 15.570$

$0.0 \%$ minimum 15.570

Moments

Mean $\quad 16.113095$

Std Dev $\quad 0.3286315$

Std Err Mean $\quad 0.0717133$

upper $95 \%$ Mean 16.262687

lower 95\% Mean 15.963504

$\mathrm{N}$ 
Exhibit A5. Anion Measurements by SME Batch

(as reported for the SME sample in $\mathrm{mg} / \mathrm{kg}$ of slurry and as indicated by the IC instrument in ppm for the diluted sample)

Analyte $=$ Formate (mg/kg slurry)

Variability Chart for Measurement

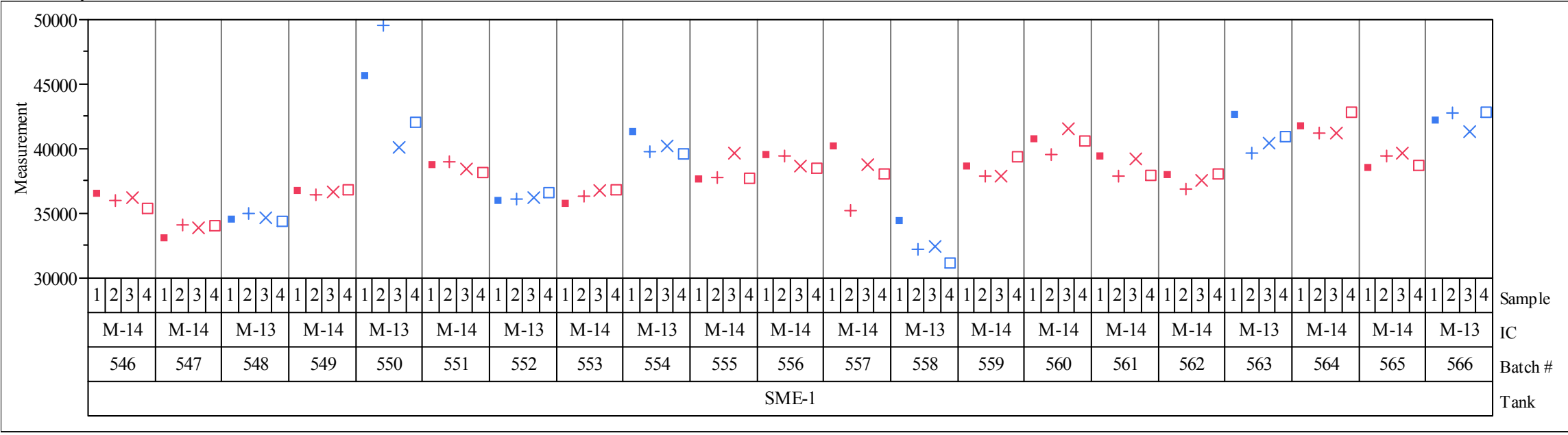

Analyte $=$ Formate (ppm/diluted sample)

Variability Chart for Measurement

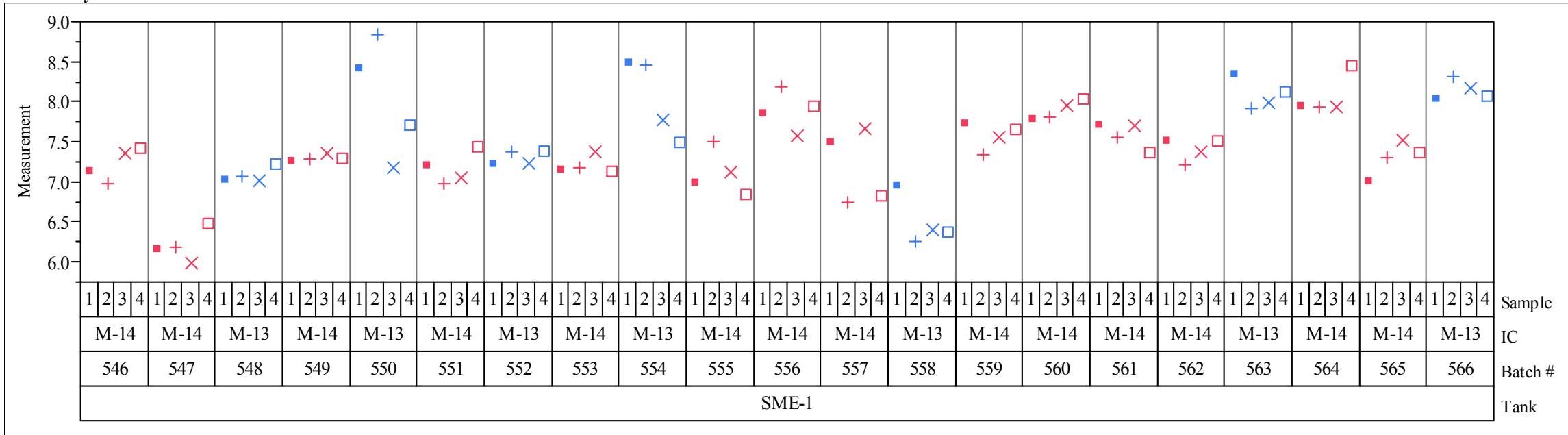




\section{Exhibit A5. Anion Measurements by SME Batch}

(as reported for the SME sample in $\mathrm{mg} / \mathrm{kg}$ of slurry and as indicated by the IC instrument in ppm for the diluted sample)

Analyte=Nitrate (mg/kg slurry)

Variability Chart for Measurement

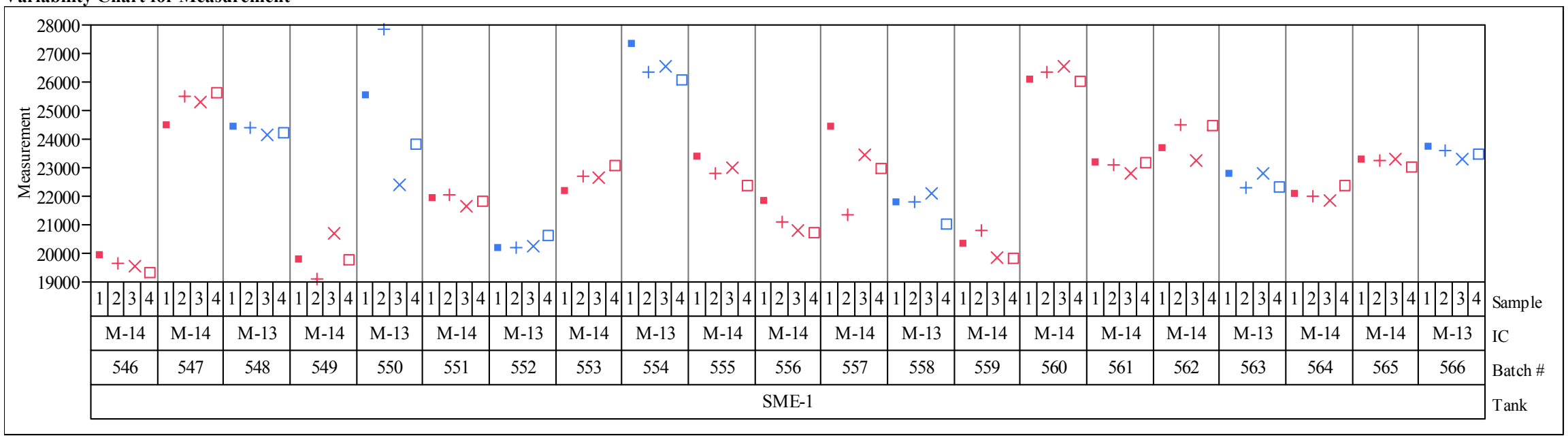

Analyte $=$ Nitrate $(\mathbf{p p m} /$ diluted sample $)$

Variability Chart for Measurement

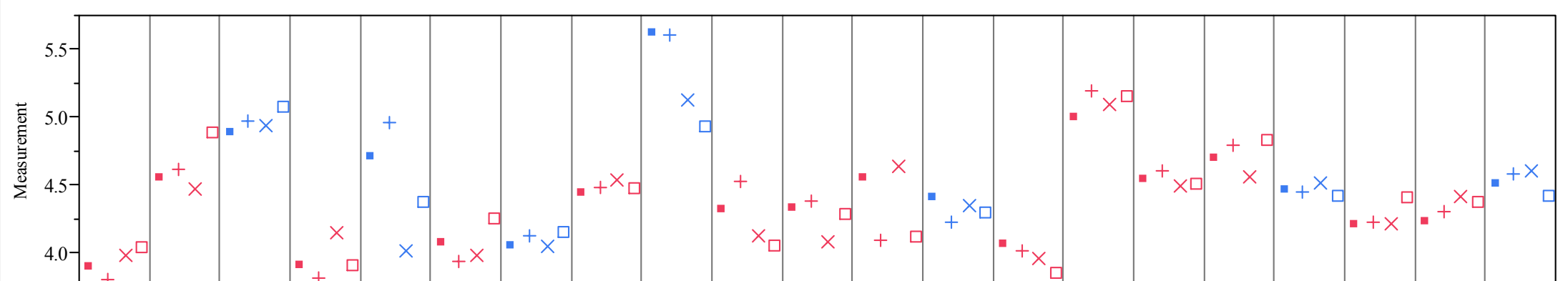

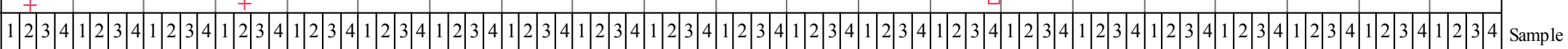

\begin{tabular}{|c|c|c|c|c|c|c|c|c|c|c|c|c|c|c|c|c|c|c|c|c|c|}
\hline M-14 & M-14 & M-13 & M-14 & M-13 & M-14 & M-13 & M-14 & M-13 & M-14 & M-14 & M-14 & M-13 & M-14 & M-14 & M-14 & M-14 & M-13 & M-14 & M-14 & M-13 & IC \\
\hline 546 & 547 & 548 & 549 & 550 & 551 & 552 & 553 & 554 & 555 & 556 & 557 & 558 & 559 & 560 & 561 & 562 & 563 & 564 & 565 & 566 & atch \# \\
\hline
\end{tabular}




\section{Exhibit A5. Anion Measurements by SME Batch}

(as reported for the SME sample in $\mathrm{mg} / \mathrm{kg}$ of slurry and as indicated by the IC instrument in ppm for the diluted sample)

Analyte=Oxalate (ppm/diluted sample) Variability Chart for Measurement

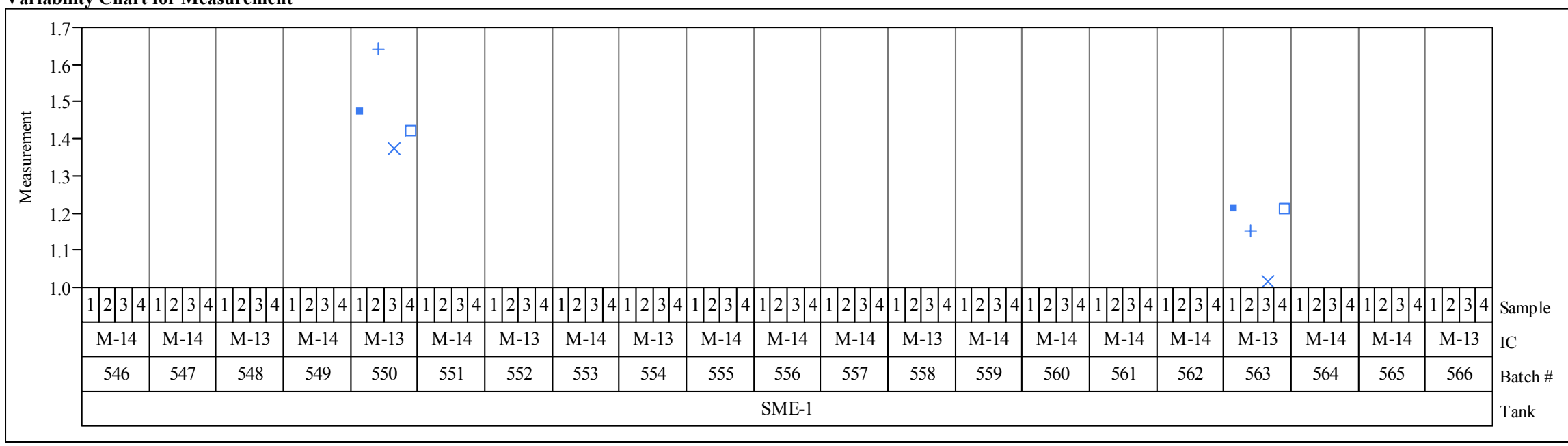




\section{Exhibit A6. Components of Variation for Anion Measurements of the SME Samples}

(as reported for the SME sample in $\mathrm{mg} / \mathrm{kg}$ of slurry and as indicated by the IC instrument in ppm for the diluted sample)

Response Measurement analyte=Formate $(\mathbf{m g} / \mathbf{k g}$ slurry $)$

Whole Model

Actual by Predicted Plot

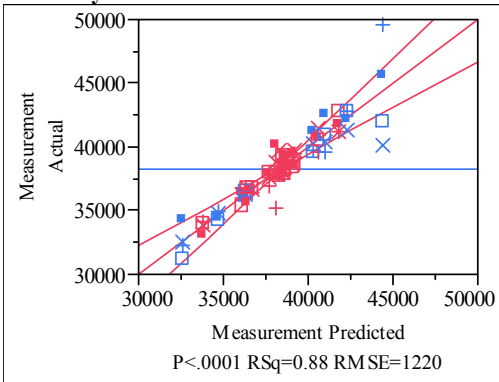

Summary of Fit

RSquare

RSquare $A d j$

0.875197

Root Mean Squar

Mean of Response

0.835577

1220.005

38233.42

Analysis of Variance

Source DF Sum of Squares Mean Square F Ratio

$\begin{array}{lllll}\text { Model } & 20 & 657571962 & 32878598 & 22.0897\end{array}$

$\begin{array}{llrr}\text { Error } & 63 & 93769985 & 1488412.5 \text { Prob }>\text { F }\end{array}$

$\begin{array}{llll}\text { C. Total } 83 & 751341946 & <.0001\end{array}$

Expected Mean Squares

The Mean Square per row by the Variance Component per column

EMS Intercept Batch \#\&Random

$\begin{array}{lll}\text { Intercept } & 0 & 0 \\ \text { Batch \#\&Random } & 0 & 4\end{array}$

plus 1.0 times Residual Error Variance

Variance Component Estimates

Component Var Comp Est Percent of Total

Batch \#\&Random $\quad 7847546 \quad 84.057$

$\begin{array}{lll}\text { Residual } & 1488412 & 15.943\end{array}$

$\begin{array}{lll}\text { Total } & 9335959 & 100.000\end{array}$

These estimates based on equating Mean Squares to Expected Value.

Test Denominator Synthesis

Source MS Den DF Den Denom MS Synthesis

Batch \#\&Random 1488412

63 Residua

Tests wrt Random Effects

Source

SS MS Num DF Num F Ratio Prob $>$ F

$\begin{array}{llllll}\text { Batch \#\&Random } \quad 6.58 \mathrm{e}+8 & 3.29 \mathrm{e}+7 & 20 & 22.0897 & <.0001\end{array}$

Residual by Predicted Plot

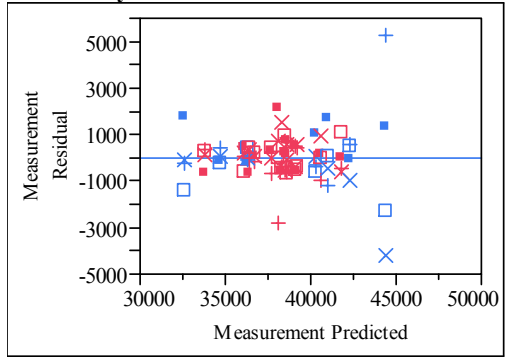

Batch \#\&Random

Effect Test

Sum of Squares F Ratio DF Prob $>$ F

$65757196222.0897 \quad 20<000$

Denominator MS Synthesis:

Residual
Response Measurement analyte=Formate (ppm/diluted sample)

Whole Model

Actual by Predicted Plot

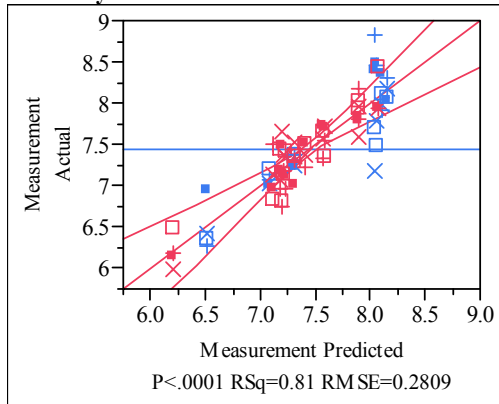

Summary of Fit

RSquare

Root Mean Square Error $\quad 0.280944$

Mean of Response $\quad 7.43369$

Observations (or Sum Wgts) 84

Analysis of Variance

Source DF Sum of Squares Mean Square F Ratio

$\begin{array}{lllll}\text { Model } & 20 & 21.752181 & 1.08761 & 13.7795\end{array}$

$\begin{array}{llll}\text { Error } & 63 & 4.972575 & 0.07893 \quad \text { Prob }>\text { F }\end{array}$

$\begin{array}{llll}\text { C. Total } & 83 & 26.724756 & <.0001\end{array}$

Expected Mean Squares

The Mean Square per row by the Variance Component per column

EMS Intercept Batch \#\&Random

$\begin{array}{lll}\text { Intercept } & 0 & 0 \\ \text { Batch \#\&Random } & 0 & 4\end{array}$

plus 1.0 times Residual Error Variance

Variance Component Estimates

Component Var Comp Est Percent of Tota

Batch \#\&Random $\quad 0.25217 \quad 76.161$

$\begin{array}{lll}\text { Residual } & 0.07893 & 23.839\end{array}$

$\begin{array}{lll}\text { Total } & 0.3311 & 100.000\end{array}$

These estimates based on equating Mean Squares to Expected Value.

Test Denominator Synthesis

Source MS Den DF Den Denom MS Synthesis

Batch \#\&Random $0.07893 \quad 63$ Residual

Tests wrt Random Effects

Source SS MS Num DF Num F Ratio Prob $>$ F

Batch \#\&Random $21.7522 \quad 1.08761 \quad 20 \quad 13.7795 \quad<.0001$

Residual by Predicted Plot

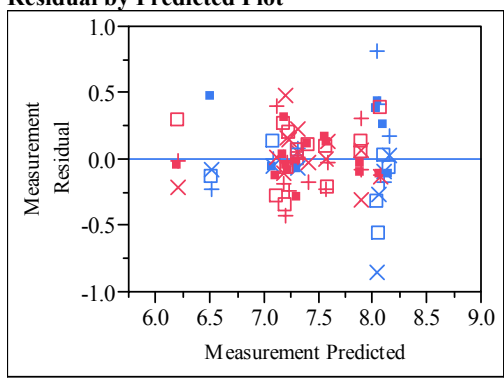

Batch \#\&Random

Effect Test

Sum of Squares F Ratio DF Prob $>$ F

$\begin{array}{rrrr}21.752181 & 13.7795 & 20 & <.0001\end{array}$

Denominator MS Synthesis:

Residual 


\section{Exhibit A6. Components of Variation for Anion Measurements of the SME Samples}

(as reported for the SME sample in $\mathrm{mg} / \mathrm{kg}$ of slurry and as indicated by the IC instrument in ppm for the diluted sample)

Response Measurement analyte $=$ Nitrate $(\mathrm{mg} / \mathrm{kg}$ slurry $)$

Whole Model

Actual by Predicted Plot

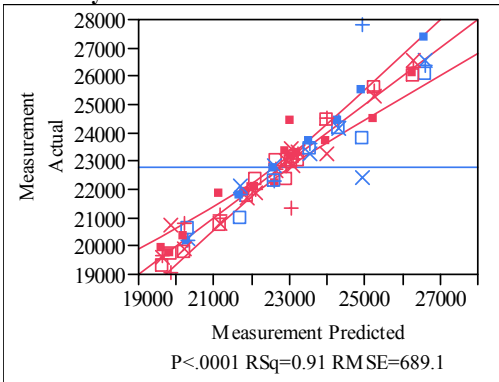

Summary of Fit

RSquare

RSquare Adj

0.913037

0.885429

Mean of Response 22777.24

Observations (or Sum Wgts) 84

Analysis of Variance

Source DF Sum of Squares Mean Square F Ratio

$\begin{array}{lllll}\text { Model } & 20 & 314088986 & 15704449 & 33.0722\end{array}$

$\begin{array}{llrr}\text { Error } & 63 & 29915738 & 474852.98 \quad \text { Prob }>\text { F }\end{array}$

$\begin{array}{llll}\text { C. Total } 83 & 344004723 & <.0001\end{array}$

Expected Mean Squares

The Mean Square per row by the Variance Component per column

EMS Intercept Batch \#\&Random

$\begin{array}{lrr}\text { Intercept } & 0 & 0 \\ \text { Batch \#\&Random } & 0 & 4\end{array}$

plus 1.0 times Residual Error Variance

Variance Component Estimates

Component Var Comp Est Percent of Total

Batch \#\&Random $\quad 3807399 \quad 88.911$

$\begin{array}{lrr}\text { Residual } & 474853 & 11.089\end{array}$

Total $\quad 4282252 \quad 100.000$

These estimates based on equating Mean Squares to Expected Value.

Test Denominator Synthesis

Source MS Den DF Den Denom MS Synthesis

Batch \#\&Random $474853 \quad 63$ Residual

Tests wrt Random Effects

$\begin{array}{lrrrrr}\text { Source } & \text { SS } & \text { MS Num } & \text { DF Num } & \text { F Ratio } & \text { Prob }>\text { F } \\ \text { Batch \#\&Random } & 3.14 \mathrm{e}+8 & 1.57 \mathrm{e}+7 & 20 & 33.0722 & <.0001\end{array}$

Residual by Predicted Plot

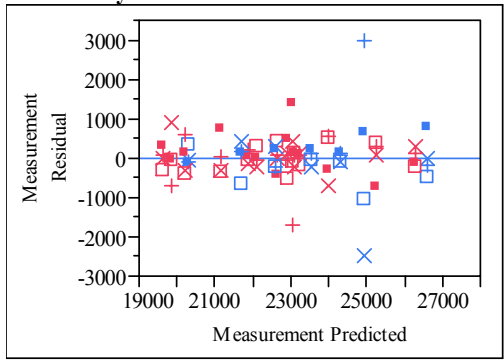

Batch \#\&Random

Effect Test

Sum of Squares F Ratio DF Prob $>$ F

$31408898633.0722 \quad 20<000$

Denominator MS Synthesis:

Residual
Response Measurement analyte $=$ Nitrate $(\mathrm{ppm} /$ diluted sample $)$

Whole Model

Actual by Predicted Plot

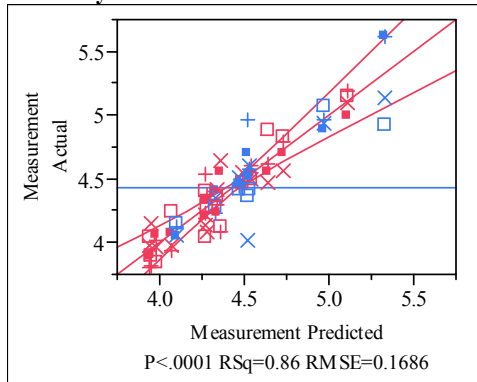

Summary of Fit

RSquare

RSquare Adj

0.86011

Root Mean Square Error $\quad 0.16859$

Mean of Response $\quad 4.427857$

Observations (or Sum Wgts)

84

Analysis of Variance

Source DF Sum of Squares Mean Square F Ratio

$\begin{array}{lllll}\text { Model } & 20 & 11.009764 & 0.550488 & 19.3677\end{array}$

$\begin{array}{lllll}\text { Error } & 63 & 1.790650 & 0.028423 & \text { Prob }>\text { F }\end{array}$

$\begin{array}{llll}\text { C. Total } 83 & 12.800414 & <.0001\end{array}$

Expected Mean Squares

The Mean Square per row by the Variance Component per column

EMS Intercept Batch \#\&Random

$\begin{array}{lll}\text { Intercept } & 0 & 0 \\ \text { Batch \#\&Random } & 0 & 4\end{array}$

plus 1.0 times Residual Error Variance

Variance Component Estimates

Component Var Comp Est Percent of Total

Batch \#\&Random $\quad 0.130516 \quad 82.117$

$\begin{array}{lll}\text { Residual } & 0.028423 & 17.883\end{array}$

$\begin{array}{lll}\text { Total } & 0.158939 & 100.000\end{array}$

These estimates based on equating Mean Squares to Expected Value.

Test Denominator Synthesis

Source MS Den DF Den Denom MS Synthesis

Batch \#\&Random $0.02842 \quad 63$ Residual

Tests wrt Random Effects

Source SS MS Num DF Num F Ratio Prob $>$ F

$\begin{array}{llllll}\text { Batch \#\&Random } & 11.0098 & 0.55049 & 20 & 19.3677 & <.0001\end{array}$

Residual by Predicted Plot

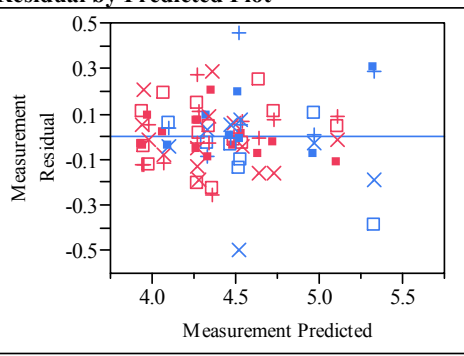

Batch \#\&Random

Effect Test

Sum of Squares F Ratio DF Prob $>$ F

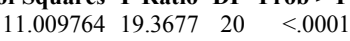

Denominator MS Synthesis:

Residual 


\section{Exhibit A6. Components of Variation for Anion Measurements of the SME Samples}

(as reported for the SME sample in $\mathrm{mg} / \mathrm{kg}$ of slurry and as indicated by the IC instrument in ppm for the diluted sample)

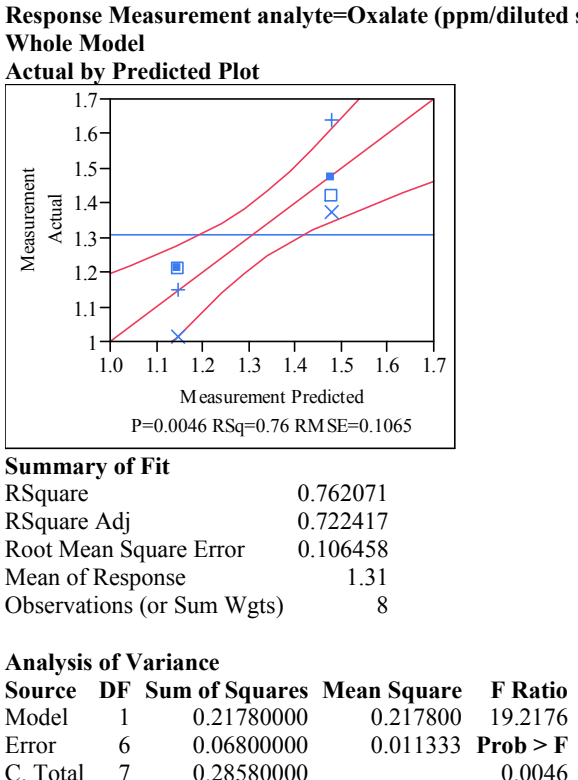

\section{Parameter Estimates \\ Term Estimate Std Error t Ratio Prob $>|\mathbf{t}|$ \\ $\begin{array}{lllll}\text { Intercept } & 1.31 & 0.037639 & 34.80 & <.0001\end{array}$ \\ $\begin{array}{lllll}\text { Batch \#[550] } & 0.165 & 0.037639 & 4.38 & 0.0046\end{array}$}

Expected Mean Squares

The Mean Square per row by the Variance Component per column

\begin{tabular}{lcr} 
EMS & Intercept & Batch \#\&Random \\
Intercept & 0 & 0 \\
Batch \#\&Random & 0 & 4 \\
plus 1.0 times Residual Error Variance \\
\multicolumn{3}{c}{} \\
\multicolumn{4}{c}{ Variance Component Estimates } \\
Component & Var Comp Est & Percent of Total \\
Batch \#\&Random & 0.051617 & 81.996 \\
Residual & 0.011333 & 18.004 \\
Total & 0.06295 & 100.000
\end{tabular}

These estimates based on equating Mean Squares to Expected Value.

Test Denominator Synthesis

Source MS Den DF Den Denom MS Synthesis

Batch \#\&Random $0.01133 \quad 6$ Residual

Tests wrt Random Effects

Source SS MS Num DF Num F Ratio Prob $>$ F

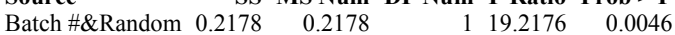

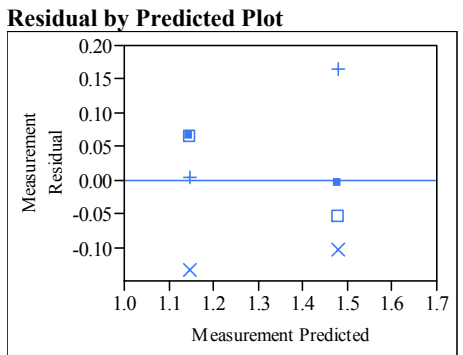

Batch \#\&Random

Effect Test

Sum of Squares F Ratio DF Prob $>$ F

$\begin{array}{llll}0.21780000 & 19.2176 & 1 & 0.0046\end{array}$

Denominator MS Synthesis: Residual 
Exhibit A7. Simple Analysis of Variance of Anion Measurements by SME Batch

(as reported for the SME sample in $\mathrm{mg} / \mathrm{kg}$ of slurry and as indicated by the IC instrument in ppm for the diluted sample)

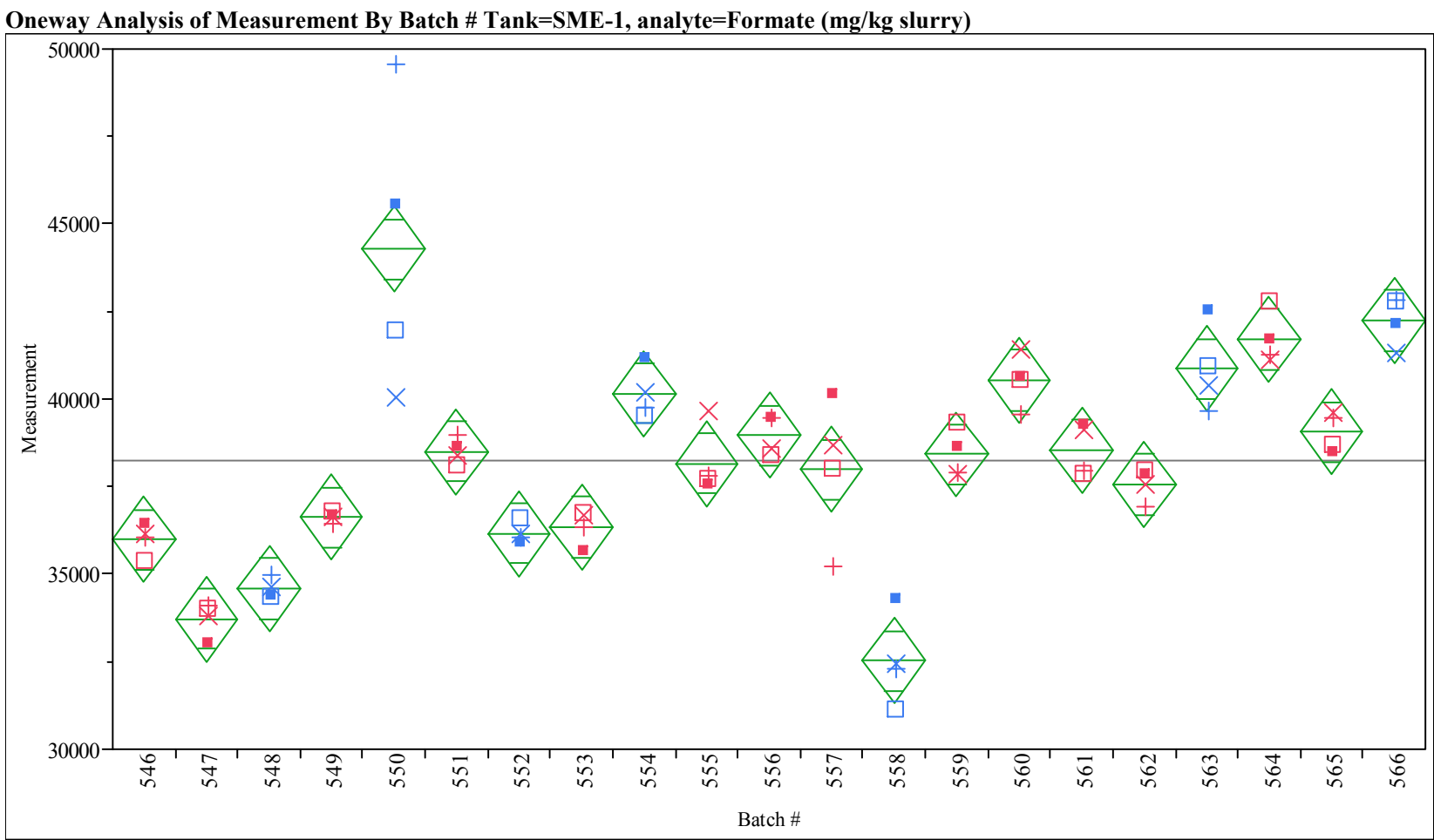

Oneway Anova

Summary of Fit

Rsquare

0.875197

Adj Rsquare

Root Mean Square Error $\quad 1220.005$

Mean of

Observations (or Sum Wgts) $\quad 84$

Analysis of Variance

Source DF Sum of Squares Mean Square F Ratio Prob $>$ F

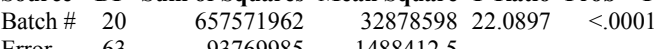

\begin{tabular}{rrr}
9376995 \\
\hline
\end{tabular}

1488412.5 
Exhibit A7. Simple Analysis of Variance of Anion Measurements by SME Batch

(as reported for the SME sample in $\mathrm{mg} / \mathrm{kg}$ of slurry and as indicated by the IC instrument in ppm for the diluted sample)

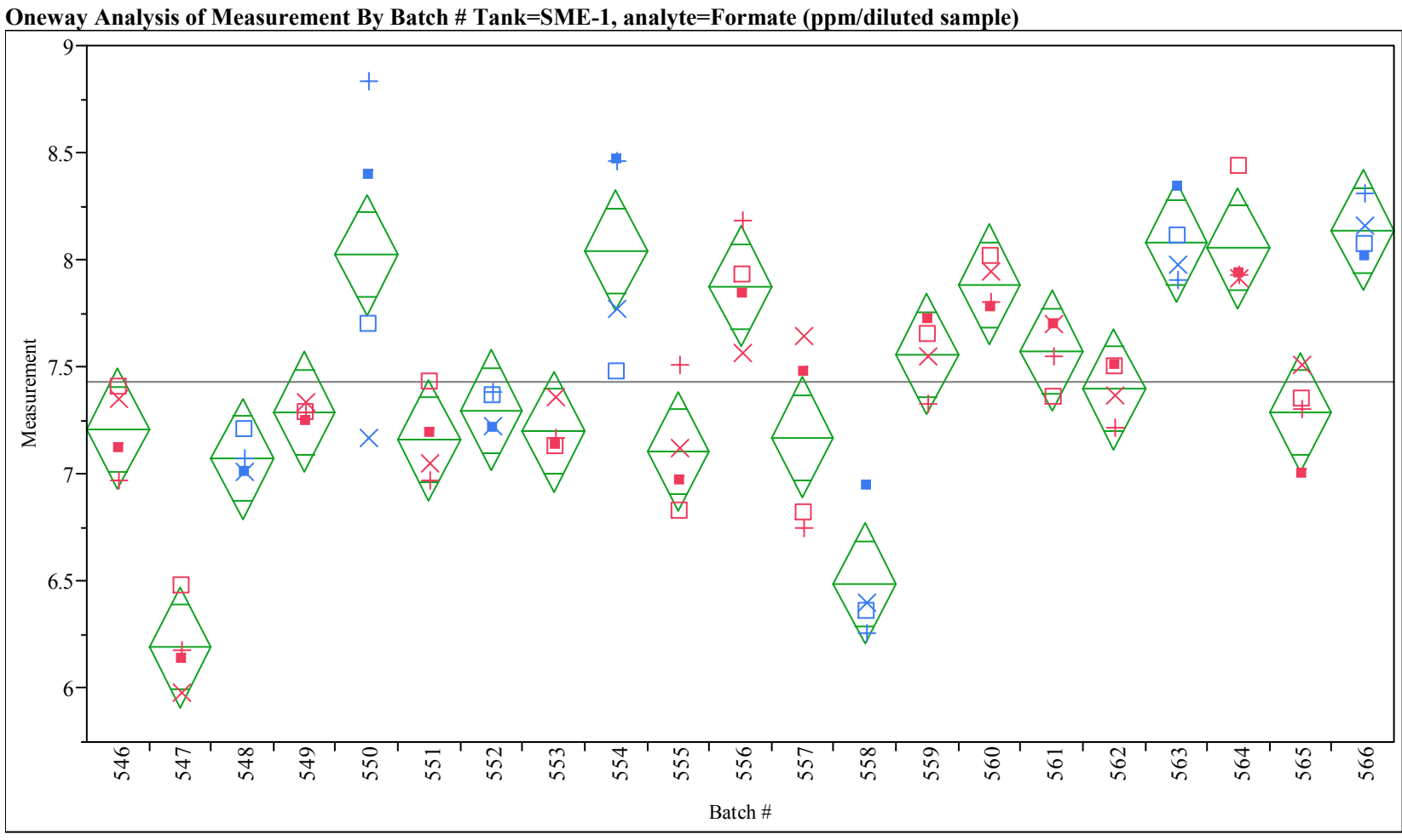

Oneway Anova

Summary of Fit

Rsquare

0.813934

Adj Rsquare $\quad 0.754865$

$\begin{array}{lr}\text { Root Mean Square Error } & 0.289644 \\ \text { Mean of Response } & 7.43369\end{array}$

Observations (or Sum Wgts) $\quad 84$

Analysis of Variance

Source DF Sum of Squares Mean Square F Ratio Prob $>$ F

$\begin{array}{llllll}\text { Batch \# } & 20 & 21.752181 & 1.08761 & 13.7795 & <.0001\end{array}$

Error $63-4.972575$

0.07893

C. Total $83 \quad 26.724756$ 
Exhibit A7. Simple Analysis of Variance of Anion Measurements by SME Batch

(as reported for the SME sample in $\mathrm{mg} / \mathrm{kg}$ of slurry and as indicated by the IC instrument in ppm for the diluted sample)

Oneway Analysis of Measurement By Batch \# Tank=SME-1, analyte=Nitrate (mg/kg slurry)

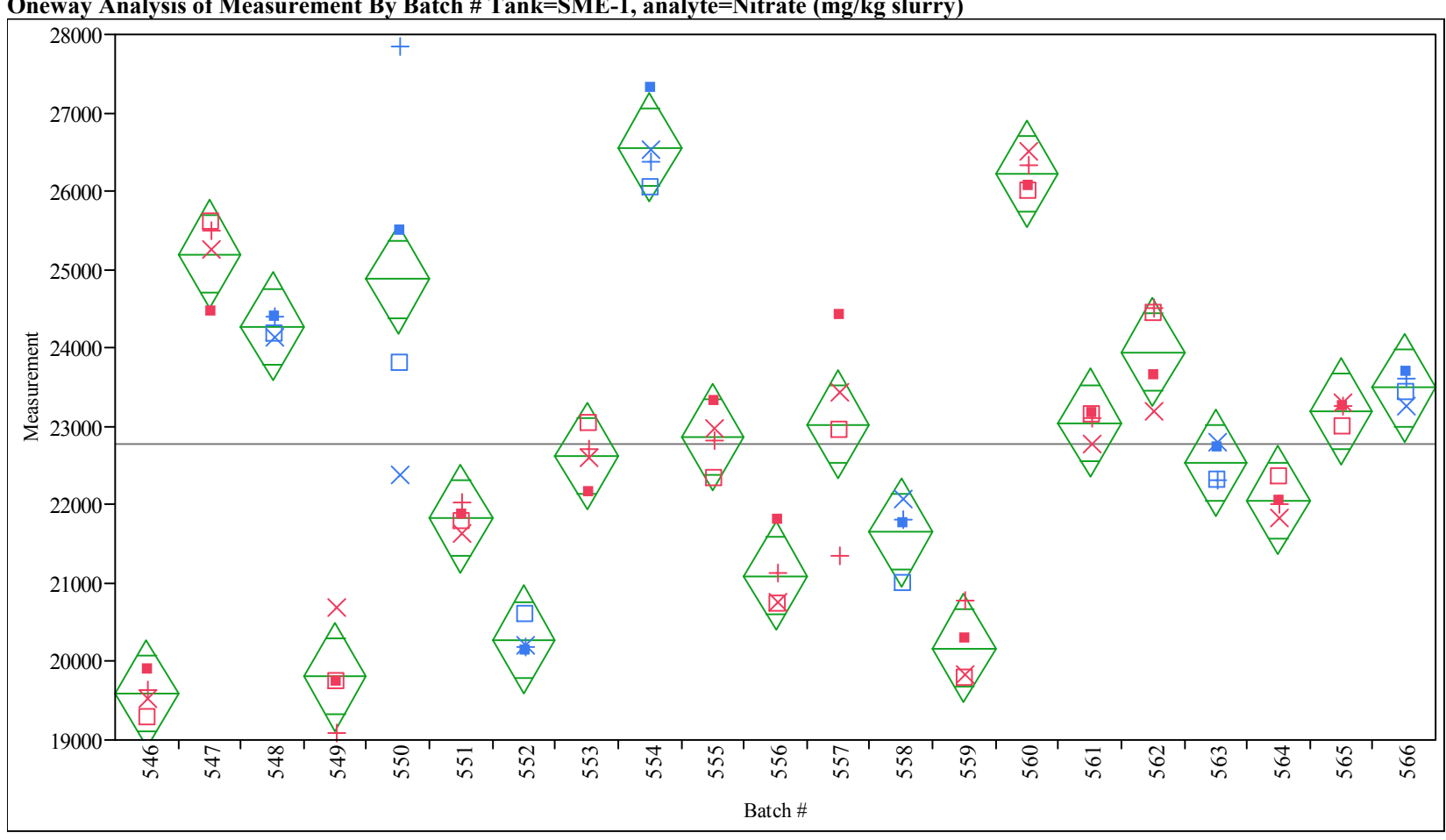

Oneway Anova

Summary of Fit

Rsquare

Adj Rsquare

0.885429

Rean of Restare Eror 2889.0958

Observations (or Sum Wgts)

Analysis of Variance

Source DF Sum of Squares Mean Square F Ratio Prob $>$ F

$\begin{array}{lll}\text { Batch \# } 20 & 314088986 \\ \text { Cror } & 63 & 29915737\end{array}$

$\begin{array}{lll}\text { C. Total } & 83 & 344004723\end{array}$

0.913037

(1)

-24
84

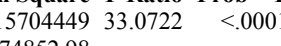


Exhibit A7. Simple Analysis of Variance of Anion Measurements by SME Batch

(as reported for the SME sample in $\mathrm{mg} / \mathrm{kg}$ of slurry and as indicated by the IC instrument in ppm for the diluted sample)

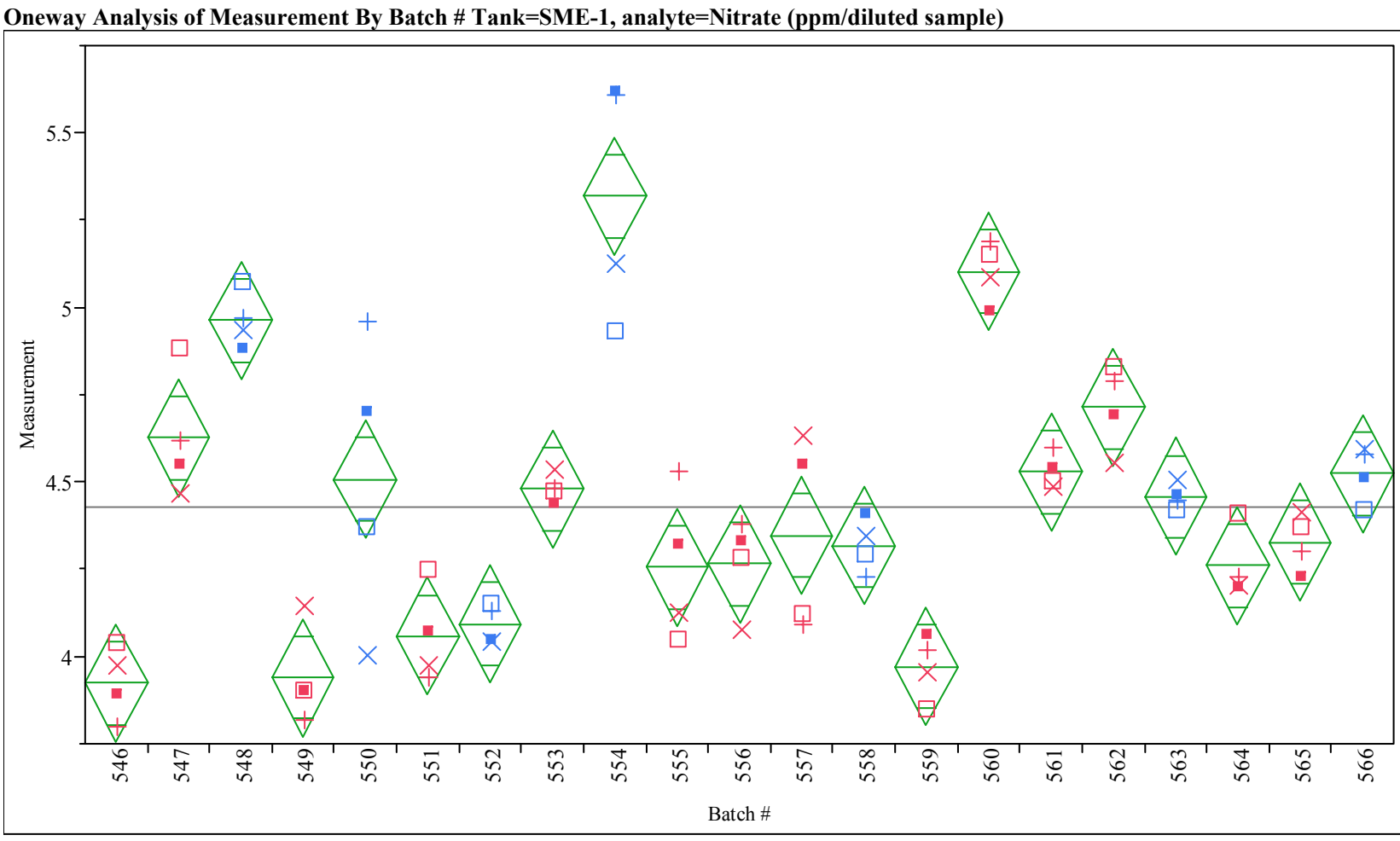

Oneway Anova

Summary of Fit

Rsquare

0.86011

Adj Rsquare $\quad 0.8157$

Root Mean Square Error $\quad 0.168591$

Observations (or Sum Wgts) $\quad 84$

Analysis of Variance

Source DF Sum of Squares Mean Square F Ratio Prob $>$ F

$\begin{array}{llllll}\text { Batch \# } & 20 & 11.009764 & 0.550488 & 19.3677 & <.0001\end{array}$

Error $63 \quad 1.790650$

C. Total 83

2.800414 
Exhibit A7. Simple Analysis of Variance of Anion Measurements by SME Batch

(as reported for the SME sample in $\mathrm{mg} / \mathrm{kg}$ of slurry and as indicated by the IC instrument in ppm for the diluted sample)

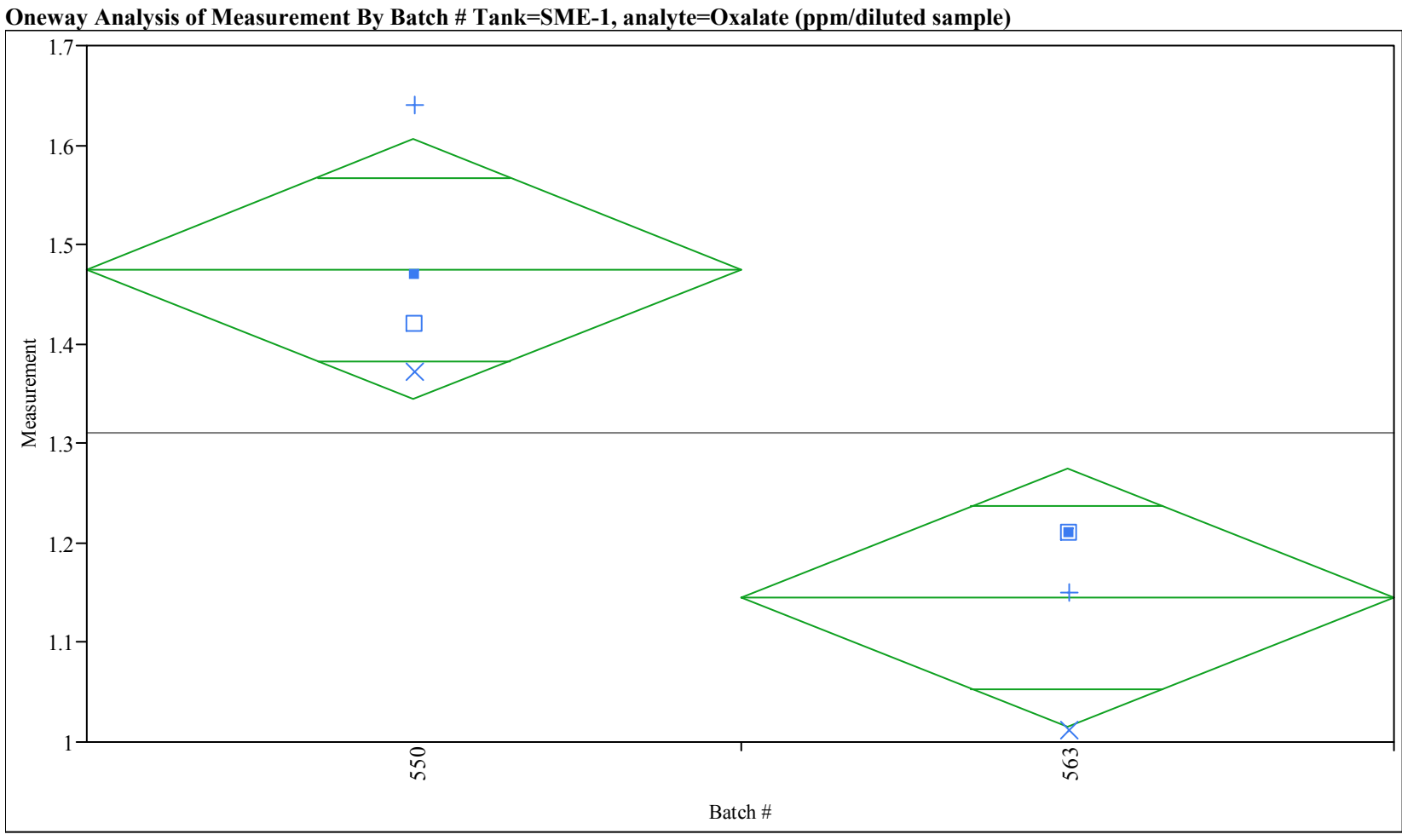

Oneway Anova

Summary of Fit

Rsquare

0.762071

Adj Rsquare

Root Mean Square Error $\quad 0.106458$

Mean of Response

1.31
8

Anctions (or Sum wg

Analysis of Variance

Source DF Sum of Squares Mean Square F Ratio Prob > F

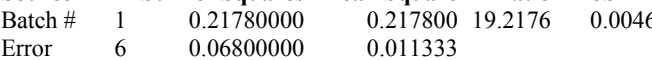

Error $\quad 6 \quad 0.06800000$

$\begin{array}{lll}\text { C. Total } & 7 & 0.28580000\end{array}$ 
Exhibit A8. Plots of the DWPF Laboratory Measurements of the TOC Standards

Type of Sample=std, ref ppm=1 Variability Chart for TOC (ppm)

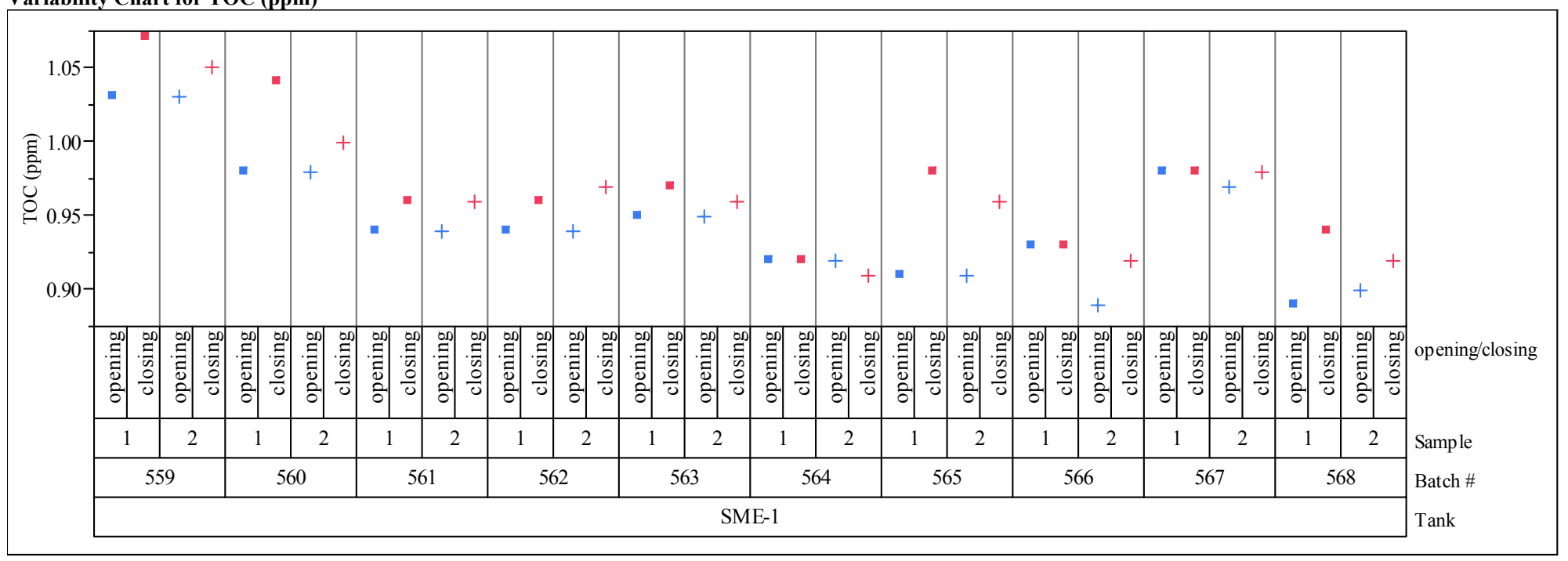

Type of Sample=std, ref ppm=20

Variability Chart for TOC (ppm)

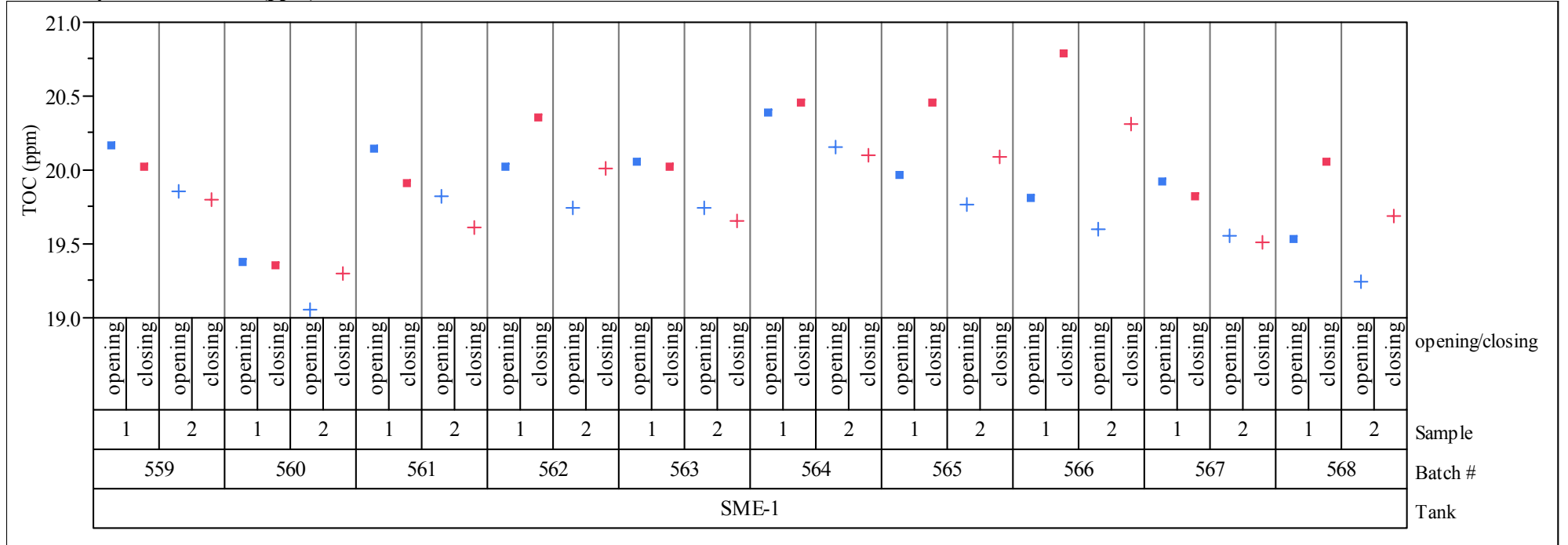




\section{Exhibit A9. Analysis of Variance for Batch to Batch Random Effects for Each TOC Standard}

Response TOC (ppm) Tank=SME-1, Type of Sample=std, ref ppm=1 Whole Model

Actual by Predicted Plot

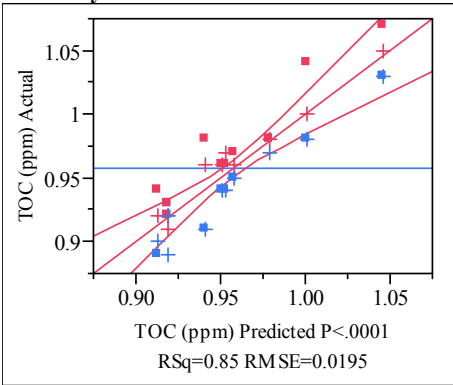

Summary of Fit

RSquare Adj

Root Mean Square Error $\quad 0.019451$

Mean of Response

0.019451
0.957

Observations (or Sum Wgts)

40

Analysis of Variance

Source DF Sum of Squares Mean Square F Ratio

$\begin{array}{lllll}\text { Model } & 9 & 0.06189000 & 0.006877 & 18.1762\end{array}$

$\begin{array}{llll}\text { Error } & 30 & 0.01135000 & 0.000378 \text { Prob }>\text { F }\end{array}$

$\begin{array}{lrrr}\text { C. Total } & 39 & 0.07324000 & <.0001\end{array}$

Expected Mean Squares

The Mean Square per row by the Variance Component per column

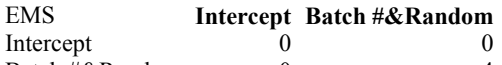

Batch \#\&Random $\quad 0 \quad 4$

plus 1.0 times Residual Error Variance

Variance Component Estimates

$\begin{array}{lrr}\text { Component } & \text { Var Comp Est } & \text { Percent of Total } \\ \text { Batch \#\&Random } & 0.001625 & 81.111 \\ \text { Residual } & 0.000378 & 18.889 \\ \text { Total } & 0.002003 & 100.000\end{array}$

These estimates based on equating Mean Squares to Expected Value.

Test Denominator Synthesis

Source MS Den DF Den Denom MS Synthesis

Batch \#\&Random $0.00038 \quad 30$ Residual

Tests wrt Random Effects

Source SS MS Num DF Num F Ratio Prob $>$ F

$\begin{array}{llllll}\text { Batch \#\&Random } & 0.06189 & 0.00688 & 9 & 18.1762 & <.0001\end{array}$

Residual by Predicted Plot

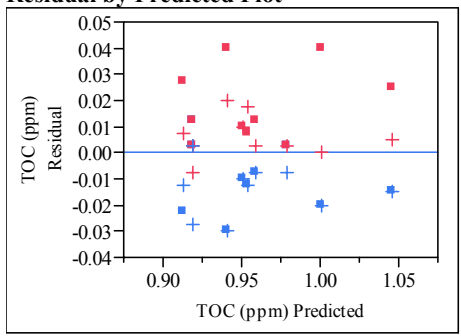

Batch \#\&Random

Effect Test

Sum of Squares F Ratio DF Prob $>$ F

$0.06189000 \quad 18.1762 \quad 9<.0001$

Denominator MS Synthesis:

Residual
Response TOC (ppm) Tank=SME-1, Type of Sample=std, ref ppm=20 Whole Model

Actual by Predicted Plot

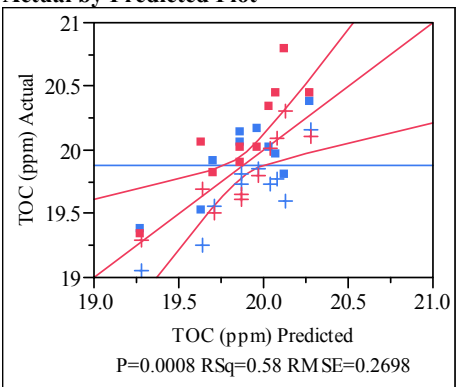

\section{Summary of Fit}

0.450007

Root Mean Square Error $\quad 0.269838$

Mean of Response $\quad 19.87625$

Observations (or Sum Wgts) $\quad 40$

Analysis of Variance

Source DF Sum of Squares Mean Square F Ratio

$\begin{array}{lllll}\text { Model } & 9 & 2.9787625 & 0.330974 & 4.5456\end{array}$

$\begin{array}{llll}\text { Error } & 30 & 2.1843750 & 0.072813 \text { Prob }>\text { F }\end{array}$

$\begin{array}{lrrr}\text { C. Total } & 39 & 5.1631375 & 0.072813 \\ \end{array}$

Expected Mean Squares

The Mean Square per row by the Variance Component per column

EMS Intercept Batch \#\&Random

$\begin{array}{lll}\text { Intercept } & 0 & 0 \\ \text { Batch \#\&Random } & 0 & 4\end{array}$

plus 1.0 times Residual Error Variance

\begin{tabular}{lrr}
\multicolumn{3}{l}{ Variance Component Estimates } \\
Component & Var Comp Est & Percent of Total \\
Batch \#\&Random & 0.06454 & 46.989 \\
Residual & 0.072813 & 53.011 \\
Total & 0.137353 & 100.000
\end{tabular}

These estimates based on equating Mean Squares to Expected Value.

Test Denominator Synthesis

Source MS Den DF Den Denom MS Synthesis

Batch \#\&Random $0.07281 \quad 30$ Residual

Tests wrt Random Effects

Source SS MS Num DF Num F Ratio Prob $>$ F

$\begin{array}{llllll}\text { Batch \#\&Random } 2.97876 & 0.33097 & 9 & 4.5456 & 0.0008\end{array}$

Residual by Predicted Plot

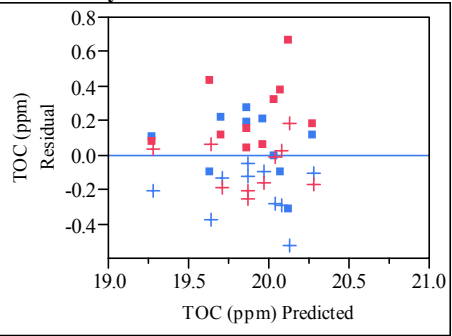

Batch \#\&Random

Effect Test

Sum of Squares F Ratio DF Prob $>$ F

$\begin{array}{llll}2.9787625 & 4.5456 & 9 & 0.0008\end{array}$

Denominator MS Synthesis:

Residual 


\section{Exhibit A10. Analysis of Variance for Batch to Batch Random Effects Over Both TOC Standards}

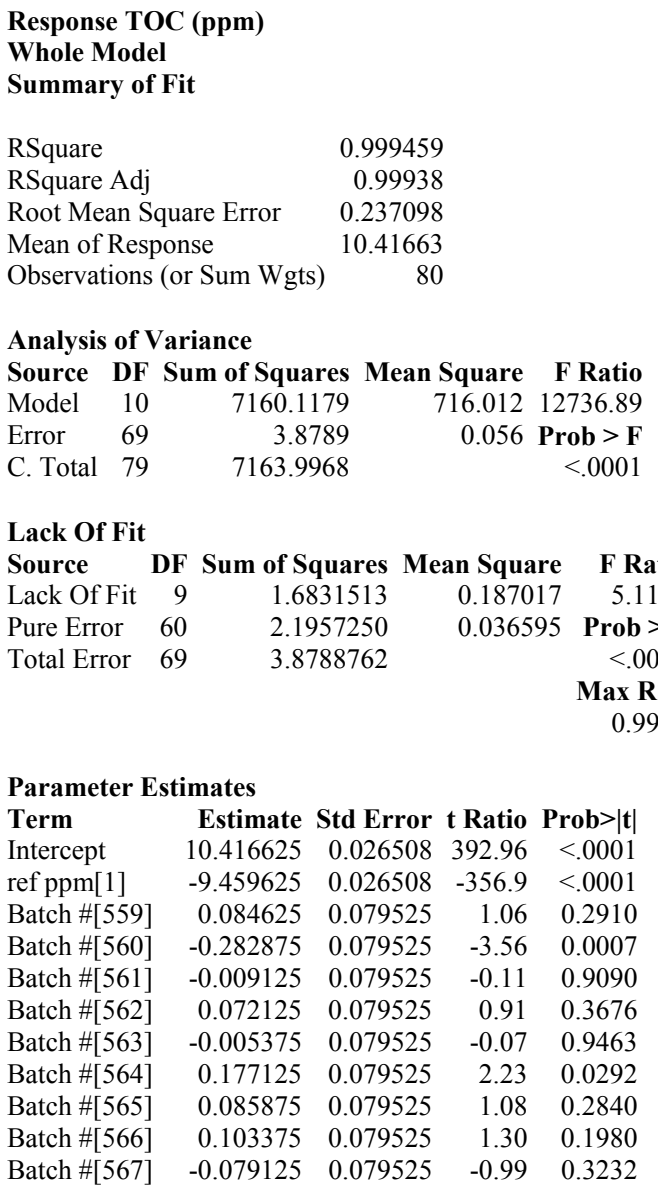

Expected Mean Squares

The Mean Square per row by the Variance Component per column

$\begin{array}{lrrr}\text { EMS } & \text { Intercept } & \text { Batch \#\&Random } & \text { ref ppm } \\ \text { Intercept } & 0 & 0 & 0 \\ \text { Batch \#\&Random } & 0 & 8 & 0 \\ \text { ref ppm } & 0 & 0 & 40\end{array}$

plus 1.0 times Residual Error Variance

Variance Component Estimates

$\begin{array}{lrr}\text { Component } & \text { Var Comp Est } & \text { Percent of Total } \\ \text { Batch \#\&Random } & 0.011827 & 17.382 \\ \text { Residual } & 0.056216 & 82.618 \\ \text { Total } & 0.068043 & 100.000\end{array}$

These estimates based on equating Mean Squares to Expected Value.

Test Denominator Synthesis

$\begin{array}{lrrrl}\text { Source } & \text { MS Den } & \text { DF Den } & \text { Denom MS Synthesis } \\ \text { Batch \#\&Random } & 0.05622 & 69 & \text { Residual } \\ \text { ref ppm } & 0.05622 & 69 & \text { Residual }\end{array}$

Tests wrt Random Effects

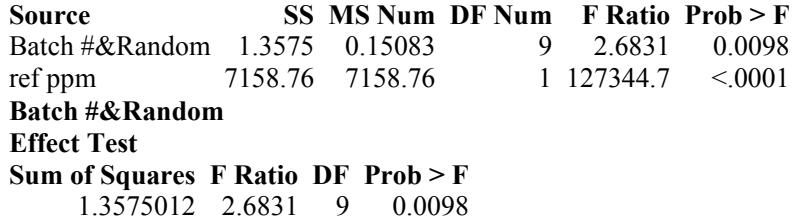

Denominator MS Synthesis: Residual

\begin{tabular}{|c|c|c|c|}
\hline \multicolumn{4}{|c|}{ Least Squares Means Table } \\
\hline Level & st Sq Mean & Std Error & Mean \\
\hline 559 & 10.501250 & 0.08382690 & 10.5013 \\
\hline 560 & 10.133750 & 0.08382690 & 10.1338 \\
\hline 561 & 10.407500 & 0.08382690 & 10.4075 \\
\hline 562 & 10.488750 & 0.08382690 & 10.4888 \\
\hline 563 & 10.411250 & 0.08382690 & 10.4113 \\
\hline 564 & 10.593750 & 0.08382690 & 10.5938 \\
\hline 565 & 10.502500 & 0.08382690 & 10.5025 \\
\hline 566 & 10.520000 & 0.08382690 & 10.5200 \\
\hline 567 & 10.337500 & 0.08382690 & 10.3375 \\
\hline 568 & 10.270000 & 0.08382690 & 10.2700 \\
\hline \multicolumn{4}{|c|}{ ref ppm } \\
\hline \multicolumn{4}{|c|}{ Effect Test } \\
\hline \multicolumn{4}{|c|}{ Sum of Squares } \\
\hline \multicolumn{4}{|c|}{$7158.7604 \quad 127344.7$} \\
\hline \multicolumn{4}{|c|}{$\begin{array}{l}\text { Denominator MS Synthesis: } \\
\text { Residual }\end{array}$} \\
\hline \multicolumn{4}{|c|}{ Least Squares Means Table } \\
\hline Level & st Sq Mean & Std Error & Mean \\
\hline 1 & 0.957000 & 0.03748853 & 0.9570 \\
\hline 20 & 19.876250 & 0.03748853 & 19.8763 \\
\hline
\end{tabular}




\section{Exhibit A11. Histograms and Summary Statistics for the Measurements of the TOC Standards}

Distributions Tank=SME-1, Type of Sample=std, ref ppm=1, Sample=1, opening/closing $=$ opening

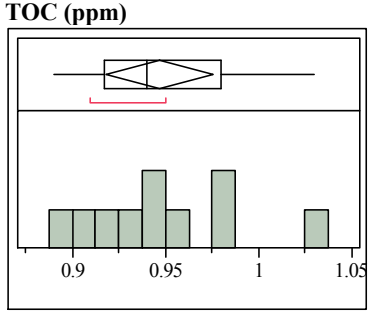

Quantiles

$\begin{array}{lll}100.0 \% & \text { maximum } & 1.0300 \\ 99.5 \% & & 1.0300 \\ 97.5 \% & & 1.0300 \\ 90.0 \% & & 1.0250 \\ 75.0 \% & \text { quartile } & 0.9800 \\ 50.0 \% & \text { median } & 0.9400 \\ 25.0 \% & \text { quartile } & 0.9175 \\ 10.0 \% & & 0.8920 \\ 2.5 \% & & 0.8900 \\ 0.5 \% & & 0.8900 \\ 0.0 \% & \text { minimum } & 0.8900\end{array}$

Moments

Mean $\quad 0.947$

Std Dev $\quad 0.0405654$

Std Err Mean $\quad 0.0128279$

upper $95 \%$ Mean 0.9760188

lower $95 \%$ Mean 0.9179812

$\mathrm{N}$

Distributions Tank=SME-1, Type of Sample=std, ref ppm=1, Sample=1, opening/closing $=$ closing

TOC (ppm)

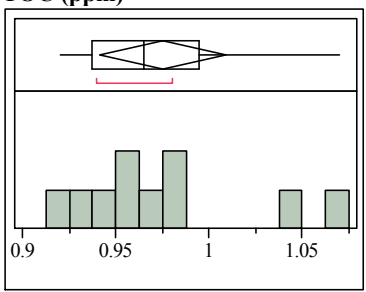

Quantiles

$\begin{array}{lll}100.0 \% & \text { maximum } & 1.0700 \\ 99.5 \% & & 1.0700 \\ 97.5 \% & & 1.0700 \\ 90.0 \% & & 1.0670 \\ 75.0 \% & \text { quartile } & 0.9950 \\ 50.0 \% & \text { median } & 0.9650 \\ 25.0 \% & \text { quartile } & 0.9375 \\ 10.0 \% & & 0.9210 \\ 2.5 \% & & 0.9200 \\ 0.5 \% & & 0.9200 \\ 0.0 \% & \text { minimum } & 0.9200\end{array}$

Moments

Mean $\quad 0.975$

Std Dev $\quad 0.0471993$

Std Err Mean $\quad 0.0149257$

upper $95 \%$ Mean 1.0087644

lower 95\% Mean 0.9412356

$\mathrm{N}$
Distributions Tank=SME-1, Type of Sample=std, ref ppm=1, Sample=2, opening/closing $=$ opening

TOC (ppm)

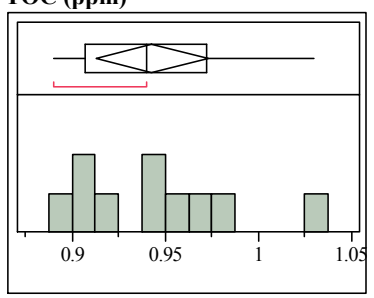

Quantiles

$\begin{array}{lll}100.0 \% & \text { maximum } & 1.0300 \\ 99.5 \% & & 1.0300 \\ 97.5 \% & & 1.0300 \\ 90.0 \% & & 1.0250 \\ 75.0 \% & \text { quartile } & 0.9725 \\ 50.0 \% & \text { median } & 0.9400 \\ 25.0 \% & \text { quartile } & 0.9075 \\ 10.0 \% & & 0.8910 \\ 2.5 \% & & 0.8900 \\ 0.5 \% & 0.8900 \\ 0.0 \% \text { minimum } & 0.8900 \\ \text { Moments } & \end{array}$

Mean $\quad 0.943$

Std Dev $\quad 0.0421769$

Std Err Mean $\quad 0.0133375$

upper $95 \%$ Mean 0.9731715

lower 95\% Mean 0.9128285

Distributions Tank=SME-1, Type of Sample=std, ref ppm=1, Sample=2, opening/closing $=$ closing

TOC (ppm)

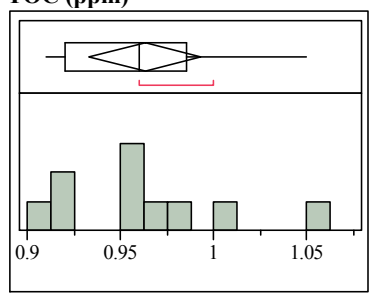

Quantiles

$100.0 \%$ maximum 1.0500

$99.5 \% \quad 1.0500$

$97.5 \% \quad 1.0500$

$90.0 \% \quad 1.0450$

$75.0 \%$ quartile $\quad 0.9850$

$50.0 \%$ median 0.9600

$25.0 \%$ quartile $\quad 0.9200$

$10.0 \% \quad 0.9110$

$2.5 \% \quad 0.9100$

$0.5 \% \quad 0.9100$

$0.0 \%$ minimum 0.9100

Moments

Mean

0.963

Std Dev $\quad 0.0419126$

Std Err Mean $\quad 0.0132539$

upper $95 \%$ Mean 0.9929825

lower $95 \%$ Mean 0.9330175 


\section{Exhibit A11. Histograms and Summary Statistics for the Measurements of the TOC Standards}

Distributions Tank=SME-1, Type of Sample=std, ref ppm=20, Sample=1, opening/closing=opening

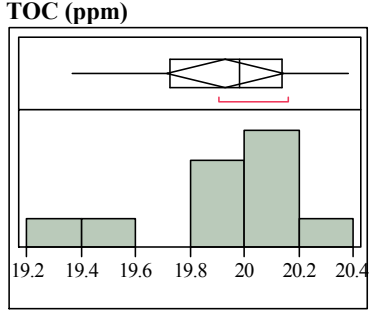

Quantiles

$\begin{array}{lll}100.0 \% & \text { maximum } & 20.380 \\ 99.5 \% & & 20.380 \\ 97.5 \% & & 20.380 \\ 90.0 \% & & 20.358 \\ 75.0 \% & \text { quartile } & 20.138 \\ 50.0 \% & \text { median } & 19.985 \\ 25.0 \% & \text { quartile } & 19.730 \\ 10.0 \% & & 19.385 \\ 2.5 \% & & 19.370 \\ 0.5 \% & & 19.370 \\ 0.0 \% & \text { minimum } & 19.370\end{array}$

Moments

$$
\begin{array}{lr}
\text { Mean } & 19.929 \\
\text { Std Dev } & 0.3011257 \\
\text { Std Err Mean } & 0.0952243 \\
\text { upper 95\% Mean } & 20.144412 \\
\text { lower 95\% Mean } & 19.713588 \\
\text { N } & 10
\end{array}
$$

Distributions Tank=SME-1, Type of Sample=std, ref ppm=20, Sample=1, opening/closing=closing

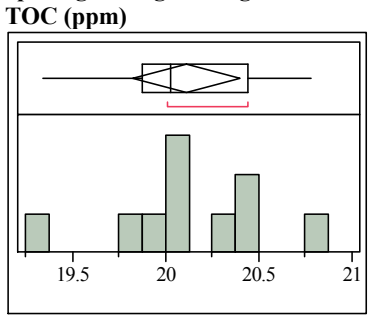

\section{Quantiles}

$$
\begin{array}{lll}
100.0 \% & \text { maximum } & 20.780 \\
99.5 \% & & 20.780 \\
97.5 \% & & 20.780 \\
90.0 \% & & 20.746 \\
75.0 \% & \text { quartile } & 20.440 \\
50.0 \% & \text { median } & 20.030 \\
25.0 \% & \text { quartile } & 19.878 \\
10.0 \% & & 19.387 \\
2.5 \% & & 19.340 \\
0.5 \% & & 19.340 \\
0.0 \% & \text { minimum } & 19.340
\end{array}
$$

Moments

Mean $\quad 20.112$

Std Dev $\quad 0.4041672$

Std Err Mean $\quad 0.1278089$

upper $95 \%$ Mean 20.401124

lower 95\% Mean 19.822876

$\mathrm{N}$
Distributions Tank=SME-1, Type of Sample=std, ref ppm=20, Sample=2, opening/closing $=$ opening

TOC (ppm)

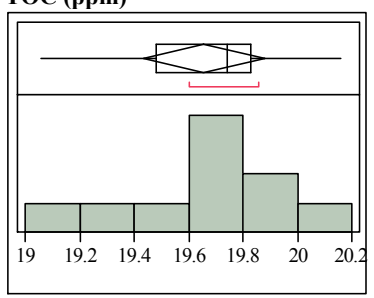

Quantiles

$\begin{array}{lll}100.0 \% & \text { maximum } & 20.160 \\ 99.5 \% & & 20.160 \\ 97.5 \% & & 20.160 \\ 90.0 \% & & 20.130 \\ 75.0 \% & \text { quartile } & 19.830 \\ 50.0 \% & \text { median } & 19.740 \\ 25.0 \% & \text { quartile } & 19.483 \\ 10.0 \% & & 19.079 \\ 2.5 \% & & 19.060 \\ 0.5 \% & & 19.060 \\ 0.0 \% \text { minimum } & 19.060 \\ \text { Moments } & \end{array}$

\begin{tabular}{lr} 
Mean & 19.656 \\
Std Dev & 0.3130566 \\
Std Err Mean & 0.0989972 \\
upper 95\% Mean & 19.879947 \\
lower 95\% Mean & 19.432053 \\
\hline
\end{tabular}

Distributions Tank=SME-1, Type of Sample=std, ref ppm=20, Sample=2, opening/closing=closing

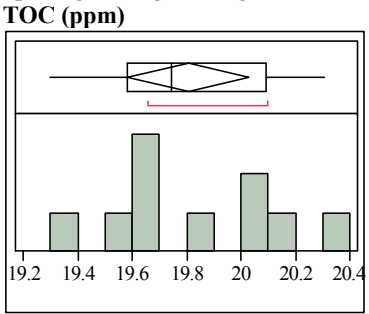

Quantiles

$100.0 \%$ maximum 20.310

$99.5 \%$

$97.5 \% \quad 20.310$

$90.0 \% \quad 20.289$

$75.0 \%$ quartile 20.093

$50.0 \%$ median 19.745

$25.0 \%$ quartile $\quad 19.585$

$10.0 \% \quad 19.321$

$2.5 \% \quad 19.300$

$0.5 \% \quad 19.300$

$0.0 \%$ minimum 19.300

Moments

Mean

19.808

Std Dev $\quad 0.3126162$

Std Err Mean $\quad 0.0988579$

upper $95 \%$ Mean 20.031632

lower 95\% Mean 19.584368 


\section{Exhibit A12. DWPF Laboratory's TOC Measurements for the SME Samples}

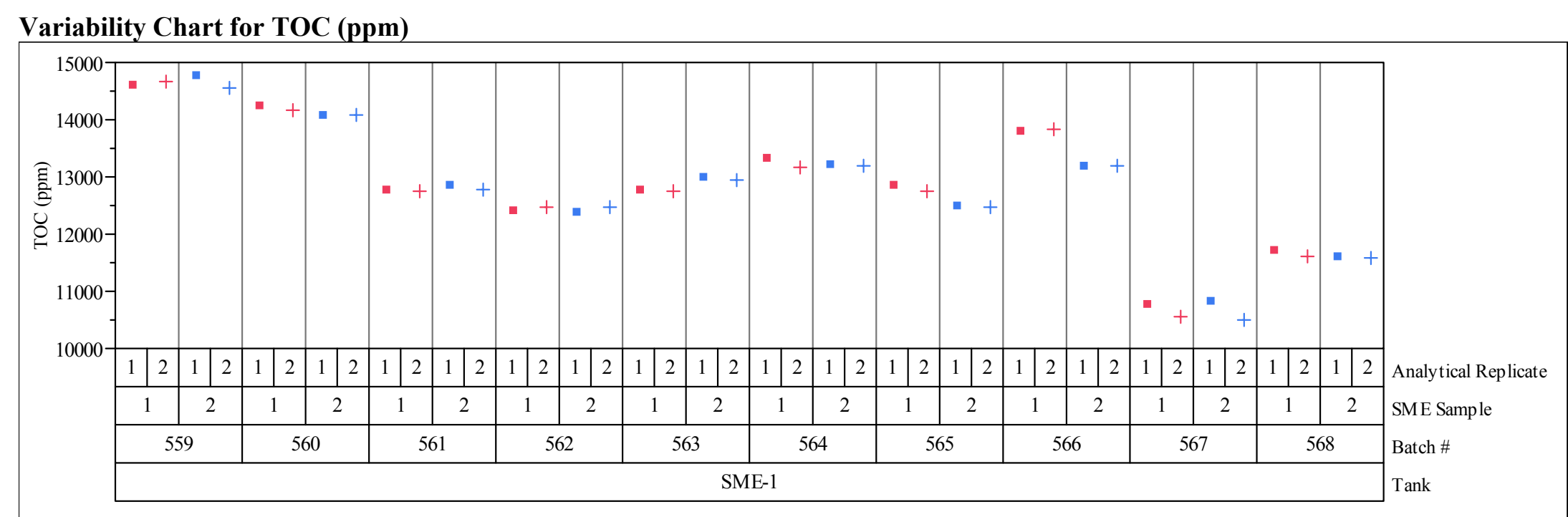




\section{Distribution:}

\begin{tabular}{|c|c|}
\hline Name: & Location: \\
\hline Sharon Marra & 773-A \\
\hline Connie Herman & 999-W \\
\hline Charles J. Coleman & 773-A \\
\hline Clint Gregory & 773-A \\
\hline Mark Barnes & 773-A \\
\hline Patricia Lee & $703-41 \mathrm{~A}$ \\
\hline Gene Shine & $703-41 \mathrm{~A}$ \\
\hline Damon R. Click & 773-A \\
\hline L. Curtis Johnson & 773-A \\
\hline Michael Stone & 999-W \\
\hline Alex Choi & $773-42 \mathrm{~A}$ \\
\hline John Pareizs & $773-\mathrm{A}$ \\
\hline David Peeler & 999-W \\
\hline Tommy Edwards & 999-W \\
\hline Kevin Fox & 999-W \\
\hline Fabienne Johnson & 999-W \\
\hline Charles Crawford & $773-42 \mathrm{~A}$ \\
\hline David Best & 999-W \\
\hline John Occhipinti & $704-S$ \\
\hline Jonathan Bricker & $704-27 \mathrm{~S}$ \\
\hline John Iaukea & 704-30S \\
\hline Aaron Staub & $704-27 \mathrm{~S}$ \\
\hline Jeff Ray & $704-\mathrm{S}$ \\
\hline Robert Hinds & $704-S$ \\
\hline Terri Fellinger & $704-26 \mathrm{~S}$ \\
\hline Ryan McNew & $704-\mathrm{S}$ \\
\hline Michael T. Hart & $210-S$ \\
\hline Roger N. Mahannah & $704-28 \mathrm{~S}$ \\
\hline Michael T. Feller & $704-28 \mathrm{~S}$ \\
\hline Omar Cardona-Quiles & $704-24 S$ \\
\hline Amanda Shafer & $704-27 \mathrm{~S}$ \\
\hline Mason Clark & $704-27 \mathrm{~S}$ \\
\hline Helen Pittman & $704-27 \mathrm{~S}$ \\
\hline Hank Elder & $704-24 S$ \\
\hline Bill Holtzscheiter & $704-15 S$ \\
\hline Pat Vaughan & $773-41 \mathrm{~A}$ \\
\hline
\end{tabular}

